\title{
"Getting on Top of Pain": \\ A critical analysis of surgical nurses' talk about their work with hospitalised patients reporting pain
}

\author{
by \\ Suzanne Lavinia Jane King
}

A thesis submitted to the Victoria University of Wellington

in partial fulfilment of the

requirements for the degree of

Master of Arts (Applied)

in Nursing

Victoria University of Wellington

1999 


\begin{abstract}
This thesis investigates the relationship between language, 'discourse' and professional knowledge and power in a specific context; that of surgical nurses' "talk" about their work managing pain in hospitalised patients. This thesis argues that the work of 'caring for' hospitalised surgical patients who report pain is influenced by discourses which are predicated on different readings/understandings of the body/patient, and from which different knowledge is constructed. Of interest to this thesis are the discourses of biomedicine and nursing, and their role in constructing a particular reality/ies which determine the ways in which surgical nurses talk about their work managing pain.
\end{abstract}

Using the method of critical discourse analysis, the "texts" of transcribed audiotaped conversations with four registered nurses working in surgical specialties were analysed to uncover 'discourses of pain management'. The results of the analysis indicate that the biomedical construction of pain, and approaches to pain management, remain the dominant influence over surgical nurses' practice. There was evidence of nursing discourses with an emphasis on nurse-patient relationships also playing a role. These discourses were critically examined for what they reveal about relations of professional knowledge and power in this specific context of the nurses' practice. The implications for nursing and nursing research are considered significant because the study critically (re)presents a different perspective on, and reality for surgical nurses' pain management practices. In so doing, it elucidates an explanation for, and understanding of, why surgical nurses take care of patients reporting pain in particular ways. 


\section{Table of Contents}

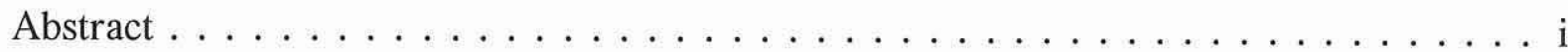

Table of Contents $\ldots \ldots \ldots \ldots \ldots \ldots \ldots \ldots \ldots \ldots \ldots \ldots \ldots$

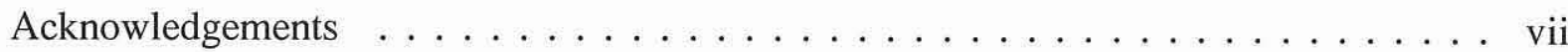

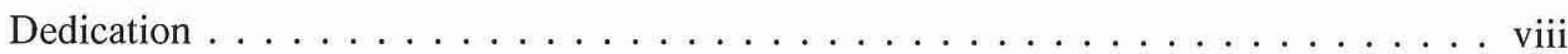

\section{CHAPTER ONE \\ INTRODUCTION: FRAMING UP THIS STUDY ON LANGUAGE AND PAIN DISCOURSES}

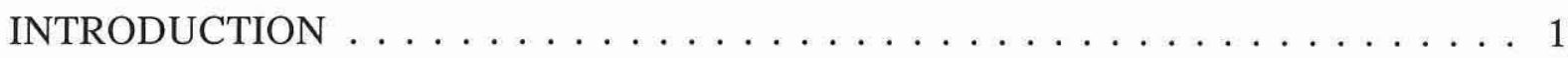

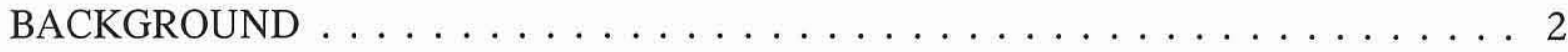

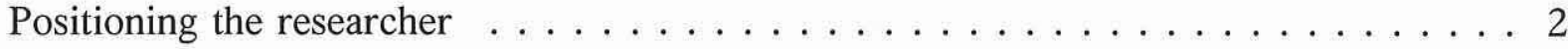

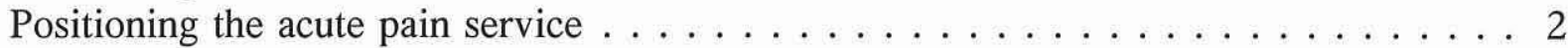

Positioning the surgical nurses' role in pain management $\ldots \ldots \ldots \ldots \ldots$

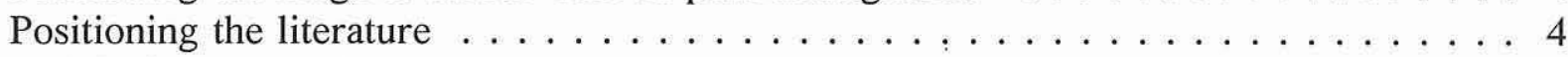

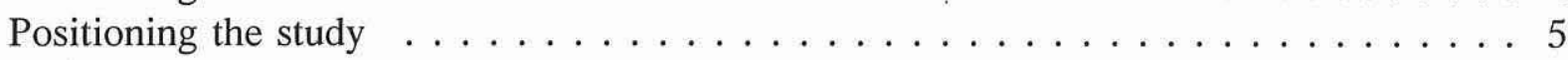

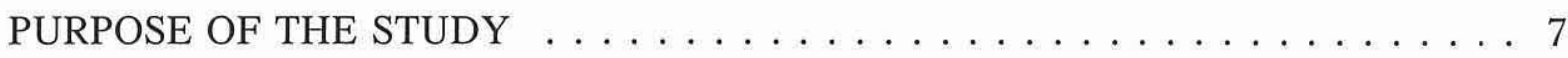

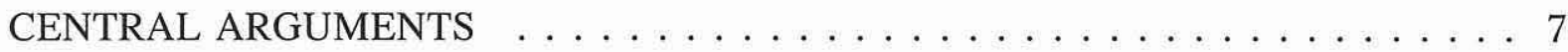

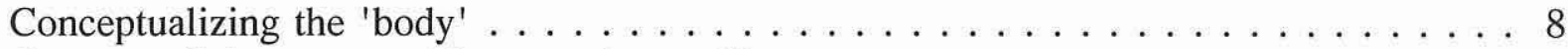

Conceptualizing power; The use of surveillance $\ldots \ldots \ldots \ldots \ldots$

Defining "pain"; The biomedical perspective . . . . . . . . . . . . . 9

Working with "pain"; The nursing perspective . . . . . . . . . . . . . 10

RESEARCH APPROACH $\ldots \ldots \ldots \ldots \ldots \ldots \ldots \ldots \ldots \ldots \ldots \ldots$

STRUCTURE OF THESIS $\ldots \ldots \ldots \ldots \ldots \ldots \ldots \ldots \ldots \ldots$

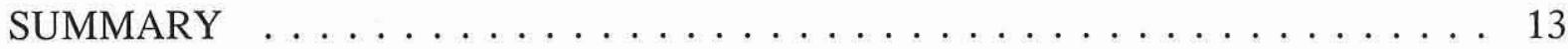


CHAPTER TWO

REVIEWING THE LITERATURE: PAIN PERSPECTIVES AND NURSING

PRACTICE

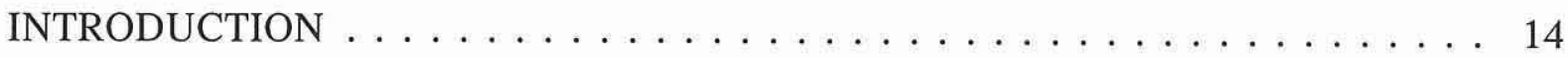

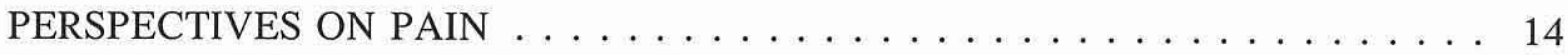

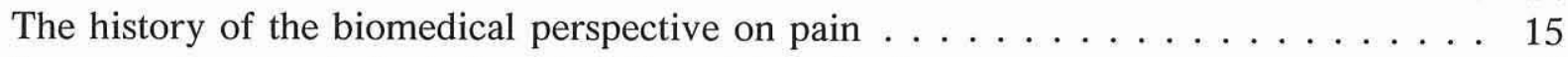

Incorporating psychological explanations into pain discourses $\ldots \ldots \ldots \ldots \ldots$

Focusing on the subjective; Pain as "embodied" experience . . . . . . . . 18

PAIN DISCOURSES AND RELATIONS OF POWER/KNOWLEDGE . . . . . . . . 20

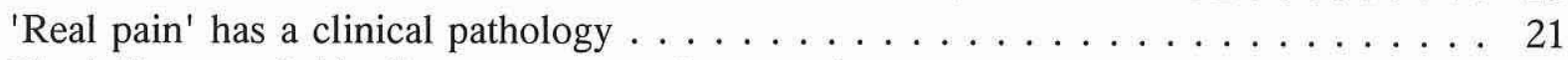

The influence of this discourse on nursing practice $\ldots \ldots \ldots \ldots \ldots \ldots \ldots \ldots$

"Pain is what the patient says it is"; Incorporating this into nursing practice . . . . 27

NURSING DISCOURSES - 'BODIES' AND 'EMBODIED' RELATIONSHIPS . . 30

'Embodied' relationships; Constructing knowledge, relations of power . . . . . . . 33

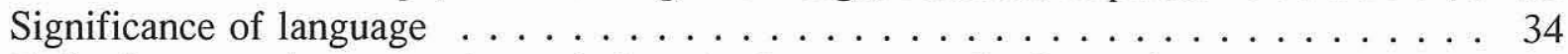

Embodiment and nurse-patient relations in the context of pain work . . . . . . . 37

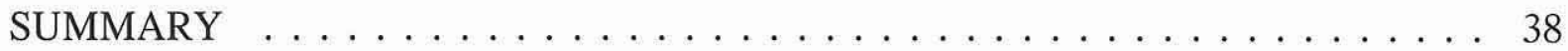

CHAPTER THREE

THEORETICAL PERSPECTIVES ON DISCOURSE AND FOUCAULT'S POWER/KNOWLEDGE: POSITIONING THIS STUDY

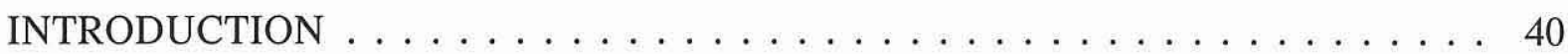

THEORIES OF 'DISCOURSE' $\ldots \ldots \ldots \ldots \ldots \ldots \ldots \ldots \ldots \ldots \ldots$

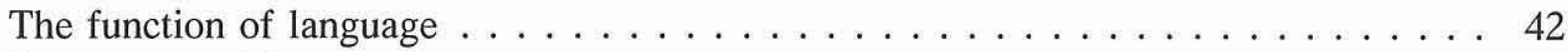

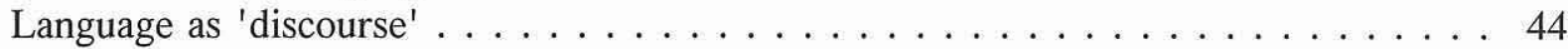

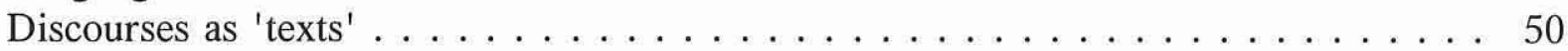

Similarities and differences between the above approaches and that of

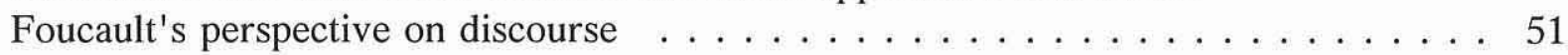

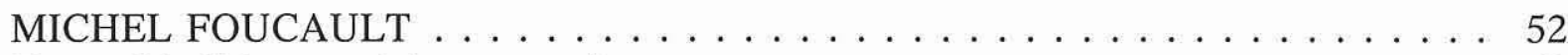

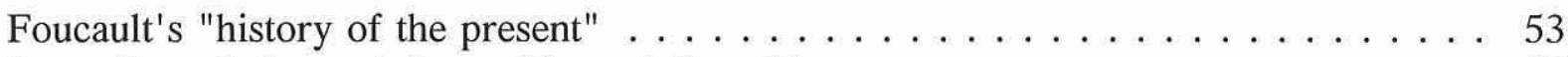

Power/knowledge and the problem of the subject $\ldots \ldots \ldots \ldots \ldots \ldots$

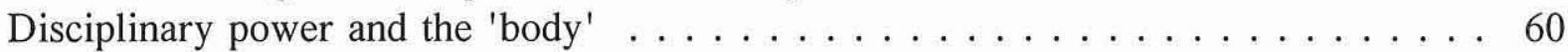

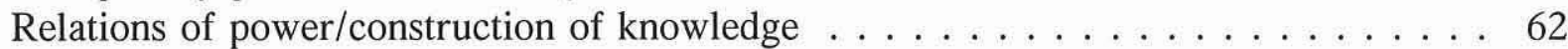

Criticisms of, and alternatives to, Foucault's position . . . . . . . . . . 63

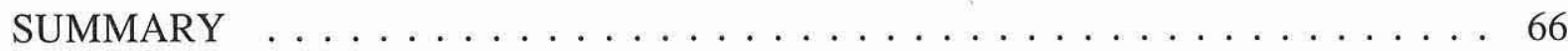


CHAPTER FOUR

CRITICAL DISCOURSE ANALYSIS AS METHODOLOGY AND METHOD: FRAMING UP THE RESEARCH PROCESS UNDERTAKEN IN THIS STUDY

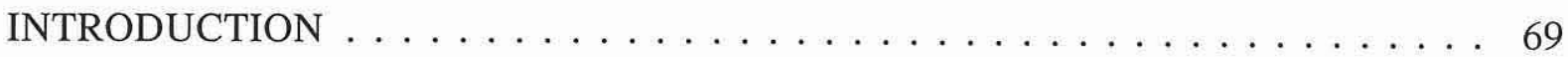

DISCOURSE ANALYSIS AS METHODOLOGY AND METHOD $\ldots \ldots \ldots \ldots 70$

PERSPECTIVES ON DISCOURSE ANALYSIS $\ldots \ldots \ldots \ldots \ldots \ldots \ldots$

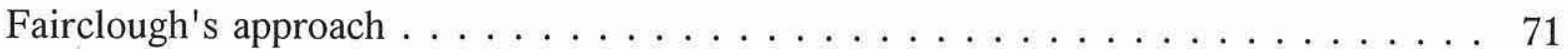

Fairclough's analytical framework $\ldots \ldots \ldots \ldots \ldots \ldots \ldots \ldots$

Potter and Wetherell's approach $\ldots \ldots \ldots \ldots \ldots \ldots \ldots \ldots \ldots$

Potter and Wetherell's ten stages of discourse analysis $\ldots \ldots \ldots \ldots \ldots \ldots$

The two approaches: Similarities and differences $\ldots \ldots \ldots \ldots \ldots \ldots$

SELECTING COMPONENTS FOR THE ANALYTICAL FRAMEWORK

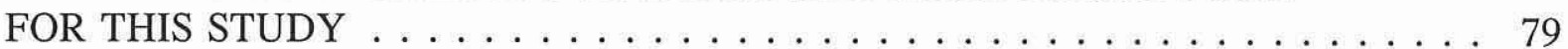

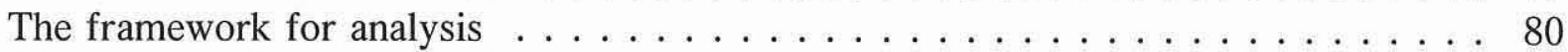

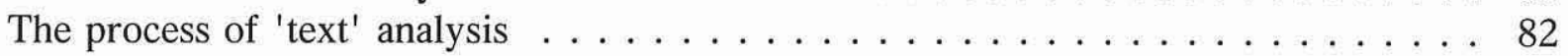

PROBLEMATIC ASPECTS OF CRITICAL DISCOURSE ANALYSIS . . . . . . . 82

THE RESEARCH PROCESS $\ldots \ldots \ldots \ldots \ldots \ldots \ldots \ldots$. . . . . . . . . . . 84

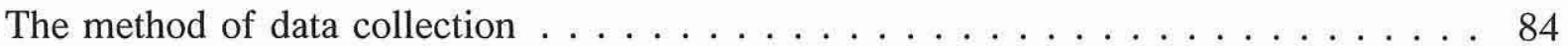

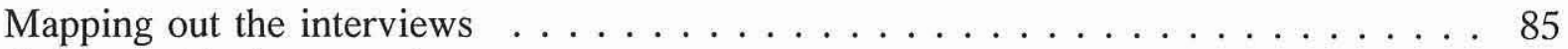

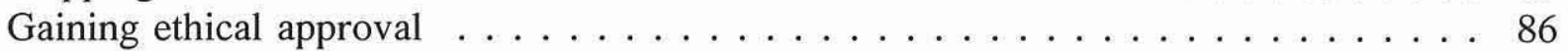

How access to participants was approved $\ldots \ldots \ldots \ldots \ldots \ldots \ldots \ldots$

ETHICAL ISSUES AND CONCERNS $\ldots \ldots \ldots \ldots \ldots \ldots \ldots$

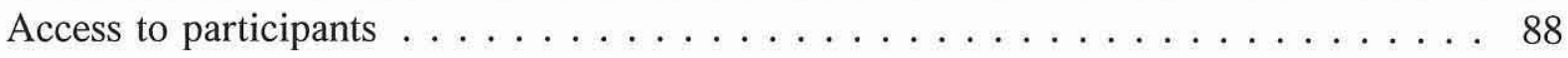

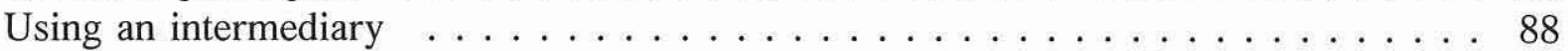

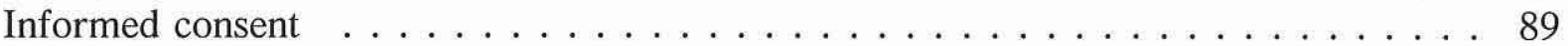

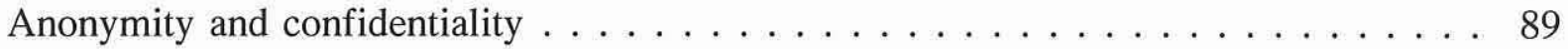

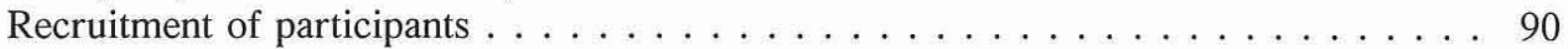

Participant's right to decline $\ldots \ldots \ldots \ldots \ldots \ldots \ldots \ldots \ldots \ldots$

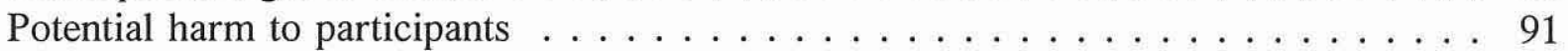

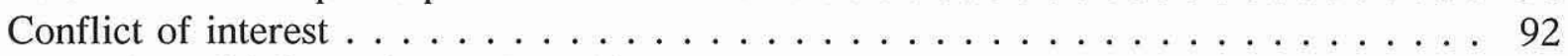

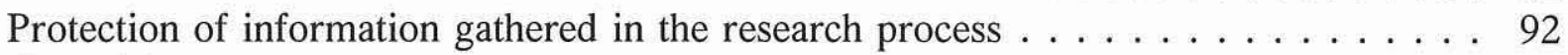

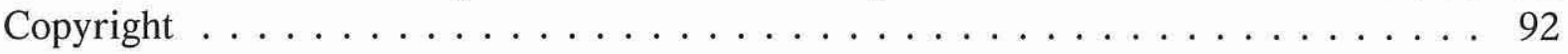

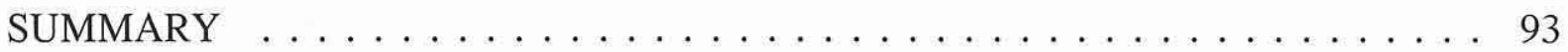


CHAPTER FIVE

ANALYSING THE 'TEXTS'; BIOMEDICAL DISCOURSES

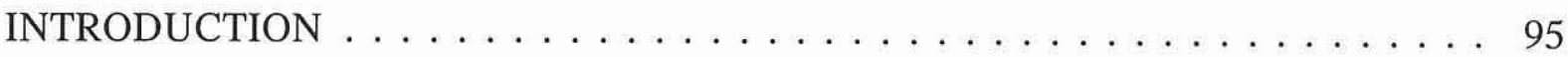

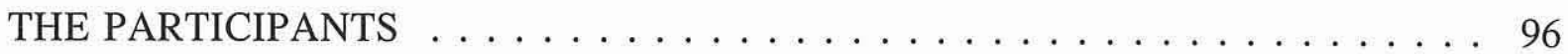

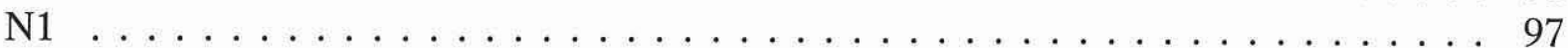

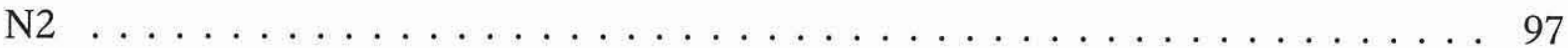

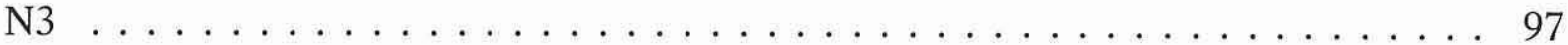

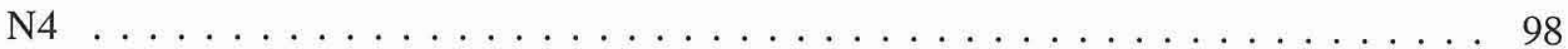

THE INTERVIEWS $\ldots \ldots \ldots \ldots \ldots \ldots \ldots \ldots \ldots$

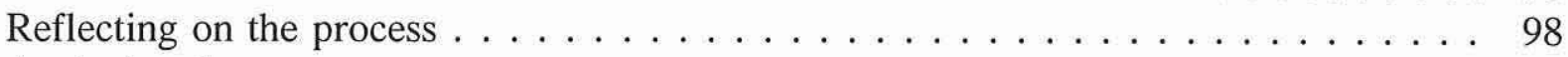

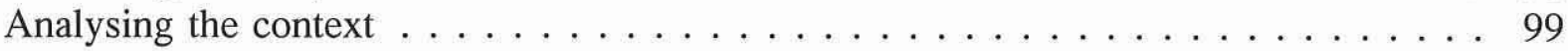

BIOMEDICAL DISCOURSES OF PAIN MANAGEMENT . . . . . . . . . . . 105

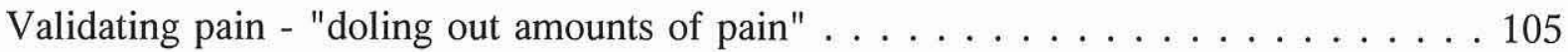

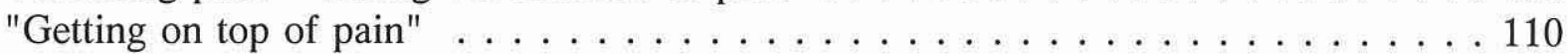

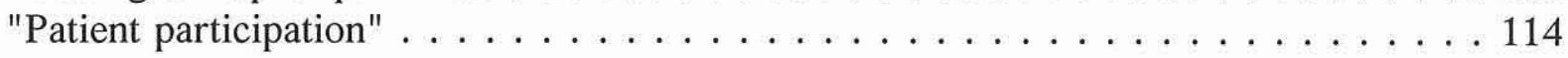

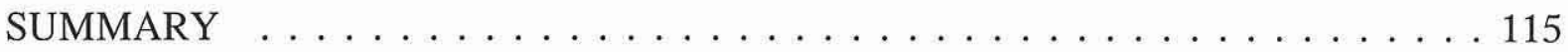

CHAPTER SIX

READING BODIES AND RESPONDING TO PATIENTS' PAIN; NURSING DISCOURSES

INTRODUCTION $\ldots \ldots \ldots \ldots \ldots \ldots \ldots \ldots \ldots \ldots \ldots \ldots \ldots \ldots$

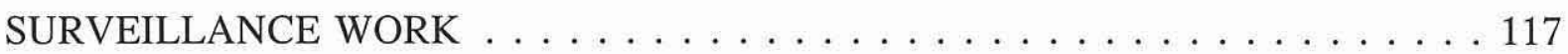

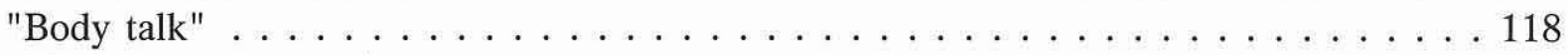

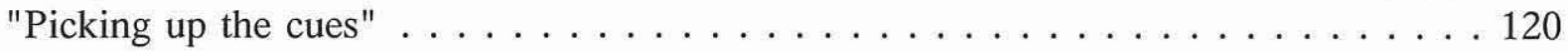

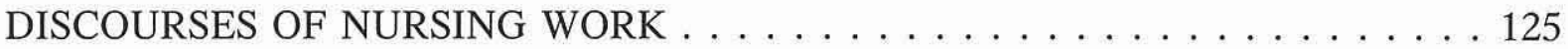

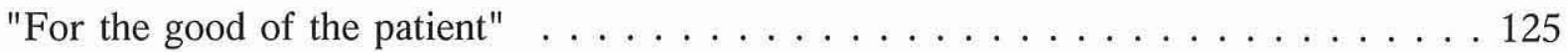

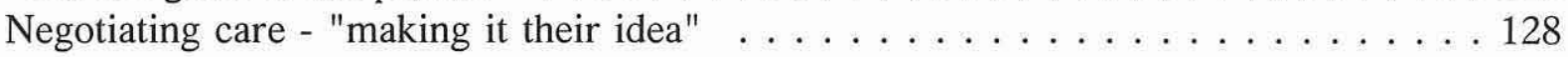

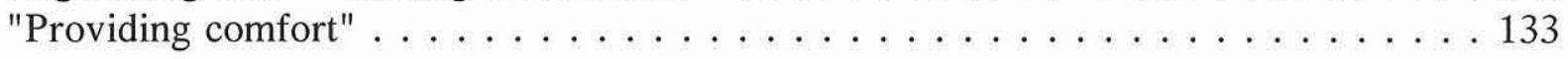

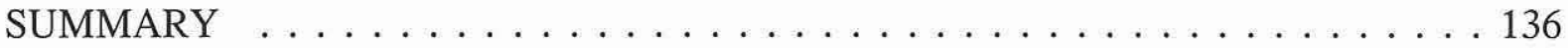


CHAPTER SEVEN

SUMMARY AND CONCLUSIONS: A CRITICAL REVIEW OF THE RESEARCH PROJECT

INTRODUCTION . . . . . . . . . . . . . . . . . . . . . . . . . . . . . . 139

REVISITING THE AIMS OF, AND JUSTIFICATION FOR, THE RESEARCH . . . 139

EVALUATING THE RESULTS; DRAWING CONCLUSIONS . . . . . . . . . . . . 142

REFLECTING ON THE RESEARCH PROCESS . . . . . . . . . . . . . . . . . 146

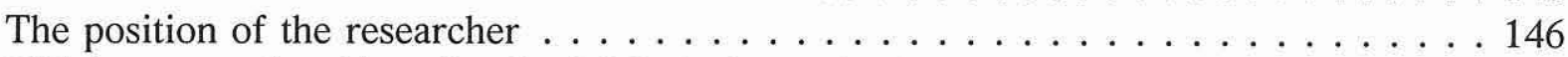

Did the research achieve its aims? Limitations of this study . . . . . . . . . . . . . . 147

Implications of the research; Making a contribution to nursing discourse . . . . . . . 149

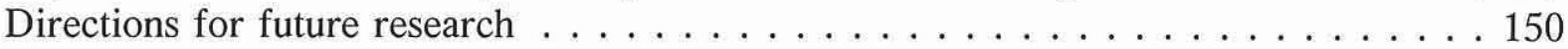

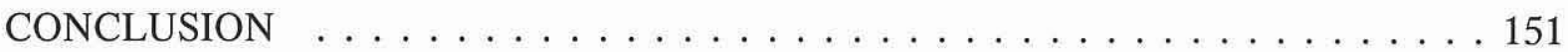

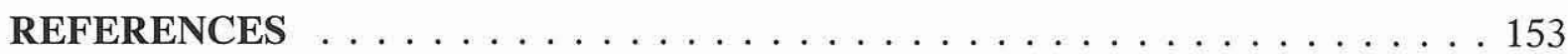




\section{ACKNOWLEDGEMENTS}

As with any work of this nature there are a number of people who make it happen besides the person who puts pen to paper. This is my opportunity to acknowledge my family, my friends and numerous work colleagues who encouraged and supported me throughout this journey. To you all, my heartfelt thanks. Special thanks goes in particular to friend and professional colleague Tracy Cadman who, having gone this way before, has proved a wonderful mentor, giving tips along the way and always there to provide companionship when it was time to take a break. Thank you too to my sister-in-law, Jill Bennett-King who, as a clinical psychologist, provided valuable comment on early drafts and for stimulating discussion on ideas about pain and its management. To Joy Bickley, my supervisor, goes a huge debt of gratitude. Critical comments on drafts were always offset with encouraging words of praise which was what I needed to hear. The critical reviews and suggestions for improvements helped enormously with showing me the way forward in order to complete the work, so thank you Joy. To Kathy Gibbison, for her speedy and professional typing support, thanks. Without your expertise in computers, I would have floundered. And lastly, I take this opportunity to acknowledge the four wonderful and professional surgical nurses who agreed to participate in this study, for without you, the study would have been a non-starter. Thank you for your time and for trusting me with your thoughts and stories about the work you do with patients in your care. 


\section{DEDICATION}

To Mum and Dad, with love and thanks for always being there. 


\section{CHAPTER ONE \\ Introduction: Framing up this study on language and pain discourses}

\section{INTRODUCTION}

This thesis investigates the alliance between 'discourse' and surgical nurses' pain management practices through an analysis of "talk". In particular, the thesis is concerned with how, through language, a certain form and understanding of the body and of the patient have been constructed, and the relationship this has to professional knowledge and power. The thesis argues that the work of 'caring for' hospitalised surgical patients who report pain is influenced by discourses which are predicated on different readings of the body/patient.

The discourses of most interest to this thesis are those of biomedicine, which situates the patient and the patient's body as an object of clinical interest, and nursing which casts the patient as the experiencing and embodied subject. The thesis examines these discourses and their role in constructing a particular reality/ies which determine the ways in which surgical nurses talk about their work in relation to hospitalised surgical patients reporting pain.

This introductory chapter summarises the background to this thesis by positioning the researcher, the surgical nurses' role in pain management and the literature on pain and pain management alongside the context for, and purpose of, the study. The chapter introduces the central themes and arguments of this thesis and briefly comments on the research approach, before concluding with an outline of the structure of the thesis. 


\section{BACKGROUND}

\section{Positioning the researcher}

I have been a nurse for twentyfive years, and an interest in the topic of pain began when I worked as a cancer nurse during the early 1980s. Pain is a common sequela of cancer therefore it has a high priority in patient care. Much of my more recent work experience has been gained as a surgical nurse, working in general surgery and urology. Surgical nursing involves working with patients who are admitted to surgical wards both acutely and for elective surgical procedures.

Acute admissions are distinguished from elective admissions by the unexpected nature of their surgical condition, such as acute abdominal pain, or as a result of injury. Elective patients on the other hand, come in for scheduled surgery or investigative procedures. Depending on the reason for admission, patients may respond to pain differently. Furthermore, post-operative recovery times between elective and acute procedures can have an impact on this experience of pain.

Upon my transfer to general surgery after working as a cancer nurse, I observed that the practices of pain management were given less status than in my previous job. Despite this, I remained intrigued with what I perceived to be inadequate recognition and care of post-operative pain. The desire to bring about change in knowledge and understanding of pain and techniques of pain management led me into my current role as the sole Acute Pain Service Nurse for a large (700 bed) tertiary care institution in New Zealand.

\section{Positioning the acute pain service}

The acute pain service (APS) is an anaesthesiology-based and funded service established in 1995 to provide hospital-wide specialist advice and support in the 
follow-up of hospitalised adult patients with acute pain management problems. These patients are predominantly surgical patients. Common pain management strategies that the service oversees are patient controlled analgesia (PCA) and epidural analgesia. Patients receiving other modalities may have input from the pain service, but infrequently.

As the sole Acute Pain Service Nurse (which is also my title), my primary responsibilities are the co-ordination and administration of pain service activities. Functionally I report to the Clinical Director of Anaesthetic Services, while my professional report is to the Director of Nursing. I work with consultant anaesthetists or anaesthetic registrars and ensure the follow-up of patients referred from other medical officers to the service with a daily formal pain round. I also provide the point of contact for any queries regarding pain management, for junior medical staff and for nurses. I offer advice on prescribing, on management of complications of pain therapies and on matters of referral.

For the nurses in particular, I provide an important resource with regard to legislative and hospital policy requirements in relation to pain management. I play a significant role in the development of medicine management policy and guidelines, especially as they pertain to clinical practice initiatives and nursing care responsibilities. Furthermore, all nursing education on acute pain management, including the teaching of nursing students and the development of education resources, is my responsibility. Clinical education on both a formal and informal basis is an integral part of my role. Formally, it involves conducting clinical assessments for organisational certification purposes, while informally, it can include demonstrating new equipment or discussing current nursing concerns in the area of pain management. 


\section{Positioning the surgical nurses' role in pain management}

In the course of my work I witness many instances of the interaction between surgical nurses and hospitalised patients who are in pain following trauma or surgery. The nurses' role in caring for patients who report pain is regarded as pivotal (Carroll, 1993; MacIntyre \& Ready, 1996; McCaffery \& Beebe, 1989; Wulf, Schug, Allvin \& Kehlet, 1998). Nurses spend more time with patients than other health professionals and co-ordinate nursing care which includes responsibility for the assessment of patients' pain and the administration of medication to relieve it.

Nurses also perform procedures which cause pain, such as wound dressings, irrigations and venepuncture. As well, nurses play an essential role in communicating with other members of the patient's primary care team, including information about any pain problems. Nurses, therefore, need to integrate knowledge of pain and its management into their repertoire of nursing skills, calling it into practice to meet diverse clinical situations.

\section{Positioning the literature}

The literature on pain management is extensive, and includes texts from medicine, nursing, physiotherapy, psychology, anthropology and sociology. The subject of surgical nurses' role in, as well as their practices of, pain management has been thoroughly investigated and discussed (Fagerhaugh \& Strauss, 1977; Nagy, 1998; Nash, Edwards \& Nebauer, 1993; Price \& Cheek, 1996; Wakefield, 1995; Watt-Watson \& Stevens, 1998). It is my belief that there is a large body of nursing literature which discusses nursing practice and role in managing pain from a position within the biomedical discourse (Cohen, 1980; McCaffery \& Beebe, 1989; McKinley \& Botti, 1991; Puntillo \& Weiss, 1994; Watt-Watson, 1992; Zalon, 1993). It is this discourse which has 
constructed a particular picture of what pain is and how it should be managed.

In my view, although valuable, much of this literature, as a consequence, presents only part of the picture because it fails to address important questions of why it is that nurses work with patients reporting pain in particular ways. It does not acknowledge the power dimension inherent in knowledge that has been constructed from a particular perspective, and that has a powerful influence on nursing thinking and practice, especially in relation to pain and pain management.

\section{Positioning the study}

My interest in pain and its management, coupled with a dissatisfaction with the picture predominating in the literature, led me to think about a study which would critically examine the language surgical nurses use to talk about their work with patients reporting pain. My growing aspiration to conduct a critical study into language was encouraged by a small project I carried out in a surgical ward of the hospital where I work.

The project focused on pain assessment, and involved working with the nurses on the ward to heighten awareness of the importance of pain assessment in pain management. My purpose was to investigate whether nursing practice and documentation of this aspect of patient care would alter with the increased awareness I hoped nurses would gain through involvement in the project.

Prior to the start of the above project I had conducted an audit of documentation on pain assessment with a review of observation charts and clinical notes. At the conclusion of my project, this was repeated to identify and record any changes to practice, which indeed there were. Increased awareness of the topic of 
assessment had resulted in more emphasis being placed on this aspect of documentation in both clinical notes and on observation charts (King, 1996, unpublished report).

As well, at the conclusion of the project, a small group of nurse participants had talked to me about the subject of pain in general, and in particular, the way in which the project had impacted on their practice. With their permission, the conversation was taped, and listening afterwards, I was fascinated by the way in which the nurses had talked about the patients reporting pain. I noticed how their "talk" presented a particular picture of the way they carried out the work of pain management, and how similar the language was to the discussions and conclusions being written up in the literature (for example, Halfens, Evers \& Abu-Saad, 1990; Wakefield, 1995).

It made me aware of how biomedical discourses permeate the language used to talk about nursing work, and looking behind it, at how this perspective colours attitudes towards patients especially those whose pain nurses assess and treat. It also made me realise how potent language is in terms of its influence; shaping and colouring how the world is seen and given meaning. Even the project I had conducted was influenced by a biomedical perspective on pain.

Yet, I surmised there was something else behind what these nurses were saying. The central focus of nursing is 'care of the body' and involves attending to the physical needs of the body, yet nursing work involves 'care of people' and is intersubjective (Carper, 1978; Gadow, 1980, 1985; Lawler, 1991; 1997; Taylor, 1994; Watson, 1979; 1985). According to this view, nursing is primarily concerned with the person, with embodiment and with attempting to understand what the person is experiencing. There is, therefore, a tension between 
biomedical and nursing discourses, and there was evidence of this in the conversations with the nurses. Could it be, I asked myself, that nurses work inbetween these two discourses, and if so, what other discourses of pain management might come to light if I were to examine the language of conversations devoted to the subject of pain management?

\section{PURPOSE OF THE STUDY}

The purpose of this study was to analyse surgical nurses' 'talk' about their work with hospitalised patients reporting pain in order to uncover 'discourses of pain management'. It aimed to examine how these discourses construct a particular reality/ies which determine surgical nurses' pain management practices. The intent was to uncover relations of professional power/knowledge in this context which, it is contended, support particular discourses and by so doing exclude other realities, such as those from the perspective of the person experiencing pain.

\section{CENTRAL ARGUMENTS}

The central theme of this thesis is situated around the subject of pain; how the body has come to be socially defined and inscribed with both object and subject status in pain management discourses. "Discourse" in the context of this study is the use of language as the medium through which relations of power, and knowledge associated with that power, are played out in social practices. This thesis takes the position that in the context of pain management, both the body and the patient are regulated by medical and nursing discourses. Each of these discourses constructs a particular view of the body and of the patient, which then becomes the location where social practices and knowledge/power are played out (Lupton, 1994; Nettleton, 1995; Turner, 1995). 
It is argued that material practices, such as the way nurses ask patients to rate their pain using pain scales or the nurse administering an injection to relieve pain, are invested with discourses. The use of such discourses reproduces the material basis of particular practices and thus the discipline or institution it is part of. By so doing, they perpetuate relations of power by legitimising certain types of knowledge and belief, which then become embedded as "commonsense".

\section{Conceptualising the 'body'}

Foucault's conceptualisation of the body as both a subject and object of knowledge/power inform some of the central ideas of this work $(1973,1977)$. He was not concerned with the material existence of the body per se, nor did he accept that there was such a thing as an 'authentic', or natural body. Instead the body, as both a site and target of power, is constituted through the action of power (Dreyfus \& Rabinow, 1982; Smart, 1985) and reproduced in discourses and specific practices, such as those of pain management.

The position taken in this thesis is that the body is defined as a text, one which is inscribed by discourses but read according to the context of the interpreter, for example, nurse or doctor. Furthermore, this thesis asserts it is through language that an understanding of the body and its place in culture and within nursing is mediated.

\section{Conceptualizing power; The use of surveillance}

This thesis maintains that any analysis and understanding of power necessitates a consideration of the interplay between discourses and social practices in the production of what is taken to be true/real in the disciplines of medicine and nursing. Power is exercised in the surveillance of individuals, and an important 
consideration is how the body and the patient as an individual has come to be known.

In medicine, it is the primacy of the clinical gaze (Foucault, 1973) as the technique which permits examination, analysis and use of the body for the construction of professional knowledge and power. Institutional practices of diagnosis and treatment work upon the body and generate knowledges of it (Armstrong, 1994; Nettleton, 1992, 1995). In order to know, the doctor must carry out an examination, a tool of surveillance that is very effective, and which in turn forms the central site for the functioning of disciplinary knowledge/power (Foucault, 1977).

Nurses also employ techniques to observe and record their evaluations of the patient when carrying out pain assessment and documenting the result. However, they extend their clinical gaze beyond the concrete condition of the patient's body, to move into the patient's private sphere of 'being'. This surveillance is no less powerful and knowledge-producing than that of medicine. The key difference is in the type of knowledge that is constructed and how this forms an ideological basis for the work of nursing to proceed.

\section{Defining "pain"; The biomedical perspective}

Foucault (1973), Lupton (1994) and Turner (1995) argue that a biomedical discourse has constructed the social reality of health and illness. This argument can be extended to the influence biomedicine has on how nurses and patients, and society in general, think about pain and how it is managed. Within this discourse, pain is regarded as an objective phenomenon manifested as both a physical and cognitive entity, overlaid with an emotional response (IASP, 1979; Melzack \& Wall, 1988). This thesis maintains that this creates a particular 
image of what pain is or can be.

This thesis also contends that surgical nurses are equally immersed and implicated in the biomedical construction and definition of pain. It is argued that as a result, the knowledge, attitudes and beliefs they hold about pain are heavily influenced and constrained by this reality. In particular, reproduction of pain discourses shaped by biomedicine can be seen through adherence to such practices as the use of verbal rating scales for the measurement of pain, emphasis on pharmacological therapies and compliance with strict protocols for regulating the monitoring of patients.

\section{Working with "pain"; The nursing perspective}

In an attempt to resist biomedical discourses, nurses have placed increasing significance on the uniqueness of nursing as centred around the patient as an embodied subject (Gadow, 1980; Lawler, 1991, 1997; Watson, 1985). Nursing invokes this alternative 'philosophy' by emphasising the experiential nature of illness/hospitalisation. Likewise, pain can be situated within this similar perspective, with the patient who is 'living the pain'. It follows that care of the patient in pain (as opposed to the patient "with pain") must be centred around the nature of the interaction that takes place between the nurse and the patient.

"Knowing the patient" has in consequence become an important means for understanding the lived experience of the person, and it would follow this too has implications for the way nurses work with patients in pain. To 'know' patients, nurses must establish a way of communicating with the patient which will allow them access to the subjective experience. This thesis argues that since both subjectivity and an experiencing subject can only be known through conversation, language becomes the means for the constitution of another reality 
for nursing (May, 1992). This thesis further maintains that discourses of nursing predicated on "knowing the patient" through "embodied" relationships are themselves constructions which have a direct relationship with professional knowledge and power.

\section{RESEARCH APPROACH}

This thesis undertakes a critical discourse analysis of the transcribed conversations ("talk") of four registered nurses working in the surgical specialty. The transcribed "talk" is viewed as the text which is analysed to reveal the discourses hidden within it. These discourses are examined for what they surface about relations of power/knowledge. The framework selected for my own critical discourse analysis was an amalgamation of some of the ideas articulated by Fairclough $(1992,1994)$ and Potter and Wetherell $(1987,1994)$.

The nurses were recruited from the pool of registered nurses working in the same organisation as myself. This raised certain key ethical issues that demanded attention in the process of applying for ethical approval. These included anonymity, confidentiality, conflict of interest, informed consent, the participant's right to decline and potential harm to participants. These concerns were addressed and minimised through taking specific precautions, including the use of an intermediary during the recruitment phase of the research.

\section{STRUCTURE OF THESIS}

The thesis is structured in the following way. Chapter Two presents a review of the literature, in particular, perspectives on pain which include those of biomedicine and pain as 'embodied experience'. The chapter also considers literature pertaining to nursing discourses regarded as possibly having an influence on the way surgical nurses talk about working with patients reporting 
pain. Chapter Three presents the relevant theoretical perspectives that underpin the research methodology and method with a discussion on the current theories and conceptualisations of 'discourse'.

It also draws selectively on the ideas of Michel Foucault (1970, 1972, 1973, 1977). In particular, his conceptualisations on professional power, knowledge and the body as both a site and construction of subject/object knowledge provide an important post-structuralist analysis and critique of the significance of language in the construction of social relations and practices.

Chapter Four outlines the methodology and method of critical discourse analysis as explicated by Fairclough (1992, 1994) and Potter and Wetherell (1987, 1994), and sketches out the framework adapted from these ideas that form the critical discourse analysis undertaken in this thesis. This comment on method includes a review of why critical discourse analysis was chosen as the most suitable method to do my research and the problematic aspects of such an approach. The chapter then outlines the research process undertaken in this thesis, which includes both the philosophical and pragmatic aspects. Ethical issues and concerns are addressed in this chapter also.

Chapters Five and Six present and discuss the results of this analysis, while Chapter Seven summarises the aims of the research, assesses the results in relation to those aims, and sets out the conclusions of the study. This final chapter also briefly discusses the limitations of this study, considers the implications and contributions it makes, and concludes with some recommendations for further research. 


\section{SUMMARY}

This chapter has outlined the background to, and intentions of, this study. It has also presented a synopsis of the central themes and arguments that inform this work, and the research approach. These will be more fully explored and developed in subsequent chapters, as outlined above. In summary, the thesis argues that the practical work of nursing patients who report pain is predicated on certain discursively produced understandings of the body/patient. Furthermore, the thesis maintains the surgical nurses' "talk" will reveal evidence that, because of their differing approaches, discourses of both biomedicine and nursing influence this work. 


\section{CHAPTER TWO \\ Reviewing the literature: \\ Pain perspectives and nursing practice}

\section{INTRODUCTION}

Chapter One introduced the central themes and arguments of the thesis. This chapter presents a critical review of the literature which illustrates how particular understandings of the body and of the patient have been created, and what relationship this has to professional knowledge and power. Given that the theme of this thesis is the subject of pain, the present chapter therefore focuses on examining some of the vast collection of material on pain taken from medical, nursing, anthropological and sociological texts.

The questions this study sets out to answer are firstly, what influence does biomedicine have on surgical nurses' thinking and practice in the context of pain management, and secondly, where might nursing ideas about the patient and the work of nursing sit in this same context? The premise is that the ways in which surgical nurses talk about their practices of managing pain may reveal that this work is influenced in different ways by both biomedical and nursing discourses. The review in this chapter therefore includes a review of nursing discourses regarded as possibly influential in the way surgical nurses might talk about their work 'caring for' hospitalised patients reporting pain.

\section{PERSPECTIVES ON PAIN}

The word 'pain' has a variety of connotations that are widely used to convey different meanings depending on the context (Autton, 1986; Waddie, 1996). Pain for instance can describe a 'broken heart', or refer to someone who, or 
something that, is considered a 'pain in the neck'. There are also a number of different dimensions to, and philosophical perspectives on, the term 'pain', such as inflicted pain as "torture" (Madjar, 1991), the pain of childbirth as "triumph" (Leap, 1996), and pain as "a gift" (Brand \& Yancey, 1993). The present work however, confines itself to a review of the literature pertinent to the scope of this study.

This chapter begins with an overview of the development of perspectives on pain, particularly those of biomedicine and pain as 'embodied experience'. This review will critique these perspectives and how they have shaped particular pain discourses and the issues they raise regarding the power of professional knowledge. The chapter then moves to a discussion of other relevant influences such as nursing discourses regarding embodiment and nurse-patient relationships, and, significantly, how they might influence the way surgical nurses talk about pain management.

\section{The history of the biomedical perspective on pain}

How pain is perceived, the meanings attributed to it as well as the ways in which societies and different cultures have responded to pain, have altered over time (Autton, 1986; Melzack \& Wall, 1988; Morris, 1991). For centuries, objective knowledge of what pain was or what triggered it could be understood only by what little early societies and cultures knew of the body and the language and beliefs they had to express themselves and that cultural understanding.

The advent of biomedicine moved the meaning and definition of pain into the realms of scientific theories, just as "illness now finds its explanation in the natural world of biological process", writes Morris (1991, p. 33). Descarte's 
(1596-1650) classic 'mind-body' dualism is credited with the development of positivist epistemology (Carter, 1998; Morris, 1991; Novy, Nelson, Francis \& Turk, 1995; Rose, 1994; Turner, 1995). Indeed, Descarte's (1664) "specificity theory" which proposed the idea of a sensation that travelled via a pathway to the brain, marked a turning point in objective knowledge about pain (Bendelow \& Williams, 1995; Melzack \& Wall, 1988; Morris, 1991). According to this simplistic model "pain is like a bell-ringing alarm system whose sole purpose is to signal injury to the body" (Melzack \& Wall, 1988, p. 10).

Thereafter, theories of pain changed little until the nineteenth century "when physiology emerged as an experimental science" suggest Melzack \& Wall (1988, p. 196; Gamsa, 1994). Access to bodies for the purpose of studying anatomy and physiology meant that scientists and doctors alike could carry out experiments to prove hypotheses. From their 'findings', they were able to construct new knowledge (Peerson, 1995; Rose, 1994; Turner, 1995). The studies conducted by early anatomists and physiologists into the causes of pain established "that the brain is aware of the outside world only by means of messages conveyed to it by sensory nerves. The qualities of experience, therefore, are somehow associated with the properties of sensory nerves" (Melzack \& Wall, 1988, p. 196; see also, Bonica, 1977; Sinatra, Hard, Ginsberg \& Preble, 1992).

This reductionist explanation of pain as the sensory output of nervous impulses, even down to the qualities of that experience as tied in with the nerves themselves contributed to the following. Firstly, the emphasis on a neurophysiological basis for pain led to specific classifications of pain into 'acute' and 'chronic', and secondly, it omitted any acknowledgement that pain and the meaning pain has is shaped by both the person and his/her particular 
sociocultural environment (Autton, 1986; Bendelow \& Williams, 1995; Morris, 1991). Indeed, Morris (1991, p. 1) contends "pain is never the sole creation of our anatomy and physiology. It emerges only at the intersection of bodies, minds and cultures."

\section{Incorporating psychological explanations into pain discourses}

The introduction of an account of influences of psychological processes on pain perception and response was formally proposed by Melzack and Wall in 1965. Known as the 'gate-control theory', it was an attempt to move away from the purely anatomical and physiological conceptualisation of pain characterising the biomedical model by recognising the place of cognition and higher brain centres on pain processes (Flor, Birbaumer \& Turk, 1990; Melzack \& Wall, 1988). It also incorporated acknowledgment that sociocultural factors, such as learning and experience, have an impact on the physiological processes involved in pain perception and response (Gamsa, 1994; Novy, Nelson, Francis \& Turk, 1995).

The recognition and acceptance of cognitive and behavioral components resulted in a more multi-dimensional conceptualisation of pain (Gamsa, 1994; Novy et al. 1995). In 1979 after much work, the International Association for the Study of Pain (IASP) released its description of pain as "an unpleasant sensory and emotional experience arising from actual or potential tissue damage or described in terms of such damage" (cited in MacIntyre \& Ready, 1996, p. 7). This definition of pain incorporates both the physiological and psychological components and is widely cited in texts on pain (MacIntyre \& Ready, 1996; Novy et al., 1995; Salerno \& Willens, 1996; Sinatra et al., 1992).

Bendelow and Williams (1995) however, remain critical, pointing out "although the gate-control theory signals the end of the mind/body split with regard to 
pain, the biological remains dominant over the social" (p. 143). Instead the authors suggest "pain is simultaneously both physical and emotional, biological and phenomenologically embodied" (p. 147). There is a need to be reminded they say "that each of us is a body and has (i.e. experiences) a body" (p. 147). The human body and embodiment distinguish the objective/subjective, separate the impersonal from the personal, the natural and the social. Although the emphasis of the biomedical approach to pain is on the impersonal, objective and natural, acknowledgment of the psychological and emotional qualities of pain as 'experience' resites the person. It is pain as "embodied" experience that this next section discusses.

\section{Focusing on the subjective; Pain as "embodied" experience}

Turner (1992, p. 168) writes that pain is one of a "great variety of human problems which are essentially grounded in our embodiment." Furthermore, when we recognise the 'emotional' quality of pain, he suggests, "we are immediately considering the idea of the person as an embodied agent with strong affective, emotional and social responses to the state of being in pain" (p. 169). In this context, work done by Leder (1990) is regarded by Bendelow and Williams (1995) among others, as particularly important, because he "has attempted to develop a phenomenological approach to pain as a form of bodily dys-appearance" (p. 148). According to this approach, people in a state of health are consciously unaware of their bodies. As Leder (1990) explains:

whilst in one sense the body is the most abiding and inescapable presence in our lives, it is also characterized by it absence. That is, one's own body is rarely the thematic object of experience ... the body, as a ground of experience ...tends to recede from direct experience (p. 1).

It is only when something out of the ordinary, such as succumbing to an illness 
or disability, or it is made to do an activity it is not used to, that the body is brought sharply into focus. Madjar (1997, p. 56) explains "what illness and pain often have in common is their capacity to call forth the awareness of the body, hitherto ignored, taken for granted, and simply lived." Pain, as catalyst, forces sufferers to turn their gaze inwards towards their bodies, to perceive and experience their bodies in a different way. Pain presents as something that demands attention; it cannot be ignored. It changes a person's way of 'being-inthe-world'; it disrupts lives, either temporarily or more permanently when the pain lingers.

"As such, pain re-organises our lived space and time, our relations with others and with ourselves," explain Bendelow and Williams (1995, p. 148). It is this quality of pain which makes it so difficult to grasp - that "one's whole being plays a part in the pain, and to concentrate on the diseased or injured area misses the event" points out Smith (1998, p. 33). In terms of understandings of pain therefore, embodiment is an essential component. Pain cannot be reduced to the Cartesian mind/body split which reflects the biomedical approach. Pain happens in the physical body, but it is the embodied person who perceives it, interprets it and responds to it. Put another way, pain as an experience has meaning for the sufferer.

It is just as important to recognise, however, that both these perspectives are very much responses to dominant socio-cultural and political interpretations/constructions which have differed over time (Armstrong, 1994; Lupton, 1994; Nettleton, 1995; Turner, 1995). The way pain is defined in terms of biological processes and embodied experience reflects particular ideas about the body/mind and person. It is to a consideration of how these perspectives have shaped particular pain discourses and the issues this raises regarding the 
relationship between professional knowledge and power that the discussion now turns.

\section{PAIN DISCOURSES AND RELATIONS OF POWER/KNOWLEDGE}

It is contended that the 'natural' categories of disease and the symptoms and signs of such are constructions (Good, 1994; Lupton, 1992, 1994; Nettleton, 1995; Turner, 1995). Indeed, Good (1994, p. 66) argues that "biology is not external to but very much within culture, and [that] clinical medicine constructs persons, patients, bodies, diseases, and human physiology" (emphasis his). Likewise, the contention is that the theories of pain which have become dominant are socially contingent (Armstrong, 1994; Good, 1994; Nettleton, 1992, 1995). Through the medium of language and using particular ways of looking at the body, medicine has constructed a different reality that has been legitimated as the truth because it is based on science, and is therefore regarded as authoritative knowledge.

The biomedical emphasis on pain as triggered by specific neurophysiological processes and thus seen as a symptom of bodily dysfunction constructed a particular approach to pain management. It has, for instance, led to the development of a specialty field of medicine, or anaesthetics, led by 'specialists' who are considered "experts" in their field. As Melzack and Wall (1988, p. 9) comment, "the problem of pain was therefore transformed from a mere symptom to be dealt with by the various medical specialties to a specialty in its own right ..." The establishment of acute pain services (APS) and chronic pain clinics are examples of the growth of specialty services working solely with patients in pain. These services are a relatively recent phenomenon, certainly since the early 1980s (Watts, 1998). As a result, there is the consolidation of a particular way of viewing and working with patients reporting pain, that is 
regulated and overseen by 'pain specialists'.

Two particular discourses have emerged from the constructions "acute" and "chronic" pain and the more recent approach which emphasises the subjective nature of pain as "embodied experience". The first discourse is entitled "'real pain' has a clinical pathology", while the second calls for taking the patients' description of their pain as valid and is entitled "pain is what the patient says it is". It is to a consideration of these that the discussion now turns.

\section{'Real pain' has a clinical pathology}

The construction of the classifications 'acute' and 'chronic' pain were the result of the biomedical perception of the body as a source of objective knowledge. Because of this emphasis on the pathophysiological basis of pain, acute pain is more readily accepted, whereas chronic pain is not (Flor et al., 1990; Good, 1994). Acute pain is recognised as part of the body's sophisticated warning system; it tells the person that something is amiss. Once the cause is established and treated, the pain is expected to disappear.

In contrast, "chronic pain challenges a central tenet of biomedicine - that objective knowledge of the human body and of disease are possible apart from the subjective experience" asserts Good (1994, p. 117). Medical practices he says are designed to deal with certainty. With chronic pain, the aetiology by which medicine seeks to explain the pain is more often than not uncertain. For a large numbers of sufferers, there is no diagnosis or cure in medical terms. Furthermore, Good continues "it is thus proclaimed subjective, a functional disorder of the subjective self, now held responsible for producing its own suffering" (p. 132). The pain is all in the mind. The message is self-evident, chronic pain is the illness. 
As a result, "we live with the legacy of the notion that 'real pain' is something that is acute with an easily observable physiological pathology ..." state Bendelow and Williams (1995, p. 145). The importance that has been attached to pathophysiology in defining the objective reality of pain is without doubt one of the coercive facets of the biomedical model of pain. Indeed, a critical dimension to the discussion in the literature is that of the role physical pathology plays in nurses' assessment of patients' pain, and acceptance of patients' reports of their pain (Fagerhaugh \& Strauss, 1977; Halfens, Evers \& Abu-Saad, 1990; McKinley \& Botti, 1991; Taylor, Skelton \& Butcher, 1984; Wakefield, 1995).

\section{The influence of this discourse on nursing practice}

In 1977, sociologists Fagerhaugh and Strauss published the results of their two year study observing the pain management practices and staff-patient interactions in eight hospitals in and around San Francisco and Northern California. The purpose of their research was to propose a different perspective on pain taken from within the organisational settings in which pain management and patient care took place. In terms of the literature on pain and its management, Fagerhaugh and Strauss's work was a radical departure from other studies in that theirs focused on the politics of pain management, and in so doing this researcher argues, revealed the professional knowledge/power dimension in this aspect of patient care.

Fagerhaugh and Strauss comment early on in their book about relations of power, particularly with regard to the powerful positions doctors hold in the hospital and the influence they have over defining "disease" and "treatment". They say:

clients tend to be regarded as having malfunctioning biological systems ... and 
they are regarded as "cases" to be diagnosed and treated as skillfully as possible ... Understandably, the management of pain, whether diagnostic or symptomatic, is no less subject to this medical ideology and its powerful organizational expressions (1977, p. 5).

Fagerhaugh and Strauss also reflected on the impact such thinking had on other staff, especially the nurses, concluding that because the staff were embedded in a disease-oriented philosophy, the social and psychological aspects of disease were under-acknowledged. This, particularly in relation to pain work, had major consequences for staff-patient interactions.

Their investigation revealed various dimensions of pain work, the working with patients in pain, or "managing pain" as was commonly talked about, and it was not just about work to help minimise or relieve patients' pain; it involved "profoundly political aspects" (Fagerhaugh \& Strauss, 1977, p. 9, emphasis theirs). By this the authors meant that when patients were admitted to hospital, they entered "the home terrain of the staff, especially of the physicians and nurses, and they make and enforce the basic rules which prevail on their wards and around the bedside" (pp. 8-9).

Of the dimensions of pain work, the authors identified the work that went into handling patients' expression and endurance of pain, the strategies that were employed to gain patients' cooperation (compliance) and the use of "pain trajectories". In speaking about these, Fagerhaugh and Strauss (1977) highlighted those that were 'expected' and legitimated as a result, while the consequence of any 'unexpected' pain trajectory was that it was perceived as illegitimate and would usually affect staff-patient relations in a negative way. Explain Fagerhaugh and Strauss (p. 22) "patients with an unexpected or atypical 
trajectory tend to be labeled as "uncooperative" or "difficult," and relations between them and the staff are likely to grow progressively worse" (1977).

Nurses' assessment of pain usually relied on the verbal report of the person in pain, yet the authors found that issues surrounding the patient's credibility became important when the pain claimed by the patient was contested by nursing staff. In such circumstances the patient had to make the pain plausible. However, "if the claimed pain matches the expected illness trajectory, then [the nurse] is very unlikely to doubt the self-assessment" (Fagerhaugh \& Strauss, 1977, p. 141).

The study by Taylor, Skelton and Butcher (1984) arose out of an earlier and similar study by Burgess (1980) who observed "... the tendency of health care professionals to dichotomize pain into organic and functional/psychogenic types ..." (Taylor et al., 1984, p. 4). The major reason for such behaviour, they claimed resides with the traditional medical model which regards illness and pain as primarily physical responses to organic dysfunction.

Their experimental study involved 268 registered nurses drawn from a variety of specialty areas and medical-surgical nursing units, with the majority, $67.9 \%$ of study participants recruited from the latter. Using hypothetical patients, as did Burgess (1980), Taylor et al. (1984) attempted to distinguish acute from chronic pain syndromes, and their influence on nurses' estimates of patient suffering, actions to relieve pain and their attitudes towards the patients.

The conclusions reached by Taylor et al. (1984) were in keeping with those reached by Burgess (1980); that evidence of pathology altered the nurses' perceptions of the patient and the way in which they responded to the pain, and 
Taylor et al. (1984) conclude:

strikingly illustrates the role of classic, biomedical models of pain in mediating staff's judgements of patients in pain [Furthermore], assessments of patient suffering, willingness to consider analgesic medication for pain relief, and attitudes toward the patient depend largely upon the patient's presenting positive evidence of physical pathology (p. 7).

In 1990, Halfens, Evers and Abu-Saad replicated the Taylor, Skelton and Butcher (1984) study, except that Halfens et al. included student nurses as well as registered nurses in the study group. The authors' results, namely the presence or absence of physical pathology for the assessment of patients' pain and the perception of the patient by the nurses, were in keeping with Taylor's et al. (1984) findings. The authors concluded "... that in order for pain to be present tissue damage should have occurred is unfortunately still widely held in the health care arena" (p. 48).

The studies so far referred to are dated and it could be argued that their results may no longer be relevant, because nursing perspectives on pain and its management may have shifted. It is my belief however, that, as Halfens et al (1990) concluded, unfortunately nurses, and doctors too, still focus on a physical basis for pain. This view is supported by the findings in Wakefield's (1995) study, which examined how nurses referred to pain and pain management in their talk. The author wrote "an intrinsic feature of nurses' pain management techniques reveals them predominantly clinging to reductionist strategies" (p. 906). In keeping with the findings of Fagerhaugh and Strauss (1977), Taylor et al. (1984) and Halfens et al. (1990), Wakefield (1995) concluded also, that "nurses (and to a large extent doctors) assume that pain experienced by the individual can, and should, only be manifest in the presence of an identifiable 
cause" (p. 906).

Wakefield's (1995) study is of particular interest because of its similarities and the possible relevance of its conclusions to this present study. She conducted a series of in-depth unstructured interviews lasting approximately an hour with a group of five registered nurses. During the interviews the nurses were invited to discuss their ideas regarding postoperative pain management, particularly how they thought it could be managed in order to make it more effective. Using a process she called 'reflexive analysis', Wakefield's aim was to explore the talk for what it revealed about nursing knowledge and understanding in terms of pain, and how this shaped pain management practices.

The talk revealed that specific pain management philosophies were operationalised by the nurses working in surgical areas. These Wakefield found were based on Cartesian ideas centred around cause and effect. Furthermore, Wakefield's study revealed how the nurses tended to categorise patients according to symptoms of pain or overt pain behaviours. The surgical patient for instance had an acceptable reason to have pain, due to the invasive procedure undertaken. In such cases, the pain was validated and the nurse willingly acted to alleviate the pain. In other circumstances, such as when pain continued beyond a reasonable time period, publicly displayed pain behaviours were regarded, said Wakefield, as "an immoral means of securing additional doses of the prescribed medication" (1995, p. 906).

Although the studies presented cannot be taken as representative of what is commonplace in nursing patients in pain, they provide an illustration that when it comes to pain management, notions of what pain is and whether it is acceptable for this patient's situation appear to reside very much with the staff, 
and particularly with the nurses. This may have implications for the provision of adequate relief of pain. It begs the question, will the participants' "talk" in my study reveal similar discourses about what constitutes "real pain", and if so, how might such discourses influence how they speak about managing patients' pain?

The results of the studies discussed above also reveal the relationship between professional knowledge and power, as noted earlier on page twentytwo. Because the biomedical construction of pain has advanced the notion of bodily dysfunction in association with pathophysiological disorder, it is now difficult to move beyond this view of pain. As the studies revealed, nurses appeared to have taken on board this dominant idea of what constitutes pain and used it to influence their interactions with those patients reporting pain. The studies provided evidence that other realities of pain were effectively excluded because of the embedded nature of pain discourses shaped by a biomedical construction of pain and approach to pain management. This is in contrast to the currency of ideas of pain as multidimensional and which emphasise it as a uniquely subjective experience. It is to the second of the pain discourses that this discussion now turns.

\section{"Pain is what the patient says it is"; Incorporating this into nursing practice} It was Margo McCaffery (1979) who introduced to nursing the notion that "pain is whatever the patient says it is, existing whenever he says it does" which has become a central tenet of nurse education, practice and research (Carr, 1990; Dufault, Bielecki, Collins \& Willey, 1995; Gujol, 1994; Harrison, 1991; McCaffery \& Ferrell, 1997; Stephenson, 1994; Zalon, 1993). Indeed, whole chapters in nursing textbooks devoted to the subject of pain assessment explicitly identify the nurse's responsibility to ask the patient whose pain it is what the 
pain is like (Carroll, 1993; Lewis, Collier \& Heitkemper, 1996; McCaffery \& Beebe, 1989; Willens, 1996). As Willens (1996, p. 19) for example, points out "the most important and reliable aspect of pain assessment is the report given by the patient."

However, the emphasis placed on patients' reports of pain should be challenged, argue Price and Cheek (1996). The authors explore the nursing role in pain management and suggest that the way in which pain is defined and the role assigned nurses are discursively constructed. They contend that nurses are constrained by a particular reality which excludes any other way of thinking. Accordingly, the reliance on patients' self-reports is yet another example of how understandings and meanings of pain are embedded within the biomedical discourse. They claim that "within scientific-medical discourse ... patients' pain and the measurement of that pain, not the patient as a person, become the focus of attention. Pain is outside the person and what is 'said' assumes truth value" (1996, p. 902).

What pain scores, visual analogue scales and descriptors do is simply quantify and therefore, effectively disembody that which is 'lived experience' and embodied. The authors advocate resistance to this dominant discourse, encouraging nurses to "provide patients the space to speak out and not interpret what is said within the scientific-medical discourse" (1996, p. 901). Both nurses and patients are constrained by this reliance on pain reporting which enshrines as objective truth a person's pain experience.

The authors are quick to point out that they are not inferring that patients should not be asked to speak about their pain. Rather, nurses should challenge the dominance of the medical construction of pain and its reliance on objective 
indicators and measurement tools, and use other means to assess the pain patients' experience. Price and Cheek assert that nurses and patients should have the space to develop a meaningful interaction where nurses support the person as an individual. This, they contend, will expand the nursing contribution to pain management by involving the nurse more completely in the implementation of effective pain relief.

The difficulty with Price and Cheek's (1996) arguments is that while they expose the association between professional knowledge and power in relation to the construction of the scientific-medical discourse and pain, they fail to critically explore this dimension within the nurse-patient relationship. Instead, they seem to regard the nature of the nurse-patient interaction as unproblematically reflecting individualised care. Their assertion that in relation to pain assessment, nurses' interpretations are "based on an understanding of the patient as an individual who has been allowed the space to speak" (1996, p. 901) raises the question, what happens when patients are not given the space to speak, they cannot speak or they choose not to? In this way it fails to acknowledge that either the relationships or the interactions between nurses and patients are predicated on relations of power.

It is my contention that such assertions can themselves be critiqued as discursively constructed, because they fail to acknowledge that within nursing itself, certain ways of thinking about patients and the work of nursing has constructed realities which exclude other ways of thinking and therefore, other possible realities. Of the nursing discourses, for instance, prominent is the claim that nursing is concerned with the subjective, that is the embodied experience of illness/disease, and that fundamental to the success of nursing work is the establishment and maintenance of a caring relationship based on "knowing the 
patient" (Benner, 1984; Benner \& Wrubel, 1989; Carper, 1978; Gadow, 1980; Lawler, 1991, 1997; Morse, 1991; Morse, Bottorff, Anderson, O'Brien \& Solberg, 1992; Tanner, Benner, Chesla \& Gordon, 1993; Taylor, 1994).

These discourses apparently play an important part in how nurses regard the work of nursing, and this may include pain management. It is to a consideration of these discourses and significantly how they might influence the ways in which surgical nurses talk about pain management that this chapter now turns.

\section{NURSING DISCOURSES; 'BODIES' AND 'EMBODIED' RELATIONSHIPS}

It almost goes without saying that nurses are, and the work of nursing is, concerned with the material body, that is, the physical body. It is after all the physical body which nurses attend to in the context of 'caring for' patients; nurses wash, turn, perform wound dressing changes on, stick needles into, attach monitors to 'bodies'. As well, the location of the subjective and embodied relationships have become regarded as central dimensions within nursing (Gadow, 1980; Lawler, 1991; 1997; Taylor, 1994; Watson, 1979, 1985).

Lawler (1991, p. 30) asserts that nurses "are fundamentally concerned with the physical care and comfort of patients - subject matter which does not readily lend itself to scientising, at least to the extent that science means objectification and reduction." According to this view and as noted already in this chapter, medicine focuses on the body as a vessel for disease/illness (or pain) which separates the body from the person inside it. As Madjar (1997, p. 55) explains, "from a phenomenological perspective, the body is our basic mode of being in the world; consciousness is embodied consciousness, and a person is an embodied being, not just a possessor of a body." 
The embodied subject is one who lives within the physical body, which acts as the mediator between the 'self' and the world in which it lives. In accordance with the perspective which emphasizes 'embodiment' therefore, in carrying out the work of nursing, nurses interact with both the physical body and the embodied 'self'. This perspective also suggests that although nurses attend to the bodily needs of patients, they cannot be isolated from the person inside the body. Thus, whilst performing cares on the physical body, nurses touch, massage, soothe, and connect with the person. In this way, nurses reintegrate the subject/object that medicine dichotomises. As Gadow (1980) expresses it:

nursing is uniquely able to mediate the lived/object body duality, inasmuch as it addresses both aspects of the person as one. It affirms the value of the lived body through the intimacy of physical care and comforting. At the same time, it affirms the reality of the object body by interpreting to patients their experience in terms of an objective framework - usually science, in Western cultures...(p. 96).

Integral to this perspective too is the centering of the individual's experience and involvement as essential components of nursing practice (Appleton, 1993; Watson, 1979, 1985). Nurses furthermore, are positioned as critical mediators in the interaction because it is regarded that the way in which nurses work with and invite patients' participation as partners in care that "embodied" relationships will develop. For such special relations to evolve, nurses must give something of themselves and 'engage' in the care encounter (Ashworth, Longmate \& Morrison, 1992; Benner \& Wrubel, 1989; Carper, 1978; Morse, 1991; Morse, Bottorff, Anderson, O'Brien \& Solberg, 1992; Watson, 1985). As Carper (1978) described it, this kind of relationship is "concerned with the kind of knowing that promotes wholeness and integrity in the personal encounter, the achievement of engagement rather than detachment..." (p. 20). 
Accordingly, it is during this process of building relationships with patients that nurses 'connect with' and get to know the 'real' person (May, 1991, 1992; Morse, Bottorff, Anderson, O'Brien \& Solberg, 1992; Tanner, Benner, Chesla \& Gordon, 1993). Indeed, the results of their study examining the development of expertise in critical care nurses led Tanner, Benner, Chesla \& Gordon (1993, p. 279) to conclude that "knowing a patient is a central aspect of nursing practice and is pervasive in everyday practical discourse of nurses."

Writing of nursing's shift away from the objective to subjective status of patients in terms of the "professional imagination", May and Fleming (1997, p. 1097) suggest that it "provides a point of departure for the construction of a professional identity, its projection into interactions and relationships, and the capacity to organise those relationships in a way that makes them meaningful." This new 'discourse' provides the framework for the everyday practice of nursing, giving it meaning and purpose, whilst also setting up a way of thinking about and enacting professional relations in terms of "aspirations and achievements" (May \& Fleming, 1997, p. 1097).

A changing orientation to the work of nursing, May and Fleming suggest, has meant that nurses can think of caring in the context of an embodied relationship with another human being, and in ways which enhance the quality of care given by nurses to patients. An alternative view would be to suggest that such ideas which construct a certain way of looking at the world of nursing, and at patients illustrate the relationship between professional knowledge and power (Armstrong, 1983b; Lupton, 1994; May, 1992, 1995; May \& Purkis, 1995; Rudge, 1997; Salvage, 1990). It is to a consideration of these ideas that the discussion turns now. 


\section{'Embodied' relationships; Constructing knowledge, relations of power}

Armstrong's earlier work (1983b) suggested that "nursing has become a surveillance apparatus which both monitors and evinces the patient's personal identity: in so doing it helps fabricate and sustain that very identity" (p. 459). Similarly, one might begin to turn Armstrong's ideas about the fabrication and maintenance of the patient's identity towards a consideration of how a nursing identity has been formed. What he suggested could be likened to how nursing and the nurse's objective and subjective identity have been constructed out of particular readings of what it is that nurses 'do' and how they are 'seen' by society.

Sharing Armstrong's critique of nursing as a "surveillance apparatus", Lupton (1994) claims that an "ideology that positions nurses as empathetic, striving to 'know the patient' as an individual, as a 'whole person' rather than as just a set of symptoms, can be interpreted as an explicit exposition of surveillance and disciplining of patients' bodies" (p. 122). Lawler (1991) would submit however that the subjection of the body and of the individual is dependent upon the character or 'quality' of the gaze, and that the 'nursing gaze' is more therapeutic in character than the penetrative gaze of biomedicine which elicits different types of information and constructs different types of knowledge. Lupton (1994) however disagrees, stating:

for nurses, the clinical gaze is extended from the external feature of the patient's body to the private thoughts, feelings and everyday lives of patients, in the quest to find the patient's 'real' or 'authentic' character in a way which may be considered even more intrusive (p. 122).

According to the views of writers such as May (1992) and Lupton (1994), the aim of surveillance through such actions as conversation and observation is to 
reveal the 'who' of the person. In demanding to know the whole patient, the public/private spheres of the patient's life become blurred, making the patient more malleable. However it is put, the intent of the nursing gaze is still the same, and that is to elicit information in order to construct knowledge, and with that knowledge there is associated power (May, 1992; see also, Cheek \& Rudge, 1994, p. 21).

This is not to suggest that patients are themselves powerless, or that the results of such power are negative; power relations can be productive. Patients exercise power by resisting nurses attempts to "know" them; they can disrupt nursing work by acting in a 'non-compliant' manner, and may even challenge the nurse's authority to know what is best for them by questioning the nurse's intent. All these act as modes of resistance to surveillance. Thus, as Gilbert (1995, p. 869) expresses it "individuals [are] vehicles of power. They simultaneously undergo and exercise the effects of power."

\section{Significance of language}

In essence what writers such as Armstrong (1983b), Cheek and Rudge (1994) as well as Rudge (1997) are advancing is that ideas of nursing as centred around embodied relationships fail to acknowledge the 'subject' as a construction of language and social processes. Indeed, Crowe (1998) suggests that it is not 'subjects' who have experiences, but rather 'subjects' who are constituted by experiences, and here is included the notion that 'subject' could refer to either 'nurse' or 'patient'.

Rudge (1997, p. 76) likewise reminds readers that "language mediates, shapes and constrains our attempts to understand the place of bodies within our culture and hence within nursing." Post-structuralist perspectives such as the one held 
by Rudge argue that it is in how language use (both metaphoric and discursive) and power relations converge that creates a particular form of the body (as object), and of the individual (as subject). Indeed, language is integral to how nurses (and doctors) think about and work with bodies as objects and patients as subjects.

Further, ideas such as embodiment are fraught with contradictions in that from a post-structuralist perspective, they are constructions and as such become discourses. As Cheek and Rudge (1994, p. 20) explain "the meanings of the body are not pre-given sociocultural realities ... but are conceptualizations that arise from, and form, 'texts' about the body" (emphasis theirs). This means that notions of nursing as embodied care are problematic because they neither acknowledge nor explore power relations which are implicit within such discourses.

The mediation of power through the use of specific language and discursive practices is examined in a paper by May and Purkis (1995). The authors critically explore some of the processes and practices through which power is enacted in nursing work. Taking an extract from their ethnographic study of surgical nurses, May and Purkis use the example of a nurse 'managing' the situation of 'persuading' a patient to take prescribed pain medication. The nurse is positioned as the 'authority' on pain and its management, whereas the position held by the patient is one of not fully comprehending the outcome of being inadequately medicated.

The interaction between the two is a picture of negotiation and a repositioning of the lines/boundaries of the relationship with the patient being "...'disciplined' into particular accounts of surgical pain," state May and Purkis (p. 291). 
Resistance by the patient is suggestive, say the authors, of the possibility of nursing work being driven by patient definitions of comfort rather than what the institution has decided and defined as 'comfort'. This ability of the patient to decline to enter into the dominant discourse, allows for an alternative discourse to emerge. However, the authors conclude that primarily what has gone on "...involved the deployment and the operation of bureaucratic circuits of power on the part of the nurse" (p. 291).

Similarly, Hewison (1995) examines nurses' power in interactions with their patients as mediated through the language used by participants in his observational study of nurses working on a ward looking after elderly people. Hewison spent thirtyseven and a half hours observing nurse-patient interactions which he then analysed using the principles of the grounded theory approach (Glaser \& Strauss, 1967). He was particularly interested in the nature of the interactions and the language used as illustration of the power relation inherent in nursing work.

He concluded that the power dimension present in nurse-patient relationships creates a barrier to open and meaningful communication between the participants in an interaction, regardless of what or who initiated it. Furthermore, Hewison claims, nurses do this by controlling the content of the interactions, and "the language used directs the outcome of the interaction to the end the nurses desire ..." (1995, p. 80).

Although the context for and methodological framework of Hewison's study was different from that of the present study, it remains pertinent for what it reveals about the power dimension inherent in the language nurses use in everyday practice, and how language shapes the reality of nursing work including how 
nurses think about that work and the relationships they have with patients. The question is how might ideas about 'embodiment' and nurse-patient relationships as explored above influence surgical nurses' "talk" about their work in pain management? It is with an exploration of these and the importance they might have in the context of the present research project that the chapter concludes.

\section{Embodiment and nurse-patient relations in the context of pain work}

Setting aside for the moment the criticisms and shortcomings of the nursing rhetoric in relation to embodiment, as the discussion has indicated in the previous section on nursing discourses, ideas about the type of relationships nurses form with patients is deemed, by many respected nurse scholars and nurse clinicians, important to facilitate 'care'. Given the conceptualisation of pain as uniquely subjective, such relationships could perhaps be regarded as equally important when it comes to the work of caring for patients experiencing pain following trauma or surgery. The establishment of empathetic and collaborative relationships with patients based on knowing the person could be regarded as the means to implement effective pain relieving strategies.

This raises the question of how significant such ideas about the patient as a person and about embodied relationships might be in the context of this present study examining surgical nurses' "talk"? How might the nurses reflect on their practice especially the nature of the relationships they have with patients? Might the conversation reveal that a significant value is placed on those relationships? If so, how might the nurses speak about nursing work and the place of embodied relationships in the context of pain management? How might the nurses talk about being able to relate to a person's pain? Will their talk reveal their emotional capacity to 'connect with' the person, and if so, how does this impact on what they do to relieve the person's pain and suffering? 
If, as Price and Cheek (1996) contend, nurses and patients should be allowed the space to develop meaningful interactions, how, if such interactions take place, might they be described by the nurses in this study? Will the nurses for instance discuss their role in terms of building partnerships with patients based on ideals of collaboration? How might they describe the work of establishing such working relationships? How might they talk about the strategies they deploy to involve patients in decision-making about pain management?

In summary, these questions regarding the possible significance and meaning nursing discourses have for surgical nurses in the context of their work caring for patients reporting pain provide the foundation for this study, as do questions about the influence discourses of biomedicine have on surgical nurses' pain management practices. For this reason, a critical review of the literature pertinent to the present study has assisted in illuminating the central elements to the perspectives regarded as critical to the position this study takes.

\section{SUMMARY}

As stated on the first page of this chapter, it is the premise of this thesis, that surgical nurses may incorporate dimensions of both nursing and biomedical discourses into their pain management practices. It is my opinion that surgical nurses are positioned within the medical model of disease/illness, which includes a biomedical conceptualisation of pain, much of the time. This means that the work practices of these nurses involves the mobilisation of knowledge about patients constructed around a clinical diagnosis and treatment pathway that is largely determined by such discourses. This problematises ideas of 'embodied care' to the extent that it is described in the nursing literature.

What this means is that although embodiment is given centre-stage in nursing 
rhetoric, the pragmatic reality for many nurses may be very different. Furthermore, from a post-structural perspective, there are some problems with the very notion of 'embodiment'. Therefore, it remains to be seen just how ideas about 'embodiment' and the nature of nurse-patient relationships are talked about by the surgical nurses, and what this might reveal about the relationship between professional knowledge and power in the specific context of pain management.

The purpose of this chapter has been to examine the role played by discourses in shaping particular thinking and social practices such as that of nursing and pain management, and the relationship such discourses have to professional knowledge and power with a review of literature pertinent to the study. Chapter Three moves to a discussion of the theoretical foundation for the themes and arguments introduced in Chapter One, and explored more fully in relation to the literature presented in this chapter.

Chapter Three considers first the current conceptualisations and theories of 'discourse'. These are integral to a post-structuralist analysis and critique of the role played by language in the construction of the social relations and practices of pain management. The remainder of the chapter is devoted to an in-depth analysis and critique of some of the key theoretical ideas articulated by Michel Foucault $(1970,1972,1973,1977)$. Included are his perspective on 'discourse', and of specific significance to this thesis, his ideas on the relationship between professional power and knowledge. 


\section{CHAPTER THREE \\ Theoretical perspectives on discourse and Foucault's power/knowledge: Positioning this study}

\section{INTRODUCTION}

In Chapter Two literature regarded as pertinent to the purpose of this study on pain and the role language plays in constructing particular 'pain discourses' which have shaped the way pain is 'managed' was reviewed. The argument upon which this thesis is based is that discourses such as those introduced and discussed in the previous chapter are constructed around a particular view of the body and of the patient, and that such discourses mediated through language and social practices such as pain management are examples of the relationship between professional knowledge and power. The purpose in this chapter is to follow through the arguments presented in the previous chapter with a discussion of the underlying theoretical assumptions that inform this study.

This being a thesis on language and 'discourse', the chapter begins with a discussion of the central strands of the various conceptualisations and theories of discourse that have emerged within the last three decades. Although Michel Foucault's conceptualisation of 'discourse' was developed before the more recent theories on discourse, the purpose in presenting first the perspectives on discourse articulated by later writers such as van Dijk (1990a, 1990b), Fairclough (1992, 1994), Parker, (1992) and Harre and Gillet (1994) is because these 'set the stage' as it were for a discussion of the different ideas Michel Foucault formulated on 'discourse' $(1970,1972)$. These are examined in the second part of the chapter. 
Foucault's discourse theory has some similarities to and distinctions from these more recent approaches. Most significant among the distinctions was his focus on discourse and power/knowledge of the professional disciplines, particularly those of psychiatry and medicine, whereas the more recent approaches to discourse identify an interest in popular discourses.

The assumptions upon which this thesis is based are taken primarily from a key set of theoretical ideas developed by Foucault $(1973,1977)$. His provocative and original analyses and concepts cover a number of major themes and issues. Most notably, and of specific relevance to this work, are his ideas on the relationship between power and knowledge, especially disciplinary power; the construction of the body as both a site and target of power; and the creation of the modern 'subject'. Following the discussion on discourse theories and Foucault's ideas on discourse, the remainder of the chapter will be devoted to presenting and critiquing these.

\section{THEORIES OF 'DISCOURSE'}

Since the 1960s, interest in discourse as a focus of study has moved beyond traditional and somewhat static views of language/linguistics and text as finished product (Fairclough, 1994). Increasingly, 'discourse' has become a central focus in many disciplines ranging from the humanities through to the social sciences, including anthropology, psychology and sociology, as well as nursing and midwifery. With this spread across disciplines, differences in approach inevitably arise, and, as a result, there is no single integrated theory of discourse (Fairclough, 1992, 1994; van Dijk, 1990a). Instead, multiple conceptualisations

of the term 'discourse' exist depending on the theoretical and disciplinary standpoint of the scholar/analyst. 
Writing in 1990, van Dijk concludes that this failure to provide any systematic and explicit description of the properties of 'discourse' has led to theoretical confusion, and limitations for the practice of discourse studies. The challenge for the 1990s, he suggests is to clarify what is meant so that an adequate description of 'discourse' will enable the proposal of "an integrated theory of types of structure in discourse. [For this] we need to know the various levels or dimensions, the kinds of organization at each level, and the type of theory that accounts for them" (van Dijk, 1990a, p. 146). What the various positions do have in common however, is a recognition of the centrality of language, and its relationship to communication, discourse and society.

\section{The function of language}

It has long been acknowledged that language has important social functions, especially as a means of communication, either in spoken or written form. The centrality in social and cultural life accorded language led to its study and the development of different language theories in an attempt to understand how human beings learn and use language. The field was led by linguists such as Noam Chomsky and De Saussure in the late 1950s and 1960s (Fairclough, 1992; Halliday \& Hasan, 1989; Potter \& Wetherell, 1987).

According to Chomsky and De Saussure, the rules of language use were part of an individual's genetic make-up. Individuals acquire language through socialisation and can do so because they already have the cognitive structures in place to allow them to make sense of language and how to use it. Language in this sense "is viewed as a formal system principally concerned with describing or representing the world" explain Potter and Wetherell (1987, p. 28). 
Building on this perspective was that of John Austin's "speech act theory" (1962). "The fundamental tenet of the theory is that all utterances state things and do things. That is, all utterances have a meaning and a force" explain Potter and Wetherell (1987, p. 17). In this sense, Austin's theory moved away from a 'natural' language postulated by Chomsky and De Saussure, and located it as human practice. Language is regarded as a social device that people use to achieve certain things; language is a tool.

However, despite these theories, consideration of the other properties or effects of language, such as its dynamic role in social structures or institutions, and social relations and practices to a large extent had been ignored. Furthermore, the traditional accounts of language overlooked the possibility that in fact language actually constitutes, reproduces and influences all aspects of social and cultural life, including the construction of a sense of self (Fairclough, 1994; Harre \& Gillet, 1994; Potter \& Wetherell, 1987; van Dijk, 1990a).

Increasing dissatisfaction with a view of language as neutral and apolitical (Billig et al., 1988; Fairclough, 1992, 1994; Lupton, 1992; Ng \& Bradac, 1993; Parker, 1992) fuelled debates over the relationship between language and power. Claims such as those made by Berger and Luckmann (1971) that "reality is socially constructed" highlighted the philosophical and epistemological distance between positivist and structuralist accounts of society and the human condition as a social fact. New perspectives in social theory have emerged which stress that the way individuals think, speak and interact are produced by discursive practices of power, and that language plays a central role through its relationship to 'discourse' (Fairclough \& Wodak, 1997; Kincheloe \& McLaren, 1994; Lather, 1991). 
In the 1970s and 1980s, a number of philosophers/analysts/historians such as Jacques Derrida (1976, 1981), Roland Barthes (1977), Michel Foucault (1970, 1972, 1980) and Jean-Francois Lyotard (1984) centred their critiques of power and ideology around the structures of meaning located in language and texts as 'discourse' (Agger, 1991; Parker, 1992). As Agger (1991) explains, for Derrida:

every text is a contested terrain in the sense that what it appears to "say" on the surface cannot be understood without reference to the concealments and contextualizations of meaning going on simultaneously to mark the text's significance (e.g. the use of specialized jargon) (p. 112).

This 'turn to language' (Fairclough, 1992; Parker, 1992) in social theory focused attention on what language and language use could tell us about the socio-cultural and political contexts in which it occurred (van Dijk, 1990b). In so doing, it conferred on language a more critical role within social events. For, it is through language that discourses are constituted, reproduced and transformed (Fairclough, 1994; Fairclough \& Wodak, 1997; Lupton, 1992; Parker, 1992; Potter \& Wetherell, 1987; van Dijk, 1990a).

\section{Language as 'discourse'}

Language, asserts Lather (1991, p. 8), "is the terrain where differently privileged discourses struggle via confrontation and/or displacement". This connection between language and discourse is a radically different conceptualization to that of the traditionally taken perspective of discourse as 'the spoken', in other words, talk or conversation. Conversation analysis for example, concentrates on the interactional accomplishment of particular social activities, and it is interested in the contextual aspects of discourse (Drew \& Heritage, 1992; Schegloff, 1991). However, it does not take a critical 
perspective when examining utterances and actions in examples of discourse (Fairclough, 1994).

In contrast, in social theory the idea of 'discourse' refers to the different ways of structuring areas of knowledge and social practice, and incorporates, as just mentioned, language and power (Fairclough, 1992, 1994). "Discourses in this sense are manifested in particular ways of using language ... [and] do not just reflect or represent social entities and relations [but] construct or 'constitute' them", explains Fairclough (1992, p. 3). This conceptualisation of discourse is predominant in Foucault's works $(1970,1972,1977)$ which are discussed in more detail later in this chapter.

In other words, all those dimensions of social and cultural life - roles, institutions, practices, belief systems, subjectivity - are shaped and/or constrained by discourses of one type or another. Language represents and imbues the world with meaning, and thereby establishes the link between how individuals as members of society share the same knowledge about who they are, and the beliefs, norms and values which may be shared or contested. How individuals see themselves and their place in the scheme of things is constructed and controlled by the social conditions (the complex structure of rules and social practices) that constitute social reality for that individual (Harre \& Gillet, 1994; Potter \& Wetherell, 1987). It is interwoven in the way people act upon their world and upon each other.

Discourses then create a space for a particular type of 'subject' to enter and invite a particular perception of who they are in situational contexts, and for the articulation of those inter-relations with other 'subjects' (Harre \& Gillet, 1994; Parker, 1992). This is the essence of Armstrong's (1983b) and May's (1992) 
ideas when they postulate that patients are constituted as subjects to be known. Nurses want relationships with patients as 'subjects'. It is all about positioning in relation to an-other. Patients as 'experiencing' subjects are thus invited to behave in a particular way vis-a-vis nurses and other health care professionals.

Explain Harre and Gillet (1994, p. 20) "this understanding of human activity requires us to interpret the behaviour of another according to some appreciation of the self-positioning of the subject with the complex structure of rules and practices within which that individual moves." Take for instance the term 'nurse'. This word readily conjures up a certain representation and meaning for most people. A nurse is a person charged with a social mandate to "take care of" people who have become sick, injured, or who are dying. The nurse uses specialised knowledge and skills to deliver care.

However, the term is also imbued with ideology; relations of power and knowledge constitute a way of being for the nurse. So this term also carries connotations of female, nurturing, torturer, handmaiden, duty, professional. These representations at once constrain and control the social identity of nurses; shape the social practice of nursing and position nurses in particular ways vis-avis other social beings, for instance doctors, patients, relatives, the general public.

It is important to grasp this idea that discourse is both a mode of 'representation' and a mode of 'action'. The representational elements of discourse are part of the power of discourses, because they "do not simply describe the social world, but categorize it [and] bring phenomena into sight", and conceal others according to Parker (1992, pp. 4-5). These representations of the world have, for Parker (1992, p. 8) "a reality almost as coercive as 
gravity, and, like gravity, we know of objects through their effects." They are talked about, practised, and reproduced and transformed in the process.

One of the most critical aspects of conceptualising 'discourses' is in exposing how they come to support particular institutions and practices, through the constitution of specific knowledge and beliefs. Material practices, such as the nurse giving an injection of analgesic medication or asking the patient to rate his/her pain, are invested with discourses. The use of such discourses reproduces the material basis of particular practices and thus the discipline or institution it is a part of.

It is this dimension which demands particular attention, because of what it tells us about relations of power and ideology. Indeed, increasingly Fairclough has come to view the social context of text production and distribution as generated by relations of power and domination $(1994,1997)$. As he explains "power is conceptualized both in terms of asymmetries between participants in discourse events, and in terms of unequal capacity to control how texts are produced, distributed and consumed (and hence the shapes of texts) in particular sociocultural contexts" (1994, pp. 1-2).

If this theoretical perspective is applied to pain, it and pain management are institutional discourses. As discussed in Chapter Two, the creation of a particular image of what pain is and how it should be assessed and treated leads to specific thinking and practices in the work of nursing patients reporting pain. The text is written in advance. Although a degree of negotiation and repositioning occurs within the context of any interaction between participants, for example, the nurse asking the patient about their pain, the power to control the discourse event remains with the person with the legitimised knowledge of 
pain, that is, the nurse. This is despite an increasing emphasis on acknowledging the patient's version of the pain experience. Contested and alternative versions of pain emerge however, as in my experience patients are never entirely passive.

One of the other facets of the power dimension is that most of the time the effects of discourse go unnoticed and therefore unchallenged, because they are embedded within the fabric of the society and the culture in which people live. The power of discourse then lies in its ability to gain compliance because it is accepted as natural or 'common-sense". Billig et al. (1988, p. 5) called common sense the "'lived ideology' of the culture". The authors took an interesting perspective, stressing ideology and common sense as comprising of 'contrary themes'. Without these the authors assert, "individuals could neither puzzle over their social worlds nor experience dilemmas. And without this, so much thought would be impossible" (p. 2).

This turns on its head the idea that ideology is a complete system of beliefs and attitudes, maintaining social order by dominating how individuals act, think and feel. Billig et al. prefer instead to emphasize the "thoughtful nature of ideology" which acknowledges the social agency of individuals. There is therefore a dialectical relationship between discourse as coercive and discourse that offers the opportunity for challenge and transformation. Social actors are social agents. Whilst discourse is reproduced within discursive practices and relations of power, social actors creatively use language to change the structure of the discourse to something other than what it was (Fairclough \& Wodak, 1997).

What this says is that there are usually more than one discourse competing/vying for position at any given moment, as there are different subject positions. Fairclough $(1992,1994)$ and van Dijk (1990b) refer to these as "order(s) of 
discourse". As Parker (1992, p. 13) contends "discourses embed, entail and presuppose other discourses to the extent that the contradictions within a discourse open up questions about what other discourses are at work". Discourses, as already alluded to, privilege different speakers, different knowledge and beliefs and hence power relations at different times.

For instance, as alluded to in Chapter Two, nurses endorse the idea that pain is an individual experience, unique to each individual. This perspective is taken into the interaction with the patient when it is time to assess that person's pain. At the same time, nurses are embedded in a biomedical discourse which posits that pain has a clinical pathology. During the context of the interaction of conducting the pain assessment, a new text will be written. This is what Fairclough $(1992,1994)$ means when he speaks of "interdiscursivity".

However, these "orders of discourse", which van Dijk (1990b) attributes to what he terms 'micro-level' or 'macro-level' dimensions, can be displaced or changed. When 'dilemmas' or contradictions within discourses arise for a number of reasons, people will challenge and transform the existing discourse, which leads to social change (Fairclough, 1992, 1994). This is an important difference from the perspective presented by Foucault, which will be explored later in the chapter. Fairclough's more recent work on discourse in association with Wodak emphasizes the dialectical relationship between discourse as shaping and being shaped by people, situations, institutions and social relations which highlights the role of social change (Fairclough \& Wodak, 1997). It is this focus on social change and the wider relations of power which underpins Fairclough's interest in critical discourse analysis (CDA). 


\section{Discourses as 'texts'}

The term 'text' is an essential property of 'discourse'. In defining 'discourses' as 'representations' which are invested with reality and therefore with meaning (Fairclough, 1994; Fairclough \& Wodak, 1997; Fox, 1997; Parker, 1992), they are, in this sense, invested with the status of 'texts'. The reason for this is that they can be read, analysed, and interpreted, depending of course on the position of the reader. Fairclough (1994) argues that careful scrutiny of 'texts' can tell us a great deal about social and cultural phenomena. Indeed, he asserts, analysis of the textual properties of texts shows them to be "extraordinarily sensitive indicators of sociocultural processes, relations, and change (p. 4)"

Fairclough (1994) describes texts as social spaces in which not only reality is represented, but also social interaction. What this means is that texts simultaneously show the reader a particular reality of the world while at the same time creating social identities and relations between individuals. This is the power of discourse. Fairclough's multifunctional view of text proposes that:

\footnotetext{
language in texts always simultaneously functions ideationally in the representation of experience and the world, interpersonally in constituting social interaction between participants in discourse, and textually in tying parts of a text together into a coherent whole... (as well as) tying texts to situational contexts (1994, p.6).
}

Texts are constructed out of other texts, hence the notion of "intertextuality" (Fairclough 1992, 1994). "Intertextuality is basically the property texts have of being full of snatches of other texts, which may be explicitly demarcated or merged in, and which the text may assimilate, contradict, ironically echo, and so forth" (Fairclough, 1992, p. 84). This perspective also stresses the "historicity" of texts, which are constructed as additions to texts already in 
existence. The other feature of texts which is discussed above is that of "interdiscursivity", or the notion that embedded within texts are different 'voices'. At any one time, different 'voices' or discourses compete for dominance in the discourse event.

Another dimension of intertextuality is the notion that texts can offer many possible interpretations (Fairclough, 1994; Fox, 1997; van Dijk, 1990b). Fox (1997, p. 32) describes this aspect of intertextuality as "the process whereby one text plays upon other texts, in the endless referentiality of texts and other elements of cultural production." Moreover, Fox claims authority lies with the reader, rather than with the author. What this means is that in the reading of the text, knowledge and therefore some degree of power rest with the reader, opening up possibilities for resistance as different readers choose to validate "or discredit the discourses with which they engage," Fox continues (p. 33).

Before moving to the second part of this chapter which focuses on the ideas of Foucault, it is useful to briefly summarise the similarities and differences between the above approaches and that of Foucault. It is to a brief comment on these that this general discussion on the current approaches to, and theories of discourse concludes.

Similarities and differences between the above approaches and that of Foucault's perspective on discourse

An obvious similarity is that Foucault and the above approaches share the same view on the constitutive nature of discourse, in that discourse for instance, constructs a sense of self (subject), social relationships, objects of knowledge and institutional practices. An important distinction between the approaches and that of Foucault's however, is Foucault's development of a more abstract 
approach to discourse analysis in that his ideas were governed by what he called the "rules of formation" which lay beyond the reach of the conscious individual (Foucault, 1972).

In contrast to the above approaches, Foucault's conceptualisation of discourse (which is explored later on pages fiftyfour to fiftysix) fails to acknowledge the social agency of individuals which makes it possible for discourses to be challenged and transformed, and for social change to take place. Fox (1997), among others, contends that Foucault never successfully addresses this in his theory of discourse. A critique of this particular aspect of Foucault's approach is explored more fully later in the chapter. It is to Foucault's ideas on discourse and his theorizing on the relationship between power/knowledge, that the second part of this chapter now turns.

\section{MICHEL FOUCAULT}

Fundamentally, Michel Foucault was interested in presenting a comprehensive analysis of human reality through an investigation of the history of thought (Dreyfus \& Rabinow, 1982; Gutting, 1994; Rabinow, 1984; Smart, 1985).

Despite some evident shortcomings in some of his analyses and conclusions that will be explored later, his ideas still hold a great deal of currency today, particularly in the critical social sciences and in research in the sociology of health and illness (for example see Armstrong, 1994, 1997; Lupton, 1994; Nettleton, 1992, 1995; Turner, 1995).

This section on Michel Foucault, which includes pages fiftytwo to sixtyone, will critically examine his conceptualisation of 'discourse', his ideas on the formation of the subject, the position he held on the body as a social and historical construction, and the relationship between power and knowledge, particularly 
the disciplinary power of medicine.

Towards the end of his life, Foucault expressed that the aim of his work had been "to create a history of the different modes by which, in our culture, human beings are made subjects...Thus it is not power, but the subject, which is the general theme of my research" (Foucault 1982, pp. 208-209). Power and the subject are intimately involved however, because "while the human subject is placed in relations of production and of signification, he is equally placed in power relations which are very complex" (Foucault, 1982, p. 209).

It was the inter-relationship between language and the production of truth/knowledge claims that formed the essence of his attempts to articulate a theory of 'discourse', or 'discursive formations' as he otherwise termed it. For Foucault, the 'subject' is not natural but created through discourse. To understand the relationship between language and the production of reality and what he termed "regimes of truth", Foucault undertook his archaeological and genealogical analyses, and it is to these, and his "history of the present" that the discussion turns (Foucault, 1970, 1972, 1973).

\section{Foucault's "history of the present"}

Foucault rejected traditional narratives and explanations of history as deficient, claiming that they presumed to report historical events as they had happened which suggested a mirrored description of what took place (Jones \& Porter, 1994; Nettleton, 1992; Rabinow, 1984; Smart, 1985). For Foucault however, the problem is that "history tends to look at the past through conceptualizations or categories that have been constructed in the present. Hence a traditional historical study tells us more about the time of writing than that period which it seeks to describe" (Nettleton, 1992, p. 123). 
Foucault's interest instead lay in how historically different periods of thought created the conditions of possibility for the emergence of particular social structures and practices. Rather than construct a general theory on history, he undertook a detailed examination of the connections between forms of human experience and the relations between power and knowledge. He was specifically interested in revealing the modern individual as an historically and culturally constituted subject and object of knowledge/power relations (Dreyfus \& Rabinow, 1982; Gutting, 1994; Rabinow, 1984; Smart, 1985).

His methodological approach towards an archaeological, and subsequently a genealogical, analysis and conceptualisation of 'discourse' was therefore to examine specific time periods. Foucault postulated that at specific junctures in history, the ontological status of language and thus thought changed or shifted. At these times, "changes in the 'discursive formations' that governed the serious possibilities for talking about things" (Rouse, 1994, p. 94) led to a different reality and the creation of new knowledge. The emergence of distinct structures of thought or knowledge practices Foucault called epistemes.

By this, he referred to "the total set of relations that unite, at a given period, the discursive practices that give rise to epistemological figures, sciences, and possibly formalized systems ..." (Foucault, 1972, p. 191). Foucault acknowledged that it is through the superstructural dimensions of language statements that 'discourses' and 'discursive practices' are constituted and reproduced. In his analysis, language practices and linguistic systems are governed by a body of rules that exist independent of human beings. These 'rules of formation' govern the structure of performative utterances or statements (enonces) and form the basis to his concept of 'discursive formations'. 
Foucault argued that when it came to a discursive analysis of the formation of objects of discourse, it is "neither about language or words nor about things" (Freundlieb, 1994, p. 165). They belong instead "to the body of rules that enable them to form as objects of a discourse and thus constitute the conditions of their historical appearance" (Foucault, 1972, p. 48). His archaeological analysis therefore treated discourses "as practices that systematically form the objects of which they speak" (Foucault, 1972, p. 49).

His conceptualisation of discourse as "a rule-governed system...that is autonomous and self-referring" (Dreyfus \& Rabinow, 1982, p. xx) denies the existence of any involvement and therefore influence through human interaction, because it exists at a pre-discursive level and beyond the consciousness of human beings. As alluded to earlier on page fiftyone, it is this attempt by Foucault to separate the development of 'discursive formations' from any subjective involvement that distinguishes his approach to a theory of discourse. Moreover, it is this aspect of his conceptualisation of discourse that, for me is inadequate, because it fails to acknowledge that discourses exist largely because of the actions of human beings in social contexts, and through the use of language. This criticism, shared by other commentators, is perceived as being one of the major flaws of Foucault's analysis (Fox, 1997; Freundlieb, 1994; Ingram, 1994).

Argues Freundlieb (1994, p. 154) "an analysis that deliberately ignores the intentions of historical agents within the process of the production of knowledge (savoir), even if these intentions are always only a part of what drives the history of the sciences, is not feasible". The problem for Freundlieb, and which I endorse, appears to be located in Foucault's object-constitutive character of discourses, which Freundlieb claims Foucault never really addresses. Freundlieb 
is driven to ask "where and how, then, do the rules that allegedly govern discourses exist?" (p. 159). Ingram's (1994) critique echoes that of Freundlieb (1994). He suggests:

Foucault's structuralist account of meaning cannot explain actual speech. Structuralism at best accounts for the formal conditions of possible syntactic and semantic combinations, transformations, and exclusions at any given time. Conditions of possibility, however, do not explain the actual selection, or genesis, of particular utterances (p. 233).

These he insists, "still depend on subjective intentions, and, more basically still, the communicative competence embodied in speaker/listener roles" (Ingram, 1994, p. 233, emphases in original). Another criticism I would make is that like Fox (1997), Foucault's ontology of discourse is at times ambiguous and contradictory. For instance, Foucault speaks about the existence of discursive formations as being independent of social actors, then appears to change his mind when he articulates his ideas about power and resistance, which is discussed later in this section.

Fox (1997) rejects Foucault's 'rules of discursive formations' as providing the conditions for the existence of discourses. This is because in Fox's (1997, p. 32) view, "texts are the product of human activity [and] as such they are created within the flow of history ... continually re-read and have no single or final meaning." He suggests an alternative approach to discourse, one that "deemphasises Foucault's concern with the historical genealogy of knowledge and subjectivity ..." (Fox, 1997, p. 32), and instead focuses on the use of texts and the importance of intertextuality.

The centrality of a theory of discourse in Foucault's early works shifted to more 
of an emphasis on "that which conditions, limits, and institutionalizes discursive formations (genealogy)" (Dreyfus \& Rabinow, 1982, p. 104). Instead of focusing on the unconscious systems of rules and relations that governed his discursive formations (the objects, statements, and theoretical concepts), Foucault began to address their conditions of existence and the complex relations between power and knowledge, particularly in the human sciences. He was also increasingly interested in the problem of the subject (Foucault, 1982).

\section{Power/knowledge and the problem of the 'subject'}

For Foucault, the individual as 'subject' is socially constructed and therefore does not have a stable reality (Foucault, 1982). This view is shared by other critical theorists, such as Habermas (1987). Together, "they regard as illusory the rational, self-determined unity that Descartes and Kant attribute to the isolated subject" explains Ingram (1994, p. 217). In order to account for the constitution of the subject within a historical framework, he concentrated on his genealogy of the modern individual and the relations of power, knowledge and the body in modern western society. Two of his works, Madness and Civilization (1965) and The Birth of the Clinic (1973) addressed specific historical relationships between forms of knowledge and forms of power with the development of the human sciences.

However, it was not until Discipline and Punish (1977), that his "conceptions of power-knowledge relations and of the body as the object of the exercise of technologies of power became explicit..." (Smart, 1985, p. 45). Foucault did not elaborate a theory of power as such but instead focused on conceptualising how power was exercised and the forms it took (Nettleton, 1992; Smart, 1985). Power is exercised through individuals and institutions acting as conductors, a view that was in contrast to other more traditional approaches to conceptions of 
power. For Foucault, the chief agents of power were firstly the State, then doctors and finally and to a much lesser degree, the family (Smart, 1985).

The more conventional views expressed power as something acquired, an attribute of someone, having "a substantive form, something that can be usurped, a force that can be exercised by those who possess it over those who do not" explains Nettleton (1992, p. 113). Traditional views for example Humanistic perspectives such as Freire (1970), Rogers (1979), have tended to associate power with social actors with power located in the minds and actions of particular individuals (Gilbert, 1995). The major flaw in such conceptions is, suggests Gilbert (1995, p. 866) "a failure to identify how these individuals are themselves a product of power, and how their identity is located with the material conditions of their lives and the social practices which operate there."

Alternatively, power was explained as being an effect of structures or systems, for example for Marx, it was rooted in the economic structure of western capitalist society. The Marxist analysis of power is a top-down view of power relations between social classes, with the ruling class oppressing and exploiting the working class (Cottrell, 1984). This subjection by the bourgeoisie is legitimized by what Peerson (1995, p. 110) calls "a superstructure of social relations, politics, law and religion", which originate from an economic base.

According to Fairclough and Wodak (1997), Western Marxist approaches to power on the other hand remove the emphasis of economic structures of capitalist society from influencing social relations, insitutions and politics, and instead argues that socio-political and cultural dimensions of societies "are established and maintained (reproduced) in large part in culture (and hence ideology)..." (Fairclough \& Wodak, 1997, p. 260). 
Foucault turned this around, arguing that power is everywhere and inseparable from bodies. Furthermore, he emphasised the relational aspects of power as "something that is exercised from a variety of points in the social body ..." (Smart, 1985, p. 122). His purpose was to analyse power from the perspective of these relations and also what he perceived as being the technologies of power (Dreyfus \& Rabinow, 1982; Rabinow, 1984; Smart, 1985).

In this sense, Foucault's power is perceived as a 'strategy', the exercise of which he regarded as the means by which knowledge is constituted and reproduced as discourses within particular social arrangements/disciplines. Accordingly, any analysis and understanding of power necessitates a detailed consideration of the interplay between discourses and social practices in the production of what is taken to be true/real in any given society.

Power is dynamic and through its reliance on 'social agents' to disperse it, so it becomes "embedded in the routinized, and often mundane activities of our daily lives" states Nettleton (1992, p. 114). In this way, power is distributed throughout our complex networks of social relations/arrangements. In my research, the underlying assumption is that the language of surgical nurses "talk" reflects power, because our understanding of the world is not merely expressed in words: it is brought into existence and is realized through them. Thus, the language used by the nurses interviewed reveals the power dimension inherent in the work they do to take care of their patients who report pain.

Although power is not possessed by any one person or agent, Foucault emphasised that power can be resisted. Indeed, power relations only exist as such because of the co-existence of resistance. As Foucault (1978, p. 95) explained "the strictly relational character of power relationships (is such that 
t)heir existence depends on a multiplicity of points of resistance... These points of resistance are present everywhere in the power network" (cited in Rouse, 1994, p. 109). This conception of power relations aligns dominant and subordinate actors who together co-constitute power through their actions to support and resist respectively. Yet Foucault doesn't successfully address his ideas on resistance, and this is nowhere more evident than in his analysis of power on the body, which is portrayed as docile (Foucault, 1977), and to which the discussion now turns.

\section{Disciplinary power and the 'body'}

Foucault repositioned the 'body' as a social and historical construction that was the ultimate site of "political and ideological control, surveillance and regulation" (Lupton, 1994, p. 23; see also Turner, 1997, p. xv). He achieved this by developing his ideas around the notion of disciplinary power, which Nettleton explains "refers to the way in which bodies are regulated, trained, maintained and understood, and is most evident in social institutions such as schools, prisons and hospitals" (1995, p. 112).

For Foucault, it was the birth of the clinic, in other words the establishment of the hospital as the bastion of medical power, that led to the development of contemporary notions of disease and illness/health. It was within such institutions as the hospital that doctors gained control over bodies. Here observation, diagnosis and treatment took place, with the body taking on a significance as the focus for medical practice. Explains Nettleton (1995, p. 23), "within the discourse of what came to be called pathological medicine, disease was formulated as a discrete phenomenon which was located in the workings of the bodily structures." 
Medicine's ideas about what constituted disease/illness were captured through the techniques of surveillance. Foucault described le regard or the clinical gaze as having primacy because it allowed the doctor to see, to visualize and bring into reality the objects which became discrete entities such as symptoms, signs of an identified/constructed pathology that were named. It is the subtlety of le regard which is both a perception and also an active mode of 'seeing' (Armstrong, 1997) that is its power.

The clinical gaze and its associated techniques of surveillance, such as the examination, therefore permits the growth of a new body of knowledge, and a whole new technology of power is created. Accordingly, "the new knowledges of human anatomy and pathological medicine could know bodies and at the same time construct them in its own image" (Armstrong, 1994, p. 21). It is at this point that the body is fabricated, and as a target for the mechanisms of power becomes manipulated and controlled.

Of all the techniques of disciplinary power and surveillance, explains Foucault (1977):

the examination is highly ritualized. In it are combined the ceremony of power and the form of the experiment, the deployment of force and the establishment of truth. At the heart of the procedures of discipline, it manifests the subjection of those who are perceived as objects and objectification of those who are subjected (pp. 184-185).

The examination "also situates (individuals) in a network of writing; it engages them in a whole mass of documents that capture and fix them" (Foucault, 1977, p. 189). What the examination and its associated practices of elicitation/documentation does is to establish an individual, a subject who is both 
the object of power and subject to the mechanisms it deploys. What it also does is turn each individual into a 'case'. In this way, the pathology of the individual is effectively objectified into a clinical specimen of interest. Thus, as discussed in Chapter Two, in terms of nursing work, nurses construct the patient as both "subject" and "object" of care.

\section{Relations of power/construction of knowledge}

Foucault argued that what can, and will be known arises out of the network of power relations, as is the case with the development of disciplinary power through the deployment of techniques of surveillance as discussed above. Foucault's analysis of the human sciences, especially medicine, situated the development of knowledge and the formation of 'scientific truth' that as a body of knowledge became authoritative and legitimized firmly rooted in relations of power.

He rejected ideas of epistemic sovereignty, that knowledge is the truth about something and that it has been extracted from other conflicting statements. For him, "knowledge is inextricably entwined with relations of power and advances in knowledge are associated with advances and developments in the exercise of power" (Smart, 1985, p. 64). This has particular relevance to any discussion about "scientific" knowledge as being objective and value-free or neutral knowledge.

What it also means, and Foucault emphasised this point, is that "there is no power relation without the correlative constitution of a field of knowledge, nor any knowledge that does not presuppose and constitute at the same time power relations" (Foucault, 1977, p. 27). In this sense, power and knowledge are intimately connected, with each engendering the other. This interconnectedness 
of power-knowledge meant that neither could be reduced to the other and is, according to Dreyfus and Rabinow (1982), perhaps one of the most radical dimensions to Foucault's work. While support for Foucault's insightful and provocative ideas continues, there are many criticisms of his analyses and conclusions, and it is with a brief review of some of these that this chapter concludes.

\section{Criticisms of, and alternatives to, Foucault's position}

Commentators on Foucault's ideas are especially critical of his conceptualisation of power/knowledge, his construction of the 'subject' and his ideas on the body (for example, see Fox, 1997; Habermas, 1994; Kelly, 1994; Lupton, 1997; Nettleton, 1992, 1995; Sarup, 1993; Turner, 1995). For instance, "Foucault's discussions of the relation between truth and power have ... provoked concerns about their reflexive implications for his own analysis" (Rouse, 1994, p. 92), while Ingram (1994), amongst others (for example, see Habermas, 1987, 1994), has charged Foucault with inconsistency in his analysis and conclusions, that his theoretical positioning in his archaeological and later genealogical perspective "succumbs to self-referential paradox."

One of the overriding results of Foucault's analyses and conclusions is to leave the reader with a sense of hopelessness, because Foucault insists that "knowing subjects and truths known are the product of relations of power and knowledge", resistance by us, and "liberation in the name of 'truth' could only be the substitution of another system of power for this one" (Taylor, 1987, p. 94, cited in Rouse, 1994, p. 104). This is reinforced by Nettleton (1992, p.130) who observes "Foucault is seen as offering little hope for the future because no means of securing socio-political change, opposition or resistance are articulated." Nettleton's comments are interesting given the profile Foucault 
gained throughout his life as a commentator on and an advocate of political action.

Although he was careful throughout his writings to emphasize that where power exists, there will always be resistances, he does not consistently address these and how they operate (Fox, 1997; Lash, 1991; Nettleon, 1992; Sarup, 1993; Turner, 1995). Foucault primarily talks about how, as Lash (1991, p. 259) observes "bodies are acted upon in discursively-constituted institutional settings. Resistances are rarely constructed, struggles are not engaged." This overly pessimistic and somewhat deterministic view of the body predominates throughout his writings, although he did make some attempt in later works, to turn from the 'docile body' to a 'self' and individuals as "reflexive, living, speaking beings" (Fox, 1997, p. 41). This work ended prematurely with his early death, but suggests that Foucault was still developing his ideas in such works as The History of Sexuality Vol. I (1979).

Fox's own position is that bodies are not primary sites for the action of power. Instead, he argues that "bodies are cultural artifacts, fabricated both in the writing and reading of 'body texts', which will include the interpretation of aspects of spatial and temporal existence such as pain, pleasure, birth, ageing and death" (Fox, 1997, p. 45). It is therefore in the reading of the 'body-text' that the exercise of power lies.

Peerson (1995, p. 107) claims Foucault's analysis of the development of medical power and knowledge is "fraught with ambiguities." She contends that the limitations in his work arise from what she calls his "sweeping overview of medicine, without resort to an analysis of society as the locus for change" (Peerson, 1995, p. 107). He undertakes an examination of specific events in 
France and takes great liberty with his generalized assumptions. Having said that, Peerson concedes his analyses are useful for assisting with an explanation of medicine in today's society.

This comment is validated by the numbers of writers who have undertaken Foucauldian analyses and critiques of medicine and health care (for example, Armstrong, 1983a; Gastaldo, 1997; Nettleton, 1992; Papps \& Olssen, 1997), and of nursing (for example, Heartfield, 1996; Henderson, 1994). Foucault's ideas have also informed feminist writings, and while not an exhaustive review of the feminist literature, a last word goes to a feminist critique of Foucault.

While some writers have identified areas of convergence between Foucault's ideas and those of feminism (see, for example Diamond and Quinby, 1988; Nettleton, 1995; Sawicki, 1994), these same commentators would highlight tensions between certain of Foucault's ideas and those of feminism. Points of convergence are situated around the body as a site of power; the analyses of disciplinary power, especially in relation to medicine and psychiatry; "the capacity of discourse to sustain hegemonic power" (Nettleton, 1992, p. 139) and the critique of Western humanism and questions of the identity of a 'self as subject'.

A criticism levelled against Foucault is his seeming lack of recognition of sexual difference in his historical analyses of the constructed 'subject' in that he uses the term 'man' as the universal form in his writings (Sarup, 1993). As a result, he fails "to address the gender specificity of many of the political technologies of the body that he described" says Sawicki (1994, p. 308). Another deficiency of his work concerns his account of disciplinary power. Sawicki again argues that from a feminist perspective, Foucault "provides no convincing account of 
how effective resistance to power is possible" (p. 293). In this aspect, feminist critique is little different from writers of other disciplines, as discussed above. Despite the shortcomings of his analyses and conclusions however, Foucault's ideas continue to challenge and stimulate debate, and they remain an important philosophical and historical contribution to the developments in social theory.

\section{SUMMARY}

My purpose in this chapter has been to present the key ideas which are regarded as relevant to my own theoretical perspectives informing this thesis. In the first part of the chapter current ideas and theories on 'discourse' from a number of sources, for example Fairclough (1992, 1994), Harre and Gilbert (1994), Parker (1992), Potter and Wetherell (1987) and van Dijk (1990a, 1990b) were outlined and discussed. These provided the backdrop for the perspective on discourse developed by Michel Foucault $(1970,1972)$ which was presented and discussed in the second part of the chapter. This section on Michel Focault included a critical review of his analyses of power/knowledge as well as his ideas on the formation of the 'disciplined body', and offered alternatives to his position.

To recap, current theories of 'discourse' take a critical perspective of language and language use and its relationship to power. Such theories stress that the way individuals think, speak and interact in society are produced by discursive practices of power, and that language plays a central role through its relationship to 'discourse'. A critical analysis of language and the social conditions of its use/existence permits an understanding of how certain social institutions and practices become embedded as 'discourses' and taken as commonplace, or 'natural', in society. The relationship between language and power in both the maintenance of social order and conditions for social change underpin the methodology and method of critical discourse analysis (CDA) (Fairclough, 
1994; Fairclough \& Wodak, 1997; Potter and Wetherell, 1987).

Underlying Foucault's theoretical position on 'discourse' was the relationship between language and the production of knowledge or claims to truth, and involved relations of power. Of greatest interest to Foucault was the power/knowledge of professional disciplines such as medicine. For Foucault all knowledge is socially contingent; it is constructed knowledge and language is the vehicle. This means that such 'natural' entities as pain are a product of constructed knowledge. As such, knowledge about pain is constructed around particular understandings of the body and of the person/patient, which becomes legitimated as the truth. This particular view of the body and of the person then becomes the location where social practices and power/knowledge are played out.

Social practices such as that of pain management are invested with relations of professional power because they have become discourses. This study aims to investigate the alliance between 'discourse' and pain management practices through an analysis of surgical nurses' "talk". An analysis of the language that the nurses use to talk about this work will facilitate an understanding of the function it has constructing and reproducing 'discourses of pain management'.

Building on the ideas on language and 'discourse' presented in this chapter, in Chapter Four, I turn to a discussion of discourse analysis as methodology and method, and a consideration of the key tenets of critical discourse analysis (CDA) as articulated by Fairclough $(1992,1994)$ and Potter and Wetherell $(1987,1994)$ which inform the approach I take in this thesis. The chapter also reflects on and discusses the research process, the philosophical and ethical issues and concerns that working with nurses from the organisation within which 
I also work potentially creates, and the ways in which I successfully worked through them. 


\section{CHAPTER FOUR}

Critical Discourse Analysis as methodology and method:

Framing up the research process undertaken in this study

\section{INTRODUCTION}

The ideas on language and 'discourse' presented and critiqued in Chapter Three provide the theoretical foundation for this chapter, the purpose of which is to discuss the focus for discourse analysis as methodology and review the key ideas underlying a critical discourse analytic method as described by Fairclough (1992, 1994) and Potter and Wetherell (1987, 1994). Ideas from both approaches form the framework for the analysis undertaken in this study. Chapter Three examined current perspectives on 'discourse' from a number of writers, and included a detailed review of Foucault's conceptualisation of 'discourse', as well as his analyses of knowledge/power.

As indicated in Chapter One, in the context of this thesis, 'discourse' is taken to mean the use of language as the medium through which relations of power and knowledge associated with that power are played out in social practices. The practice of interest in this study is that of surgical nurses' pain management. I am interested in how language is used by surgical nurses to talk about their work with hospitalised patients in pain. An analysis of this language and the function it has may assist with an understanding of why it is that surgical nurses take care of patients reporting pain in particular ways.

Critical discourse analysis (CDA) is considered the most appropriate method for this study because it involves a focus on the sociocultural and political processes which, through language, lead to particular 'discourses'. It accomplishes this 
through a critical scrutiny of 'texts'. Here, the surgical nurses' 'talk' is regarded as the text, able to be analysed or 'deconstructed'. From within the text, different voices as 'discourses' are uncovered. These become the 'discourses of pain management'.

The chapter is divided into two distinct parts. The first begins with a review of discourse analysis as methodology and method, before turning to a consideration of those ideas regarded as central to a critical discourse analysis as articulated by Fairclough $(1992,1994)$ and Potter and Wetherell $(1987,1994)$. This is to locate the critical discourse analysis framework adapted as the method for this study, which is also presented. Included in this part of the chapter is a brief critique of the problematic aspects of critical discourse analysis. The second part of the chapter is devoted entirely to a discussion of the practical aspects of the research process, as well as the ethical concerns with which I was confronted and how these were resolved so the study could proceed.

\section{DISCOURSE ANALYSIS AS METHODOLOGY AND METHOD}

As noted in Chapter Three, many disciplines including that of nursing, have become increasingly interested in the constitutive properties of language and the role it plays in ideas about reality and the maintenance of social order. The study of language as "discourse" has led to critical discourse analysis. Discourse analysis as methodology incorporates both linguistic and social analysis in order to understand the relationship between language, discourse and power. This is in recognition of "an integral and intertwined relationship [that] exists between discourses - the way we speak or visually represent phenomena - and practices the actions and activities surrounding these phenomena" (Lupton, 1994, p. 18).

There is a good deal written on the methodology and method of discourse 
analysis, and like the positions on 'discourse' theories, there are a range of approaches described in the literature. See, for example, Barthes, 1977; Lyotard, 1984; Lupton, 1992; Parker, 1992; Fox, 1997. A review of these, however, is beyond the parameters of this thesis. Instead, as indicated above, this chapter considers only those ideas articulated by Fairclough $(1992,1994)$ and Potter and Wetherell $(1987,1994)$, as these form the basis of the method that was selected for my own critical discourse analysis.

Fairclough's $(1992,1994)$ and Potter and Wetherell's $(1987,1994)$ positions are not radically different. Broadly speaking, they differ only in how they each talk about their positions on discourse analysis, which are shaped by their backgrounds - Fairclough's in critical sociolinguistics; Potter and Wetherell from within social psychology. What follows is a brief overview of the central tenets of each of their positions, elements of which are amalgamated into the framework of analysis used in this study.

\section{PERSPECTIVES ON DISCOURSE ANALYSIS}

\section{Fairclough's Approach}

Fairclough describes his analytic approach as a three-dimensional framework, which connects text, discourse practice and sociocultural practice. His approach to critical discourse analysis incorporates a focus on textually-oriented discourse analysis while incorporating aspects of a social theory of discourse. Because of the emphasis he places on context, his method foregrounds "links between social practice and language, and the systematic investigation of connections between the nature of social processes and properties of language texts." (1994, p. 96). In this, his position is similar to that described by Potter and Wetherell (1987, 1994) whose approach is considered later in the chapter. 
In Fairclough's $(1992,1994)$ view, it is essential that critical discourse analysis undertakes to include the linguistic characteristics and form of the text, an interpretation of why the text 'is', and an explanation of what the relationship is between the text and sociocultural structures/processes. In other words, the analyst must seek to address the "how" question in order to answer the "why" question, by asking "how do texts 'work' to support particular discourses, which in turn sustain particular institutions, social arrangements and practices?"

A text is inscribed with discourses, that according to Fairclough leave 'traces' on the surface of the text. It is up to the analyst to 'read' the text in such a way so as to reveal the nuances and contextualisations hidden within it. This reading takes place at different levels. Firstly, the text is read as a piece of discourse embedded in the immediate situation. Next it is examined for what it can reveal about the wider institutional context in which it is situated, and finally, it must be scrutinised as an integral part of the sociocultural and political environment.

Thus, when examining the 'texts' of the surgical nurses' 'talk' for instance, it is important to consider the impact of influences beyond the immediate situation on the conversation. When examined at the level of the institutional discourses, we may begin to see evidence of such things as the way nurses have been instructed to conduct pain assessments using specific tools to measure pain; and the way in which they are educated to comply with policies and guidelines that highlight particular institutional requirements, especially those influenced by ideas disseminated by an acute pain service and the biomedical model of pain.

Fairclough's approach emphasises the production, distribution and consumption of texts. Texts are produced in specific ways in specific contexts, for example, a political speech, a conversation or an advertisement (for example, "BE WISE: 
IMMUNISE"). Some texts have a simple distribution, for example, the casual conversation belongs to the encounter but may become part of another context, as another conversation. The advertisement given as the example above, has a far wider audience and potential influence for the message within the text suggests that only wise people immunise. Those who don't are not and put their children at risk. This latter aspect of the text is all about consumption of texts. Whose voice is privileged? What does this say about constructions of knowledge/relations of power?

\section{Fairclough's analytical framework}

Text analysis according to Fairclough $(1992,1994)$ can be organised under four main headings; vocabulary, grammar, cohesion and text structure. These form an essential part of the linguistic analysis and they connect with and build on each other. Thus, vocabulary is about individual words; grammar deals with how words are put together into clauses and sentences. Linked clauses and sentences give cohesion and meaning to the whole, and they all form part of the structure of the text (Fairclough, 1994).

A copy of the New Zealand Listener (December 19-25, 1998) offers, for example, "Gut reactions: How safe is our water?" This sentence can be broken down into its constituent parts. The main elements are the clauses or phrases "gut reactions", "our water" and "how safe". Separated, each phrase loses some of its impact; together they portray a particular image and one constructed for effect by the writer (Welch, 1998).

As well, Fairclough proposes that the 'force' of utterances is acknowledged, in other words, what sort of speech acts the words/phrases constitute. The headline above asks a question; other sorts of speech acts that Fairclough alludes to are 
threats, promises and requests. It is important to 'read the situation' of the text. He also stipulates that after interpretation, there should be a coherence, a sense of the whole.

A final and critical component that Fairclough describes is the intertextuality of texts. A text cannot come from nothing; rather, texts "are shaped by prior texts that they are 'responding' to, and by subsequent texts that they 'anticipate'" (Fairclough, 1992, p. 101). In other words, when people speak, they simultaneously use other people's words and phrases as well as their own. Speakers have assimilated others' ideas and ways of expressing them, and incorporate them into their own speech.

This is what is meant by the historicity of texts. What is essential on the part of the analyst is critical recognition of how particular historical conditions and thinking have shaped discursive events in particular ways. Thus, it necessitates an understanding that at any one time, different 'voices' compete for dominance in the discourse event. These Fairclough refers to as "orders of discourse", and the boundaries between different discourses are constantly shifting. In this way, texts are rewritten and become new texts.

These specific properties of texts constitute Fairclough's $(1992,1994)$ approach to textual analysis. The discussion now turns to some of the central tenets to critical discourse analysis as proposed by Potter and Wetherell $(1987,1994)$.

\section{Potter and Wetherell's Approach}

For Potter and Wetherell, discourse is centred around notions of constructed knowledge, institutions and practices, and the impact this has on the actions/behaviours of individuals who are themselves produced "through the 
workings of a set of discourses" (p. 47). For them, discourse analysis "is concerned with talk and texts as social practices" (1994, p. 48). In their view, people use language creatively, to achieve certain effects and actions. What they do not say can be just as significant as what they do say, and perhaps more so in some situations. During the course of an interaction for instance, people create a particular version or argument for a reason; it is not arbitrarily selected, and it can be either explicit or implicitly read into the text. Therefore, the "focus on language function is also one of the major components of discourse analysis..." (Potter \& Wetherell, 1987, p. 32).

The emphasis then is on discourse as social practice as well as on the context of its use. Potter and Wetherell's approach to discourse analysis pays careful attention to the linguistic 'content' of these (they refer to these as "meanings and topics") - as well as the 'form', such as the grammar and cohesion of the text, in similar fashion to Fairclough (1994). Critically, however, while linguistic analysis forms part of the process, "the discourse analyst is after the answers to social or sociological questions rather than to linguistic ones," say Potter and Wetherell (1994, p. 48). This forms an important distinction between their approach to critical discourse analysis and that of Fairclough's as outlined earlier, although more recently it can be argued that Fairclough is after social/sociological answers rather than linguistic ones (Fairclough, 1995, p. 209).

People act through language. Discourse analysis therefore is not just concerned with construction, but also with action. "People perform actions of different kinds through their talk and their writing, and they accomplish the nature of these ... partly through constructing their discourse out of a range of styles, linguistic resources and rhetorical devices" say the authors (1994, p. 48). An 
example of what the authors mean is to be found in such material as New Zealand Government publications.

"The Code of Social Responsibility" (1998) is a recent document which provoked a range of opinion and debate. The aim of such publications is to present a particular description or explanation about the topic/issue, and to persuade the reader of the 'facts' and any conclusions drawn or recommendations being made. Such 'discourse' constructs particular images and acts as the means through which particular ideological rhetoric can be disseminated. A major aim of critical studies into discourse therefore, is to reveal the workings of these constructive processes.

Potter and Wetherell focus on 'interpretative repertoires', which they describe as "a lexicon or register of terms and metaphors drawn upon to characterize and evaluate actions and events" (Potter \& Wetherell, 1987, p. 138). These repertoires represent "systems of signification and as the building blocks used for manufacturing versions of actions, self and social structures in talk" they explain (1992, p. 90). As such, interpretative repertoires are not so much 'discourses' as a way of "understanding the content of discourse and how that content is organized" (p. 90).

\section{Potter and Wetherell's ten stages of discourse analysis}

For Potter and Wetherell, the practical application of analysing discourse involves ten distinct stages, and begins with the setting of the research question through to issues of validation and application of findings. The stages are not necessarily discrete, but merge into each other as the work proceeds. The setting of the question determines the way forward, for example, sample size. However, the authors reiterate that the size of the sample group is not important 
in the final analysis, because the purpose of the research and the research question will determine what is required with regards to method of data collection.

The third and fourth stages are about data collection, either documents and records or interviews. Potter and Wetherell stress both consistency and variation are the targets in the collection of data during interviews. They write "consistency is important ... [but] only to the extent that the researcher wishes to identify regular patterns in language use" (1987, pp. 163-164). Of as much significance, indeed they suggest of more value, is variation in the talk. They comment:

consistency suggests that participants are drawing on a limited number of compatible discourse or interpretative repertoires ... [therefore] analyses which identify only the consistent responses are thus sometimes uninformative because they tell us little about the full range of accounting resources people use when constructing the meaning of their social world ... (1987, p. 164).

Another critical point they make, is that the researcher's questions are a topic of analysis. The analyst must ask "how do these questions construct a reality in themselves?" The interviewer is an active participant in the conversational encounter, therefore the whole interview must be transcribed. This aspect to their discourse analysis has links with Fairclough's (1994) ideas on context and that analysis must include a reading of the text as a creation of the situation in which it took place.

The fifth stage involves transcription, and is a timely and important process. As Potter and Wetherell (1987, p. 165) explain "transcription is a constructive and conventional activity." There are a number of different transcription conventions 
available (for example, Atkinson \& Heritage, 1984; Jefferson, 1985). The decision of what transcription conventions to use will be based on the purposes of the research project. For instance, in my research I was not interested in timing pauses between groups of words as part of the speech pattern of a particular speaker. The transcription conventions used in this study were taken from Parker (1992), and are listed in Chapter Five.

In stages six and seven, the authors talk about 'coding' and 'analysis', both of which are time consuming and laborious as the transcripts are read over and over again. Coding has nothing to do with the analysis of the data; it simply pulls it into more manageable bits. During the analysis there is the search for patterns which may involve differences and similarities in the text, and for the function and consequence of what is said/written. The authors write:

the basic theoretical thrust of discourse analysis is the argument that people's talk fulfils many functions and has varying effects. The second phase of analysis consists of forming hypotheses about these functions and effects and searching for the linguistic evidence (1987, p. 168).

Stage eight is the validation of findings and Potter and Wetherell explore various analytic techniques to facilitate this. One of these, 'coherence', is similar to the ideas articulated by Fairclough (1994), and emphasises how a body of discourse should fit together as a complete explanation. Stages nine and ten cover the final report and application of findings. "The goal [of the report] is to present analysis and conclusions in such a way that the reader is able to assess the researcher's interpretations", they write (1987, p. 172).

This then is Potter and Wetherell's approach to critical discourse analysis. Many 
of its features overlap with Fairclough's $(1992,1994)$ approach and it is to a brief overview of these that I now turn before moving next to an outline of the framework selected for my own study. In presenting the framework, I explain why certain components were selected and how these were utilised.

\section{The two approaches; Similarities and differences}

The authors all share a view of discourse as both a mode of representation and the way people act on their social worlds to give it meaning. They acknowledge the place of discourse in shaping knowledge, beliefs and practices. They also focus on language function as a critical dimension to discourse analysis. However, because they are grounded in different disciplines, Potter and Wetherell in social psychology and Fairclough in sociolinguistics, the questions they seek to address through discourse analysis necessitate a different focus. Therefore, while Fairclough's $(1992,1994)$ approach emphasizes the 'linguistic turn' although more recently includes social analysis (Fairclough, 1995), Potter and Wetherell's $(1987,1994)$ method highlights the social analysis of discourse.

\section{SELECTING COMPONENTS FOR THE ANALYTICAL FRAMEWORK FOR THIS STUDY}

As stated at the beginning of this chapter, the framework for analysis is an amalgamation of some of the key ideas articulated by Fairclough $(1992,1994)$ and Potter and Wetherell $(1987,1994)$ as discussed above. Selecting components for the framework was based primarily on the focus of the research question. To a lesser extent, the ability to conduct a critical discourse analysis to the depth that Fairclough's method in particular describes, was precluded by the twelve calendar month timeframe for completion of the study. 


\section{The framework for analysis}

The method used focuses on the transcribed 'talk' as the 'texts', which are read critically for both the form and content, as well as the context, which borrows from both Fairclough $(1992,1994)$ and Potter and Wetherell's $(1987,1994)$ approaches. The decision to incorporate all three aspects as part of the analysis was because they are crucial components and could not be omitted. Indeed, as Fairclough (1992, p. 74) points out "in analysing texts one is always simultaneously addressing questions of form and questions of meaning." The context as described by Fairclough (1994) is also considered important here.

The question of what goes on in a conversation, or in this case, the interviews, is an important one for critical discourse analysis. This is because the text is created out of the environment in which it occurs. In this way, the con-text (with-text) takes the reader beyond the language used during the course of the interaction. A casual conversation between friends, for instance, is commonly a shared encounter with meaning between the participants in that encounter. They often share the same reality; indeed, this is why they consider themselves friends. However, in the process of communicating with each other, they construct a another reality which is constituted out of the language each uses during the conversation. This reality is shaped also by the mannerisms, the tone of voice, inflections, the turn-taking and politeness conventions of speech acts. Likewise, it is important to consider that depending on the context of an encounter, the participants' talk may be coloured by both personal and professional or institutional discourses.

Similarly, what goes on between the participants in an interview contributes to the texture of the 'texts' as much as the final transcripts of the 'talk'. It is therefore essential that an exploration and critique of the context of the texts is 
carried out, because the interviews are an occasion for the construction of reality. It is in how this reality comes into being that provides the rich source of material for the discourse analyst.

Much of this richness and valuable detail in an interaction is incapable of being reproduced in transcripts. The body language and gestures for instance cannot be transcribed from an audio-taped conversation. However, there is still much that can be picked up from an analysis of transcribed conversations, especially with regards to what is going on in the context of the interaction. In examining the texts of the transcripts, the intent is to reveal something about the wider context in which they are situated.

They are therefore scrutinised as texts created within the immediate context of the conversations I had with the four surgical nurses. Questions that arise from this are centred around how the interviews were structured. In other words, what went on during the course of the conversations? In reading the texts, what do they reveal about how the talk proceeded? What power relations are evident? How is resistance enacted, and what of the shared views between discourse participants?

In association with the contextual aspects, the textual elements of the text are explored. Here the particular focus is on the form and content of the language of the conversations; how rhetoric and metaphor are incorporated into speech, and the purpose they serve; what's implied or made explicit; what words are used which by their incorporation highlight which words are absent. Metaphor, for instance, is a device used commonly to bolster an account; to persuade the listener of the 'truth'. 


\section{The process of 'text' analysis}

The work will proceed in the following way using some of the steps outlined by Potter and Wetherell (1987) in their ten stages of discourse analysis. First of all, each of the transcripts will be read, and common words or phrases that are related to the intent of the research extracted. Potter and Wetherell (1987) speak about 'coding' as the means of reducing an enormous amount of material into something more manageable. 'Coding' pulls out categories or aspects within the text that share common features or references. The categories of relevance in this work will be references made to "the body", "pain", "person/experience", and "nursing/work". All those instances from within the transcripts will be collated into their own file.

Next, the work of analysis will include the search for some sense of consistency between the features of the talk. This should show up as patterns, either as differences or similarities between accounts. The two questions that I will have in my mind as I read the texts are, "what is the function of this?" and "what effect does it create?" As pointed out above, specifically the interest is in focusing on the way the talk proceeds and how the linguistic features of the texts can be 'deconstructed'. The outcome of the analysis will be some key themes as 'discourses of pain management', which will be discussed. As alluded to earlier in the chapter, the analysis of the language and the function it has may assist in an understanding of why it is that surgical nurses take care of patients reporting pain in particular ways.

\section{PROBLEMATIC ASPECTS OF CRITICAL DISCOURSE ANALYSIS}

Critical discourse analysis is not without its problems. According to Parker and Burman (1993) who listed thirty-two in a chapter of their book, Discourse, action and the research process (although it is not my intention here to list and 
speak to each of these), one of the first issues is that of the method being a labour-intensive and time-consuming process. This view is shared by Potter and Wetherell (1987). Discourse analysis often entails the collection and reading of a large volume of material. It means therefore that should the researcher have limited resources, a study using discourse analysis could be compromised. Parker and Burman (1993) point out that one of the dangers of a too superficial analysis is that it ends up merely reporting on 'phenomena' while leaving out a much more in-depth analysis of the contextual and performative functions of language in which discourses are produced, reproduced and/or transformed. This the authors refer to as "reductionism".

Another of the issues is that the results of discourse analysis cannot be generalisable; in other words, "it is difficult to move from a specific text, from a particular usage, to a wider context" suggest Parker and Burman (1993, p. 156). Each context for conversation, even about the same subject, will result in a different 'text'. Such is the creative power of language and language use.

Furthermore, each text is open to different readings and interpretations. This, say Parker and Burman (1993), has been one of the traditional complaints about the method of discourse analysis, in "that discourse research does not provide a sufficiently rigorous methodology, in which the reader is satisfied that the analysis has produced the only possible reading ..." (p. 156). This concern with 'closure' prevents other possible and alternative readings and interpretations of texts.

This surfaces another important question, and that is, what gives someone else the right to claim to know the meaning and intent behind someone else's words? There is a concern over the power and control of the analyst to determine what 
the text is saying. This, write Parker and Burman (1993, p. 157), "raises the issue of experts legitimating discourse ... [and] are issues of power and morality in research." In effect, the author's concerns again highlight the discursive properties of language, and the relationship between knowledge and power. Finally, and following on from that above, another of the problems identified by Parker and Burman is that of the researcher as both reader and as producer of discourse. In the process of 'analysing' the text to reveal the discourses, the researcher is simultaneously reproducing and/or transforming the discourse(s) into something other than what they were.

I was aware of all these problematic aspects of discourse analysis identified by Parker and Burman (1993) and to a lesser extent by Potter and Wetherell (1987) when I decided to proceed with critical discourse analysis as the method for this study. On that basis my decision was to go ahead taking them into account. In chapter seven, the ways in which the research process was affected by them is more fully reflected upon and discussed.

\section{THE RESEARCH PROCESS}

\section{The method of data collection}

Because discourse analysis is a time-consuming process as already noted, I had to carefully weigh up the intent/purpose of the research against what I could achieve practically. The selection of a method of data collection was therefore a key consideration as was the numbers of participants. The research topic was structured so that audio-taped, one-to-one conversations would offer the most efficient and effective means of obtaining the data, while the number of participants I decided on was four. The study involved registered nurses recruited from the nursing staff of eight adult surgical wards of the 700 bed tertiary healthcare institution in which I work. 
Registered nurses (RNs) were selected because they have primary responsibility for overseeing patient care, including that provided by enrolled nurses (E/Ns) (Nursing Council of New Zealand, 1995). It was my contention that registered nurses play a key role in pain management practices. They provide direction and supervision of enrolled nurses including support and guidance in decisions concerning pain management. It is the registered nurse who is discussed in relation to the topic of pain and its management in the nursing, medical and sociological texts (for example, Fagerhaugh \& Strauss, 1977; Geisser, Bingham \& Robinson, 1995; Wakefield, 1995; Price \& Cheek, 1996). My only other requirement of participants was that they had worked for at least six months within the surgical area. This was to provide them with sufficient experience upon which to draw when talking about their work.

\section{Mapping out the interviews}

My plan was to conduct two interviews with each participant. The first interview would gather most of the data, while the second would be an opportunity to explore further any areas or issues that arose out of the first interview, and to clarify any queries I had about what had been said at that time. The interviews would not last any longer than one hour, with the initial interview being conducted within three weeks of recruitment. The second round of interviews would be completed within three months. All interviews were completed within the projected timeframe.

I learned early on that two of my participants had holidays planned which put pressure on me to get the interviews under way immediately. The first interviews were completed inside the hour; the second interviews were over within thirty minutes. There were still many pages of transcribed material from each of the conversations. This of course is one of the potential issues with 
discourse analysis; so much data, leaving you wondering what to do with it all (Potter \& Wetherell, 1987).

My intention was to allow the interviews to be largely unstructured in format; to develop as 'conversations'. Structured interviews do not allow for the development of variability and richness which is the fertile ground of discourse analysis (Potter \& Wetherell, 1987). I did have some questions as a way of starting off the conversations, but wanted the participants to determine the course of the discussion, with as little topic guidance from me as was necessary to stimulate conversation. The questions I drafted were broad, such as 'how long have you been working as a surgical nurse?', 'what do you see as the nurse's role in pain management?', and 'can you tell me about any instances which you vividly recall about patients who have experienced pain'. It was hoped that these would stimulate remembering and speaking on the topic of pain.

\section{Gaining ethical approval}

I submitted an application for ethical approval to the Victoria University of Wellington Human Ethics Committee as is the requirement for post-graduate research students. I also contacted the Chairperson of the Waikato Ethics Committee to enquire about local requirements for proceeding with my study. I was informed that ethical approval from the University's Human Ethics Committee was sufficient because the proposed study did not directly involve patients. However, the Waikato Ethics Committee requested a report on the project at its conclusion.

Apart from a minor change to my participant consent form and the participant information sheet I was granted ethical approval to proceed. The Committee requested that I clarify ownership of information once the analysis had begun, 
something that I had omitted. This correction was made and the documents resubmitted to the Committee for their records.

\section{How access to participants was approved}

Because the research participants were being recruited from the pool of registered nurses within the organisation where I work, I needed an access agreement from senior hospital management before I could proceed. This was considered vital for the protection of the nurses who, while taking part in the study away from the workplace, were nevertheless being approached as employees of the organisation. The access agreement, as an integral part of gaining ethical approval, provided assurance to hospital management that the study would be conducted properly within the bounds of the agreement.

I contacted the Manager of Hospital Services and Facilities personally to explain the nature of my proposed project and to discuss any concerns he had about the study. As the most senior manager in charge of the co-ordination and delivery of services and facilities within the hospital, he had direct responsibility to the area of the organisation where I was going to conduct my research. Following our initial discussion, I followed up my request for access with a letter to him, and received formal confirmation from him personally approving access to registered nurses from within the hospital once ethical approval from the Victoria University of Wellington Human Ethics Committee had been granted.

\section{ETHICAL ISSUES AND CONCERNS}

There were a number of ethical issues and concerns that I identified as needing careful consideration, aside from the issue of access, and these along with the precautions I took are discussed on pages eightyeight to ninetythree. Many of the concerns that I identified as perhaps influencing surgical nurse's participation 
in my research arose because of my role and responsibilities as the acute pain service nurse, which are outlined in chapter one on page three.

\section{Access to participants}

As alluded to above, I was aware of a potential difficulty in recruiting RNs to the study. For instance, many nurses would not feel comfortable talking about pain because they might see themselves and their practice under the spotlight. I believed that they might feel vulnerable talking with the pain service nurse about a subject that has not always been favourably reported on, especially in the literature (for example, Fagerhaugh \& Strauss, 1977; Taylor, Skelton \& Butcher, 1984; Wakefield, 1995; Zalon, 1993).

Indeed, also as discussed in Chapter One, a major reason for conducting the research was because from my own experience in surgical nursing, practices of surgical pain management were given less status than the management of cancer patients' pain. I imagined therefore, that the topic and focus of the research along with my name as researcher might put nurses off applying to take part. It was important therefore that any nurse wanting to participate was assured that involvement in the research would not bring them harm as employees.

\section{Using an intermediary}

Because of my position and the nature of the research I was wanting to undertake, I was sensitive about avoiding coercion. For all the above reasons, I nominated an intermediary to assist with the recruitment process. Ethically, I felt that the nurses who came forward to seek information about the study must have someone to explain it who had no other personal or professional involvement in the research process. In this way they could be assured no pressure was being exerted on them to participate. They also needed reassurance 
from the person with nothing to gain from their recruitment that taking part would in no way compromise their working relationship with me.

The person I recruited for the role is a work colleague, although the area she works in was unconnected with any of the participants. Furthermore, she does not hold a position of line responsibility that could adversely affect the participant's involvement in the study. She is a nurse who has a background in research, understood the nature and purpose of the proposed study, and responded appropriately to the issues or concerns of the prospective participants. Following the recruitment and enrolment process, she had no further role in the study, although she was bound not to reveal participants' identities.

\section{Informed consent}

Written informed consent was obtained from each participant, the process for which is described over the page. This consent covered the collection and use of the data obtained during individual interviews which were audio-taped, then transcribed for analysis purposes. It also included permission for me to incorporate direct quotations from the transcripts where appropriate to support any opinions or conclusions drawn by me. It did not cover my use of the material for subsequent reports/articles or other research projects. That will need to be sought separately.

\section{Anonymity and confidentiality}

The issues of anonymity and confidentiality are always important in research. It became doubly so given the fact that in my study participants and researcher work in the same organisation. Given the small number of participants, the risks of identifying them are high. I could not claim the research was anonymous; this was impossible since I knew who my participants were. Likewise, once the 
research is published, readers will know that the participants came from my workplace.

Each participant however, was assured that wherever possible their identity would be protected and no information would be used by me that could personally identify them. I had no control over the participants discussing the research with friends or colleagues. However, the typist I employed to transcribe the material from the tapes signed a confidentiality agreement as part of the contract for her services.

For my part, I minimised any contact I had with the participants during work hours, other than for work reasons, such as patient follow-up. All communications were either through the intermediary (initially), or by letter to arrange the dates and times for interviews. In the thesis itself, where direct quotes are used, they are identified by "N1" , "N2" and so on.

\section{Recruitment of participants}

One flyer briefly outlining the study and the name of the researcher were posted throughout each of the eight adult surgical wards. Interested registered nurses were invited to contact the person acting as the intermediary to discuss the study. At an initial meeting with each prospective participant, the intermediary was instructed to discuss the purpose of the study and describe the method of obtaining the data. Following this discussion with the intermediary, each prospective participant was given an information sheet and consent form to take away, read and reflect on.

\section{Participants' right to decline}

The nature of the nurses' participation was also addressed at the initial meeting 
and the voluntary nature of the study emphasised. It was imperative that the nurses retained control over their decision to participate knowing that should they subsequently decide they no longer wanted to be involved, no pressure would be put on them to give a reason for their withdrawal. They were also made aware of the right to decline to answer any questions or pursue any discussion if they so wished, without needing to give a reason. However, they were made aware of the fact that once analysis of the material had commenced, they could no longer withdraw that information. It became the property of the researcher.

Written informed consent was obtained by the person acting as an intermediary. This was carried out at a second meeting two to three days later. The time lapse between the initial meeting and gaining informed consent was to allow adequate time for the prospective participants to mull over the information they had received and consider any additional questions/issues they wanted explained further.

\section{Potential harm to participants}

My senior role within the organisation does not extend to line responsibility. The nurses needed to be reassured that involvement in the research would not jeopardise their employment in any way. However, I was still mindful of their feeling at risk from taking part in the research, from what the outcome of the research might reveal, and what the final report would illustrate. The 'discourses of pain management' are about what lies behind their practice.

It was emphasised that the study was not about a professional evaluation of them, such as a performance appraisal. My reason for conducting this research is so that an understanding of why surgical nurses take care of hospitalised 
patients reporting pain in particular ways can perhaps lead to open discussion and the development of a critical awareness of the coercive power of such discourses.

\section{Conflict of interest}

The concerns about conflict of interest centres around whether, given the job I have, the seniority of my position and the fact that my research involved critical analysis I should have conducted the study so close to home, as it were. The role responsibilities in association with my job and the relationship I had with any potential participants mean that the research may have been more properly conducted in another institution. However, it was more convenient to carry out the research in the organisation where I work. I felt confident that I could take sufficient care to protect my participants, and still collect quality data. Indeed, the fact I did do the research in my organisation behoves me to be transparent about my role in the organisation and the research process. Furthermore, I am aware that some of the nurses who agreed to participate, did so because they knew me and trusted the intent of my study.

\section{Protection of information gathered in the research process}

As the researcher I kept demographic data, including the signed consents, locked in a filing cabinet to which noone else had access. Similarly, the tape recordings, once labelled with an identification code, were locked away in the filing cabinet. The only people to listen to the tapes were the transcriber and me, and this took place in private. The transcripts were also filed away in a locked drawer, and were only accessible to me.

\section{Copyright}

The transcripts from each of the participants' interviews was returned to them 
for verification and for signing off so I could action the next process of coding and analysis. Few of the participants deleted material they did not want me to work with, although there were some minor corrections made. These were initialled by the participant. Ownership of the information belonged to the participants at this point. However, once analysis of the transcripts was commenced, ownership of the documents passed over to me as the researcher.

\section{SUMMARY}

In this chapter I have presented an overview of the methodology and method of discourse analysis, and the rationale for the selection of this approach in the design of this study. Discourses are constituted and reproduced through language, but take on a life independent of language, such as in certain social or cultural practices, such as that of pain management. Critical discourse analysis therefore provides the most appropriate approach to analyse language and the functions it has in order to gain an understanding of why surgical nurses take care of patients reporting pain is particular ways.

I have also discussed the key features of a critical discourse analysis as articulated by Fairclough $(1992,1994)$ and Potter and Wetherell $(1987,1994)$, whose ideas formed the basis of the framework used in this study. In sketching out the structure of this framework which includes an analysis of the form and content of the texts, as well as the context in which they are embedded, I have commented on which aspects of Fairclough's and Potter and Wetherell's approaches were selected. As well, my discussion on critical discourse analysis has included some of the problematic apsects of this method.

In the second part of the chapter I reviewed both the pragmatic aspects of the research and the ethical considerations that had to be carefully thought through 
so that approval to proceed with this study could be granted. The central ethical issues revolved around my relationship with the participants and how I would protect them from harm. The practical consequences of these have been summarised. In Chapters Five and Six I present the results and a discussion of the analysis. 


\section{CHAPTER FIVE \\ Analysing the 'texts': Biomedical discourses}

\section{INTRODUCTION}

Chapter Four presented the method of this thesis. The central elements to critical discourse analysis (CDA) as proposed by Fairclough $(1992,1994)$ and Potter and Wetherell $(1987,1994)$ were briefly discussed, then the framework selected for this study was outlined. Some of the problematic aspects of critical discourse analysis were also considered. The practical aspects of executing the research as well as ethical issues and concerns considered integral to the study's design were reflected upon, discussed and justified by the precautions taken. In this chapter and that of Chapter Six, the results of the analysis of the surgical nurses' "talk" are presented. To support the analysis, selected excerpts from the texts are introduced into the discussion.

Because multiple readings of the texts are an integral aspect of discourse analysis, it was essential to have consistency between the transcriptions. As remarked on in Chapter Four, this assists and supports the researcher's analysis of the texts. Therefore, specific transcription conventions were used in this thesis. These were adapted from Parker (1992) and include the following: (//) for overlaps; (.) for short pauses; (-) for longer pauses. Emphases were underlined; (ye::s) for extended sounds; [laughs] for an explanation; doubts about accuracy or clarity of material in brackets (like this).

The two chapters are structured in the following way. Chapter Five begins with a brief description of the nurses who took part in the study; their backgrounds and present work environments. Examined next is the context of the interviews, which as commented upon in the previous chapter forms a crucial dimension of 
critical discourse analysis. The chapter moves then to consider what the analysis of the 'talk' revealed about the influences on the ways in which the participants talked about pain and their pain work, and what this told me about the relationship between professional knowledge and power. This aspect of analysis is covered further in Chapter Six.

As Fairclough $(1992,1994)$ theorised, the text was interwoven with different 'voices'. This made the job of singling out themes and discourses a challenge. Particular themes reflecting a dominant voice are presented and discussed. For example, such themes as "validating pain - doling out amounts of pain" and "getting on top of pain" reflected a strongly biomedical discourse. On other occasions it was not clearcut; several voices emerged and these are identified and explored.

\section{THE PARTICIPANTS}

All four were women, and between them they had a wealth of nursing experience. Three of the participants had extensive histories in surgical nursing, the longest period being around twentyfive years, although two had taken time out to have children. The fourth participant had a long tenure in cardiac care nursing. Her recruitment to surgery was recent, a few months short of two years.

Education on pain during their $\mathrm{R} / \mathrm{N}$ preparation was limited to science lectures where they were told about "endorphins and pain receptors and things like that. We actually did quite an indepth in science about all the neuroreceptors and all those sorts of things ..." (N4, 1st interview). Much of what they now know, the nurses admitted learning over the years through experience working with patients in pain, or through institutional education programmes. 
Her nursing career had started as an enrolled nurse (E/N) back in the 1970s. She worked as an $\mathrm{E} / \mathrm{N}$ for a total of ten years before taking the step to become a registered nurse $(\mathrm{R} / \mathrm{N})$ through the bridging programme offered at the local Polytechnic. Following her registration she returned to orthopaedic nursing, the surgical area she had worked in prior to undertaking her registered nurse education, and where she still works.

\section{N2}

She had undertaken a hospital-based nurse training programme in the United Kingdom, working there and overseas for a number of years before travelling to New Zealand to find a job as a nurse. Following a long history in medical nursing, she decided to have a complete change and applied to work as a surgical nurse in the high dependency unit (HDU) where nurses care for a range of surgical patients requiring intensive monitoring and support.

\section{N3}

She also works as an orthopaedic nurse although on a different ward to N1. She completed her diploma as a comprehensive nurse eleven years ago, worked for a period of nearly two and a half years before travelling overseas. She worked abroad as a surgical nurse for three years before returning to New Zealand to work in a private hospital. In early 1997 she decided to go back into the public hospital system and secured a position in her chosen specialty of orthopaedic nursing.

\section{N4}

She started work as an enrolled nurse in 1970, and apart from time out to have 
a family, has worked fairly consistently since then. She has been a night nurse and worked in the hospital "nursing pool" or "Agency" as it is now called, gaining experience in a range of different nursing specialties. In 1995 she commenced the bridging course at the local Polytechnic and completed her diploma and became a registered nurse in 1996. She is currently working in general surgery.

\section{THE INTERVIEWS}

\section{Reflecting on the process}

The nurses talked candidly about their backgrounds, their thoughts and feelings, and their work practices. They answered the questions which I had prepared as "openers". As the 'conversations' developed, further questions arose. I was painfully aware of not wanting to lead the conversation with the participants. However, I realised early on that when two people interact in the course of a conversation, values and beliefs held by each participant in the encounter will influence what is said, or not said, and how it is said.

Further, a situation such as an interview can in no way be likened to an 'ordinary' conversation. As the researcher, I was aware that in the process of audio-taping the conversation, some of the spontaneity was lost. This may have been minimised perhaps had I taken the advice of a colleague who suggested that I try out the questions with someone as a "dummy run", to give me a sense of what interviewing would be like. Potter and Wetherell (1987) also advise that novice interviewer's conduct pilot interviews for much the same reason. In hindsight, this may have been a sensible idea, because there is definitely a skill to successful interviewing.

As a result, for me at least, I was conscious initially of every nuance, every 
word, every half-completed/stalled comment. I became more attuned to how I spoke, the words I chose or avoided, the rhetorical questions, the lack of time given for the other participant in the conversation to answer more genuine queries, the talking over and interrupting. This of course is all fodder for the analyst. This nervousness eased somewhat as the interviews progressed. A relationship developed between the participants and me which allowed the conversation to develop along more relaxed lines as we each became immersed in the topic under discussion.

\section{Analysing the context}

Perhaps the most important thing to address first is that of the relationship between the participants and me, and the fact that my position within the organisation as the acute pain service nurse was likely to influence the context of the 'conversations'. Indeed, the very choice of topic was influenced by assumptions I had about pain management issues as I identified in chapter one. Therefore, even before the interviews commenced, there existed an unequal relationship based on knowledge/power.

As the researcher, I had advance knowledge of the study's aims. The questions I decided to ask the participants were based on a recognition of meeting my need to gather material for analysis. As the researcher, I needed to 'tap into' their remembrances to record the 'talk' that would be transcribed, collated, then analysed to reveal the 'discourses of pain management'. Controlling the agenda of the interviews therefore, was largely up to me.

A feature of this was my choice of questions as "openers". These were clearly posed to reflect a particular focus of mine and initiate a train of thought on behalf of the participants. This I believe is an exercise of power. Another 
feature related to interactional control through my use of rhetorical questions. The rhetorical question "do you want to talk about that", which I used often, was a polite way of inviting the participant to speak in more detail about an aspect of the topic in question.

This is a politeness strategy. Posing the question in this way removes the command. Yet, it is also a way out for the respondent who might choose to reject the invitation and change the subject. I successfully deployed the strategy on a number of occasions to stimulate reflection by the participant. Clearly, I had no control over what each of the nurses would tell me. However, it was I who set and asked the questions that initiated the conversations, and who kept steering the conversation when it looked as if it might be veering off the topic.

Take this following sequence as an example of the former:

I: $\quad$ This is my first interview with N3. Thank you for coming along N3.

N3: That's all right.

I: That's good. Umm, I guess the first question is how long have you been working as a surgical nurse?

N3: Well. That's bit scary. Probably 8 years.

I: Okay and orthopaedics the whole time?

N3: Orthopaedics for five years and then general surgery, yeah, combined surgery for the others.

I: $\quad$ So where did you work before you came to [names hospital where currently both 
work]?

N3: I was at [as above]. and then//

I: //were you?//

N3: //Yip, I trained here. Graduated here, did two years, two and a half years. Most of that was in [names ward], then I went to [names country]. And I had three years in a female surgical ward that was for literally everything. Every surgical specialty was there. And then I went to [names another hospital] for two years so that was all surgery as well. Then I came back here at the beginning of last year//

I: //and worked in orthopaedics//

N3: //and worked in orthopaedics.

This beginning sequence of the first interview with N3, which was similar in each of the initial interviews, is about creating an environment for both participants to "settle in". It is about establishing a tentative interviewerinterviewee relationship, hence the courtesy and politeness of thanking the nurse for coming along, and the nurse's confirmation of the interviewer's appreciation of her time. The interviewer controls the agenda all the way through this sequence. A question is asked, the nurse responds. The talk proceeds as background information about the participant is elicited. As each question is answered, it opens the way for another.

The "okay", a common colloquialism, is used as a confirmation of what has just been said. It also suggests an end to that which has just been talked about. The statement of the nurse about the length of service being "a bit scary" may have been an invitation to the interviewer to explore the source of the nurse's 
comment. However, it is not picked up by the interviewer. Seemingly, it is not deemed of necessary import to comment upon further. The control over the flow of the conversation remains with the interviewer.

What transpires is a picture of N3's working history in surgical nursing. The final closing remarks in this sequence are interesting. The interviewer realises that N3 in reviewing her history of work, has reached the present day, and shares this knowledge by finishing the sentence for her. This is common in conversations, that predictions about what will be said next are made by one of the speakers. It is like "we know what the other person is going to say", suggest Halliday and Hasan (1989, p. 9); that we understand each other's reality. Here, the interviewer's prediction is confirmed as correct, when N3 repeats the same statement.

Although control over agenda rested largely with me, on occasions, this was contested by the participant, usually because of something I had said or asked. Resistance occurred at different times, as we each countered what had been said, or what had been implied with our own interpretation. This can be seen in the following excerpt, taken from the same interview. The nurse has just been asked to reflect on her experience overseas, and compare it to our own thinking about pain:

N3: I think we tend to be far more empathetic to patients that 'we" we as in the westerners I worked with, we also (-) I don't know maybe I'm just being myself as well, but someone who's screaming and crying and carrying on doesn't convince me of their pain any more than someone lying there gritting their teeth because as I say, these women that I nursed were so over the top that you actually end up almost dismissing it because it's so over the top all the time. And you know you're doing it// 
I: $\quad / /$ but you//

N3: //you know you're doing it//

I: //it's a hard thing to stop//

N3: $\quad / / \mathrm{hmm} / /$

I: //I guess. And I, if you perceived it as something that was acceptable because other people, you know, they're just basically told to grit their teeth and bear it. Then you perhaps start taking on the actions of the people that you work with.

N3: No, I think it was more that these women would just scream and yell and yet the minute you put the needle into their skin they got instant relief, You know when you knew full well that the medication hadn't had a chance to work. It was just because something was happening that they were getting a response that you actually tended to be quite, quite cynical.

Besides the contextual elements of this piece of text, the content is worthy of analysis too. Using the word "empathy" which evokes an image of sympathetic and sensitive response to a situation, the nurse's next statement would seem to contradict this sense of accord between nurse and patients expressing pain. Instead, the implication is that empathy is given if and when the nurse can validate the pain from a perspective that is more in keeping with her own ideas/discourses of pain and how it should properly be articulated.

This surfaces the whole issue of cultural difference in vocalising pain, and how perhaps the empathy that was expressed resides in a particular cultural reality of pain. Being brave and "gritting your teeth" is used as a comparison with the description of the womens' exaggerated behaviour. Clearly, for the women who 
'performed' as is the implication, N3 could neither validate the pain, nor express empathy.

The interviewer appears to be searching for meaning and an explanation to what N3 has admitted, hence the interruptions and predictions every few words or so, about what she is going to say next. N3 however, counters these suggestions, and responds with her own reason for why she did what she did. In the process, she constructs a reasonable account based on knowing "full well that the medication hadn't had a chance to work." By implication, the pain was not real.

This sequence also highlights the different "voices" I spoke about earlier in the chapter on page ninetysix. In relation to the interviews and the construction of the 'texts', each of us brought more than one subject position to the context of the interaction. For instance, I was at once the researcher and a nurse, and my participants were also nurses and co-partners in the research endeavour. We were all members of society, with differing roles and responsibilities that come with that. Furthermore, we all have a different experience of pain.

At distinct times within the interviews, one of these positions would become dominant, overshadowing the others. For the most part, the voice that was heard in the participants' cases was that of the nurse. For my part, it was difficult to separate the researcher and nurse positions, though clearly, the former predominated.

In the above sequence, there is a glimpse of different voices coming through the text. Firstly there is the voice that is oriented to a dominant culture - that of the western world. Next there is the voice of the individual embedded in a social world that defines certain behaviours as the 'norm' and acceptable, and lastly, 
there is the voice of the nurse who is constrained within a particular definition of pain and pain management. It is to a presentation of the results of the analysis and the 'discourses of pain management' that this chapter now turns.

\section{BIOMEDICAL DISCOURSES OF PAIN MANAGEMENT}

This part of the chapter focuses on the critical analysis of the transcriptions for both the form and content of the language used in order to reveal the discourses which influenced the surgical nurses' pain management practices. The key themes that encapsulate the 'discourses of pain management' as they emerged from my reading of the nurses' talk, shaped the nature of nursing work and the ways in which nurses spoke about it. They are situated around particular understandings of the body and patient. The first of the discourses is situated around what qualifies as pain, and who has permission to know this. It is entitled "validating pain - doling out amounts of pain" and reveals how recognition and validation of pain as a physical entity, as something linked to anatomy and physiology of the body is situated within a biomedical discourse.

\section{Validating pain - "doling out amounts of pain"}

In the following sequence taken from the first interview, N3 explains her view on attitudes to pain:

N3: I think there is to a certain extent in that they've had a hip replacement they will be sore. They've only stubbed their toe they can't possibly be sore. You sort of dole out amounts(.) you know the amounts of pain a person is allowed to have with regard to their injury or with regard to//

I: //so if it's a major injury you can relate to it more easily//

N3: //um, you can have pain and therefore we will treat it and we will do something and 
if you've stubbed your toe - well "live with it", you know//

I: //very sore [laughs]. We all know when we stub our toes//

N3: //exactly.

Within a biomedical discourse, pain is talked about as being part of the nervous system, and usually located within a specific body part or area of the body (Bonica, 1977; Melzack \& Wall, 1988). Moreover, it is regarded as having a recognisable clinical pathology such as a surgical procedure or injury (Sinatra, Hard, Ginsberg \& Preble, 1992; MacIntyre \& Ready, 1996). This is classified as "acute pain" because it has a pathophysiological cause. Nerves and body tissues are damaged, eliciting a neural response. Depending on the degree of perceived trauma to the body, more or less pain is recognised as the outcome. With such pain, it is expected that once treatment is initiated or healing takes place, the pain disappears.

In the sequence above, the nurse is speaking quite openly about how pain is apportioned according to the clinical status of the injury. Thus, as the interviewer interjects and asks, the more serious the injury or surgery, the more acceptable the pain. This is acknowledged by the nurse, which she states then influences what attempts are made (if any) to treat the pain. This would seem to endorse the conclusions of the studies conducted by Wakefield (1995), Taylor, Skelton and Butcher (1984), and Fagerhaugh and Strauss (1977) as discussed in Chapter Two.

Following an analysis of nurses' talk about pain, Wakefield's position was that pain was credible only when it could be clearly attributed to an identifiable cause, such as within a certain period of time after surgery. Here we see, pain 
being "doled out" in the vernacular provided by the nurse, according to perceived extent/degree of trauma or surgery. That is because nurses can gaze upon a wound.

In the experimental study by Taylor and colleagues (1984), it was revealed that nurses rated pain as less credible and assigned lower priorities on treating the pain when it could not be attributed to an organic cause. In Fagerhaugh and Strauss's (1977) study, the authors highlighted the role of pain trajectories. These were the expected course of events following an injury or surgical procedure, when again, pain was accepted because it was expected; fall outside the trajectory for pain, and the patient's credibility was questioned. The authors write:

when nurses and other staff members are dubious about a claim to pain, they talk among themselves about the physical signs that the patient exhibits, and also about the pain expression and even the person's character. Their observations can lead to a discounting of claims concerning the amount of pain or even its presence (1977, p. 142).

Throughout this short sequence of talk around the 'doling out of pain', both participants in the interaction share in the construction of the reality that emerges. Looking at the flow of the conversation, the way in which the interjections and overlaps occur, it becomes possible to see how this construction takes place. This is a shared discourse. Each participant recognises and affirms the shared reality by the way they build on what the previous speaker has just said. Each of them knows for instance how a stubbed toe 'feels'; they can relate to the pain that such a stimulus evokes, yet it is given as a pain that is regarded as less valid than the pain of a surgical incision for the person undergoing a hip replacement. 
During her second interview, another of the other participants admitted that it is still the practice of some nurses to assume a certain pain trajectory:

N1: I think it's about fifty fifty. There'd perhaps be fifty percent of nurses that would say that, um, "no, they've had enough pain relief. That they're two or three days down the track", then there'd be others who'd say "well no, they need it tonight". And one dose after three days isn't much//

I: $\quad / / \mathrm{Hmm}$. How do they make that assumption do you think?

N1: I think they do that by looking at their patient, um, and plus the patient normally wouldn't say it. If they hadn't had it at all, all day until night. And sometimes it can be to do with mobilising. They could have been mobilising all day so they've had that extra work load on their muscles or wherever their incision was, so they're going to need more pain relief anyway to settle for the night if they've overdone things.

Although she gives a percentage of nurses who she believes work in this way, the arbitrary figure of fifty-fifty is actually implying she doesn't really know. She therefore uses this figure to average it out. N1 also recognises the factors that can exacerbate pain and uses this as an explanation to account for the need for ongoing analgesia. The point here is that pain is still given a timeframe, in this case a time of two or three days. Again, by implication once this is expired there should not be pain that warrants nursing intervention.

In contrast to these comments she makes about some of her peers, in an earlier statement during the same interview, N1 had remarked that for her pain was an experience unique to each person:

N1: I think what really stands out more is that you have to relate to the patient as each patient's pain is different. 
I: So where did you get that idea that each person's pain is recognised as being an individual experience?

N1: Well, some of that is from my own experience, being in the hospital and knowing what the pain is like...

I: Okay, do you want to talk about that? Do you think it is relevant for how you see pain now and work with patients who get pain?

N1: Ye::ah. (.) I think sometimes you can have a better picture if you have experienced something, um, because pain affects you in different ways, like pain can make you feel nauseous...The same patient can come into hospital twice and have a different experience...

Here, N1 is explaining an expanded view of pain and its causes. Personal experience showed her that she has to be open-minded about people's pain, because it can be so different even for the same person depending on circumstances. The nurse, she implies, has to be mindful of this, and it is easier if you have been there yourself. Treating the individual's pain as unique did not run to accepting what the patient said necessarily as the 'truth' of the matter. Indeed, during the first interview she had commented on the situation with elderly patients' self-report of pain:

N1: I find sometimes the elderly patients can miss out. We'll only give them panadol and to me that perhaps they could have done with more. The elderly patients quite often underestimate their pain. Uncomfortable quite often might be confused with moderate and if they've got no pain, well (-)...

Here I get the impression that although "pain is what the patients say it is", in the situation with elderly patients they don't really seem to know what their pain 
is like, hence the word 'confused'. This is a clear example of where the patient's reality over their situation is questioned. Permission to decide what pain is and how much a person has, in this instance, been highjacked by the nurse, although she doesn't appear to realise she had done so.

In the next section, the theme "getting on top of pain" will reveal a particular focus on the management of pain, and how this influences the way nurses (and doctors) talk about this work.

\section{"Getting on top of Pain"}

During the interviews, each of the participants was asked to talk about the nurse's role in pain management. Here in the initial interview, N3 explains her position on this aspect of nursing care by illustrating her strategy for talking to patients about 'managing pain':

N3: I try to (-) Generally it only happens with bookings. Actually go through the pain thing with people "make sure you tell us if you're sore", "we don't know if you don't tell us" basically. You know. Once again we can't, we won't probably be able to get rid of all your pain but we can certainly make you a lot more comfortable. You've got to let us know if its not working, and I actually tend to tell them "being in pain's a bit like being in debt"//

I: //okay//

N3: //if you're, if you can stay on top of it, it's a lot easier to stay there than it is to crawl your way up from underneath//

I: [laughing]

N3: //which is true. 
The discourse of 'managing pain', (and here the focus is on 'acute pain'), is caught up within an approach that aims to achieve freedom from pain. Although pain is regarded as having some protective functions, these are short-lived. Thereafter, pain becomes a hazard, and the longer pain stays with the person, the more harmful it becomes, both physically and emotionally. The basis for this is the pathophysiological changes within the body caused by a stress response to pain (McIntyre \& Ready, 1996; Sinatra, Hard, Ginsberg \& Preble, 1992).

Pain 'management' therefore is directed towards the relief of pain, and if total freedom from pain cannot be achieved, then the next best thing is to minimise it. Pain is perceived as an affliction of the body, as something that must be removed, 'taken away'. The above conversation would seem to suggest that nurses are both taught and socialised into thinking that pain, especially acute pain, must be got rid of.

This attitude towards pain has led to the development of ways of talking about pain management. Different metaphors and phrases are used, such as "beating pain", "controlling pain", "knocking pain on the head" or "staying ahead of pain". The nurses' talk was liberally sprinkled with these phrases, and it became evident early in the textual analysis, that the theme of getting on top of pain was one of the key discourses that informs their work in the area of pain.

The use of figurative language in day to day communication is commonplace. As Rudge (1997, p. 77) asserts "nurses, doctors and patients alike frequently use metaphors as a way of communicating the experience of health and illness." Metaphor has a central place in that it assists the speaker with the creation of reality by conceptualising it in terms of something else. Figurative language persuades the listener of the 'truth'. Thus, the association of pain with debt as 
used by $\mathrm{N} 3$ above is an interesting analogy.

The purpose of such a relationship is to create the idea of pain having no value to the person, other than to weigh them down. It highlights a belief in a 'truth' of 'being in charge' of pain, of taking control and keeping pain away or at least 'managed', in the same way that debt is to be avoided or 'managed'. What is implied however, although at first not explicit in this excerpt, is that responsibility for assisting the nurse to look after the patients' pain is being situated with the patients themselves. Indeed, an alternative view of such an analogy suggests that debt belongs to the person, and if they are in debt it must be their own fault.

The example from the conversation with $\mathrm{N} 3$ suggested that pain is an individual experience, and should the person not do their utmost to work with the nurse to eradicate it, then it will be their own fault should the pain not be relieved. This ties in with N3's earlier statement "make sure you tell us if you're sore". Behind the message of accountability on the part of the patient, however, is another which puts the nurse in charge. She is laying the ground rules, and perhaps using the occasion to justify what cannot always be achieved, even though the nurse may try hard to succeed on the patient's behalf.

The position to the patient is made clear: 'we cannot take all your pain away, but with your help we can certainly work at a level of comfort that is satisfactory'. Yet, on another level, this sequence could be read as meaning that the nurse is properly 'forewarning' the patients, mindful that in her experience, complete relief from all pain is difficult to achieve. Indeed, in terms of patient comfort, in the second interview N3 admits that she believes total freedom from pain is not in the patient's best interests. Accordingly, she points out: 
N3: I've always said to patients "we can't take your pain away completely" and I also see pain as a protection thing.

I: $\quad$ Yes...

N3: ... What they don't realise is that the pain is actually there as a warning as well. That if they are doing too much or if they are doing something wrong, their body is letting them know and to a certain extent it is. Your leg is sore, so you should rest it.

What was perhaps the most interesting facet of N3's position on being unable to 'take all pain away', was that it was in contrast to her earlier remarks on the breakthroughs in the way pain is regarded now, specifically the focus on 'getting on top of pain'. "All that's just come along in leaps and bounds..." she said (1st interview). Despite the rhetoric of 'freedom from pain', the reality is different. Indeed, while not alluding to complete relief of all pain, N1 in her first interview described her approach to "keeping on top of the pain" in terms of it having better outcomes for the patient:

N1: I also like to tell them that if they leave the pain until it is excruciating then it is harder to keep it under control because that is something I have found (-) that if you can tell the patients, as soon as they have got pain, it is better to to give them something for it, they'll feel better. They will usually get over pain better in the first 24 hours//

I: $\quad / / \mathrm{hmm}$.

In this sequence, the nurse has designated a timeframe during which in her experience, pain is usually worse. According to N1, 'excruciating' is the worst pain a person could possibly experience, so for her it is far better both physically and emotionally for patients if they avoid this state. The importance 
of achieving an optimum level of comfort for the patient was expressed by another of the participants, N2, who recognised the difficulty of bringing about a state of freedom from pain, and asked:

N2: I mean what amount of pain is permissable? ... I think it's ... important to assess with your patients what they do expect ... some patients realistically don't expect to be pain-free. They'll soon let you know and then you've other patients that if they've got a slight bit of pain will let you know because you've asked them to, that's what you've asked them to do, report any pain at all. But often you find that they start declining analgesia when they've got it down to, what they might give you a level of one or two and you'll say "do you want something?" and they'll say "no".

The nurse perceives a continuum of expectation on the part of patients, some of it guided by nursing definitions of comfort which is associated with "one or two" on the pain scale and the fact that the nurse may have insisted they report all pain to her. Thus, as she points out, patients may not realistically expect total freedom from pain, but the nurse needs to establish this. For N2, what might be okay for one patient in terms of level of pain, may be quite unacceptable to another, and it is up to the nurse to find out what each person is prepared to accept and work out a suitable compromise with those patients.

\section{"Patient participation"}

One of the voices that emerges from within the text is that of patient participation, and the importance of individualising patient care, which would seem to endorse the ideas Price and Cheek (1996) expressed about the nursepatient interaction in pain assessment. Thus, in speaking about patients in the way she does, N2 constructs a reality that draws patients into the decisionmaking loop. In the process, she reaffirms the need to treat each person as an individual, with unique needs and expectations. N1 expressed similar feelings 
about working with the patient to determine what was required for analgesia. She said:

N1: If one of my patients is in pain, I'll just go and give them some panadol ... (You can) negotiate with them without wasting time and even discuss with them about "how severe is your pain"? I mean if it's going to be over five, well then, you're not going to give them panadol. I'd be thinking that's too high for panadol, but if it's two or three, then maybe panadol will be enough (.) That's what they need and get.

Within these two pieces of text however, there emerges as well, the influence of the biomedical construction of pain as something quantifiable. Hence words/phrases such as "amount of pain", and "level" and "if it's over five" use the science of numbers to give a measure to the pain that people are experiencing. The continued use of such scales as talked about by all the nurses re-inforces the dominance of a bio-medical reality of pain which through such measurement tools turns a subjective experience of pain into something objective. The would seem to support the observations made by Price and Cheek (1996) as commented on in Chapter Two.

\section{SUMMARY}

My purpose in this chapter has been to begin the process of presenting the results of the textual and contextual analysis of the participants' talk. To support my analysis and the themes that emerged from my reading, selected excerpts from the texts have been introduced into the discussion. The contextual analysis focused on the immediate situation in which the conversations between myself and the nurses took place, and how it reflected relations of power. I examined the way in which I structured the opening questions and the use of particular linguistic styles such as politeness strategies to 'invite' the nurses to speak and to 'encourage' more detail about an aspect of the topic in question. I looked also 
at how resistance was enacted and how shared realities emerged from the texts.

The form and content of the language of the texts concentrated on revealing some of the themes which emerged as the 'discourses of pain management'. These included 'validating pain - "doling out amounts of pain"', "getting on top of pain", and "patient participation". Each of these themes was supported with examples from the conversations and discussed in relation to the discourses of pain that were explored in the literature review. In Chapter Six I continue the presentation and discussion of the results of the textual analysis. 


\section{CHAPTER SIX \\ Reading bodies and responding to patients' pain: \\ Nursing discourses}

\section{INTRODUCTION}

Chapter Five commenced the task of presenting and discussing the 'discourses of pain management' that emerged from my reading and analysis of the texts. Excerpts of the nurses' "talk" which surfaced these discourses informed the discussion. These discourses are entitled "validating pain" and "getting on top of pain". This chapter continues with a presentation of the themes that emerged as evidence of what the four surgical nurses saw as important in their work with patients, and particularly how they regarded their responsibilities towards providing care and comfort.

Under the general theme entitled "surveillance work" fall two important discourses. These are "body talk" and "picking up the cues", and are discussed first. The chapter then moves to a consideration of the other themes which are grouped under the heading "discourses of nursing work". These are entitled "for the good of the patient", "negotiating care - making it their idea" and finally, "providing comfort". The chapter concludes with a summary in which the themes presented and discussed in Chapters Five and Six are positioned in relation to the aims of the research and the existing arguments/debate on knowledge/power as illuminated in the literature review in Chapter Two.

\section{SURVEILLANCE WORK}

Nurses spend a good deal of time, performing certain tasks which provide information on what is going on with the patient. The data are gathered to 
construct a picture of the patient and the progress patients are making, or not making as the case may be, in the course of their hospital stay. The information collected is that which is regarded as important for making ongoing decisions about patient care. The work of managing pain is another example of observing patients.

This section will reveal how surveillance work is conducted by the participants. As remarked on in Chapter Five, the nurses talked about asking patients to rate their pain. However, they also monitor patients' behaviour and body language as other means to construct a picture of patients' pain, as the next section will disclose.

\section{"Body Talk"}

This work necessitates a 'reading of the patient', although in many respects the more appropriate title is 'reading the body'. Indeed, in the conversations, bodytalk successfully displaced the embodied person. Take the following excerpt from the first interview with $\mathrm{N} 3$ as an example:

N3: You can actually in orthopaedic pain do a little bit extra without medication.

I: Okay, do you want to clarify that?

N3: Limbs for example especially lower limbs that get (.) If they're flat on the bed they swell up, they get really sore. If you whack them up on pillows and lift the foot of the bed up a bit suddenly the swelling goes down. You can put ice on them. You can put pressure cuffs with ice on them. You can actually make a difference....

Similarly, in this next sequence taken from her second interview, N2 is describing the skills she considers important to the surgical nurse's role in 
attending to the patient reporting pain. The focus of the speech is on the body as a 'system' of interconnected parts working. N2 claims that because of the potential for post-operative complications, the nurse must:

N2: Look for an increase in bodily excretions or a decrease that could indicate that they've got a blockage in chest drain tubes, that have got a blockage in (-) bowel tubes, etcetera. We had a very interesting patient with oesophageal gastrectomy and (.) he'd actually developed a leak so just looking at his discharge, if you like, we could see that the chest drain, there was empyema developing and that was quite interesting.

I: And did that empyema mean an increase in associated pain in his chest?

N2: Yes, it did actually. We would find it very difficult to relieve his pain and luckily the nurse who was looking after him, well lucky for the man, she had actually nursed somebody a couple of months back and she happened to voice it in report and said "I hope he's not developing a leak". I wouldn't have done that but she is very good and um she was watching a chest drain and saw him develop, um, he was actually getting a leak from the feed if you like so it was draining into the chest drain only just slightly and she actually tested it, the um aspirate, because it was only slight and you would have missed it. They took him back and resewed him (.).

Both the examples provide a vivid picture of nursing work that sets out to find the answer to the 'problem'. In the first excerpt, the nurse knows automatically that "whacking the leg up on pillows" will reduce the swelling and ensuing pain experienced by the patient. Although there is no explicit reference to a person being attached to the limb, the implication is there. The above example would seem to suggest that this form of talking about patients is commonplace among nurses and doctors. Examples of such talk about the body/person is "the appendix by the window" and "the broken leg in room 8" as N3 herself remarked, which suggests an acknowledgement of her peer's knowledge of the 
patient's condition.

The assumption is made that when a nurse talks of a body-part, another nurse (or doctor) understands the implied reference to a person. Yet there is evidence of a power relationship in this pattern of speaking about people as patients. In deconstructing and removing the person from the picture, nurses emulate the way of talking favoured by doctors. The person is a clinical case marked by symptoms as in the above example. Nowhere in either of these two excerpts is there a sense of a living, feeling person, although it is the person's pain she is trying to relieve by reducing the swelling to the person's limb.

In the latter account, the nurse is reviewing the skills necessary to ascertain the correct information about the pain in order to help the patient. Here, as in the former example, the discussion of the events of the 'leak', are all focused on the body and the way in which the body is monitored. Words like "look for", "watching", "saw" re-inforce the observational skills nurses regard as critical to their job of patient care.

\section{"Picking up the cues"}

Another way of constructing knowledge about the patient is what the nurses in the study attributed to their experience and 'intuition'. This is the very essence of what separates the novice from the expert (Benner, 1984; Benner \& Tanner, 1987), and which is explored a little later on in the chapter. It is the ability to 'read the signs', and what I have called "picking up the cues", which is exactly what the above sequence of talk has just described. The following sequence is a further example taken from another of the participant's interviews. Here, in her first interview, N1 has been asked to talk about how she assesses patients' pain: 
N1: That assumption, um, sometimes it can be the way they're lying in bed, it can be a facial expression, um, sometimes they'll just be moving in bed and obviously just uncomfortable. Sometimes you can just find somebody in tears and they won't say a word 'cause they're keeping quiet about it because they don't know how to cope and they think that perhaps this is natural. You can't be seen to be having too much pain relief. You see there again everybody's different and it's just something that you just pick up [laughs] as a nurse and just through experience.

The nurse has described observing the physical signs - the body's position in the bed, the way the body is moved - which for her suggest the patient is uncomfortable. The emotions exhibited by the patient are read by $\mathrm{N} 1$ as indicative of "suffering in silence", which she also attributes to the distress of the pain and of isolation - not knowing how to cope. What she is doing, is reading her own interpretation into what she observes, and in the process casting the patient into a specific role based on her reading of the body. She can do this, because she has the knowledge based on experience. The association with experience is addressed in this next sequence, also taken from the same interview:

I: You talked before of um, of walking in and patients might be lying in bed but you can just tell//

N1: //[laughing] Yeah, I think its something you learn, isn't it?//

I: $\quad / /$ where do you get it from?

N1: I think it just because of experience. You can see when a patient's comfortable and it's something that you learn, and not something that just comes to you. ... Um, because when you're first out there's so much of what you have to know, that those quite often aren't the things that you have to pick up first. You're too busy thinking, 
"oh, I've got to take his temperature at ten o'clock, I've got to fill out this fluid balance." You can sometimes be task oriented when suddenly thrown in. But then I think you know, some of it's maturity. I think some of it is your own lived experiences. Things that you know bringing up a family. Um, that you know from your own experience.

The nurse's explanation focuses on the stark difference between the knowledge and confidence of the beginning practitioner and the more seasoned practitioner, who has incorporated years of work with life experiences to draw upon that gives them the edge. Each of the participants targeted the experience of the practitioner as having a key role in the way in which nurses 'read the patient'. This skill was regarded not as something innate in the person, but learned over the years of working as a nurse.

The differences between the less experienced nurses and those who had been practising for some time was talked about in terms of knowledge and utilising time more effectively. Experience gave the experienced practitioner the "nous" to act outside the bounds of expected practice, as the following example from N3's second interview suggests:

N3: That's your whole novice to expert thing isn't it, ... that someone who has been out 2 months is going to do everything exactly by the book, me that's been out eleven years, if I miss one lot of half hourly post-op obs because I have been busy but I have stuck my head round the door and the patient looks fine, I'm going to be a lot happier about that because you know that everything has been okay, you've got a better sense of what's fine with the patient and what's not. You're not so rule bound.

I: It's making assessments based on, I suppose, what you observe.

N3: Rather than what you are meant to be doing, so using your eyes.... 
The nurse, prompted by the interviewer's remark about "making assessments based on observation", confirms the accuracy of the interviewer's interpretation by continuing the sentence as if there had been no change in speaker. Thus, she talks about a reliance on the visual - what she can 'see' using her eyes, rather than carrying out a more "hands-on" assessment that dictates the novice's work practices. The former entails casting the eye over the room, like a scanner, to detect anything that may require the nurse's attention.

An extension to the "reading the patient", is the practice of "reading the room" as the above example illustrates. Florence Nightingale called it "nursing the room". This next sequence taken from the first interview with N4, is another example:

N4: When I precept somebody into the ward my line to them, so to speak, is that you should be able to walk into this six bedded room and you should be able to identify by just looking around the room who's in pain, who's just uncomfortable, you know, who needs assistance, who's, you know, looking frightened and apprehensive or whatever, you know you should be able to (.) who needs another pillow kind of stuff, you should be able to identify just looking at your patients' body language how they are feeling and if they are in pain they have quite a distinct uncomfortable look about them. And I just say to them "if nothing else, you should be able to identify those things and there is no excuse to leave somebody in pain".

At a glance, the nurse surveys the rooms and elicits information with which to work. It is the 'taking in' of what is going on in the room, from the position of the patients through to their emotional status that is all-encompassing and all powerful. "Reading the room" implies that the bodies of patients are constantly under surveillance. This is disciplinary power at its most pervasive according to Foucault (1977). The character of the 'gaze' may differ between nurses and 
doctors, because different information about the patient is required. Regardless of the outcome, the intent is still the same. When the nurse reads the room, she/he constructs knowledge which is then used to deploy nursing care. Who gets what is pretty much dependent upon the nurse's reading of the situation, the nurse's interpretation of events as they unfold before her/his eyes in that instant of surveillance.

As the sequences from the texts clearly indicate, experienced ("expert") nurses can pick up on the more subtle cues that they then collate into meaningful data about what is happening to the patient. This information influences decisions about what treatment or care is appropriate. Less experienced nurses, on the other hand, have less developed skills in reading the patient, or "picking up the cues", so they rely on following a more regulated approach to patient monitoring and documentation, as was highlighted in the excerpts from the interviews with $\mathrm{N} 1$ and N3.

Benner (1984) and Benner and Tanner (1987) characterize the work of those nurses defined as "experts" as based on "intuitive conclusion". According to the authors, such nurses have a perceptual awareness that less experienced nurses lack. Intuition suggests that expert nurses make judgements and reach conclusions without perhaps knowing how they were made; they just 'knew' . Taken from a post-structuralist perspective, notions such as "intuitive conclusion" are at odds with the view that language constructs particular realities that take on a life of their own as 'discourses'. In this case, it is the idea of intuition which constituted as a reality has become 'discourse'. As 'discourse', "intuitive conclusion" serves the interests of nursing to explain what is in effect relations of power enacted through nurse surveillance. The results of such power is the construction of certain types of knowledge which the nurse uses to deploy 
nursing care.

\section{DISCOURSES OF NURSING WORK}

\section{"For the good of the patient"}

This next section will reveal how the nurses talked about their work in terms of its impact on patients, and how they identified with what I have entitled "for the good of the patient". It will be shown that this discourse locates nursing practice as an ethical endeavour: doing what nurses regard as being in the best interests of the patient. Taken at face-value, it reflects a compassionate and caring foundation, and one that is bounded by nursing's concern with patient advocacy and meeting societal expectations for appropriate and safe care. Examined more critically, nurses' claim 'to know' what is in the best interests of the patient has to be questioned.

Take this following excerpt for instance. In this the second interview with N2, she spoke about how patients hand over responsibility for everything to the 
N2 has just acknowledged that when patients are in the 'system' they try to stay out of trouble by seemingly absolving responsibility for themselves by handing it over to the health professional they will probably have the most to do with, the nurse. She suggests that this is because patients are powerless and vulnerable, but then concludes that whilst it may not be the ideal situation, at least patients can be reassured by the fact that nurses are trying to do their best for them.

In line with the arguments proposed in this thesis, this example illustrates how an alternative interpretation of nurses acting in the best interests of the patient is possible. It could be argued instead that this is a subtle illustration of how professional knowledge and power are exercised. The reason for this is that on the one hand there is a benevolence in nurses taking responsibility for ensuring the welfare of patients in their care; on the other, is the coercive power exercised in determining what's best by exploiting the idea of care as 'negotiated'. I mention this because a discourse "negotiating care - making it their idea" emerged from the texts and is examined next in this chapter.

$\mathrm{N} 3$ echoed N2's perspective, but couched it in terms of approval and validation of nursing care by members of the public who witness what nurses do. This excerpt was from her second interview:

N3: I think what comes across is that we are doing things for the good of the patient, and that we are not just doing it because that's the way it's done, that there is actually a reason behind it and we've got enough confidence in what we are doing to actually stand up for it...

For N3, it was part of the growth in professional standing as well as the knowledge that nurses have. Nurses act for a reason rather than blindly carrying 
out the orders of someone else, especially doctors. However, N3 suggests that nurses recognise that patients and the general public perceive and respond differently to nursing work and authority, because of where they each stand in relation to the nurse and the nurse's professional and organisational status. N3 had alluded to this in the previous interview, which she described in the following way:

N3: You're in the front line a lot more as a nurse. ... The nurse is there all the time - it's the nurse answering the bell when the pain, the patient's in pain and giving the pain relief and assessing the pain relief ...

Using words like "front line" imply nursing is like 'doing battle' and that the nurse becomes the target when things are not going so well, or the patients is fed up. Indeed, nurses are with patients more than doctors, and because of this must respond to their concerns and demands. As N3 admits, in order to get their job done, nurses take charge:

N3: I think that we probably come across as quite bossy sometimes, we're sort of telling them what to do because when you're busy a lot of the time you haven't got time to say like "if you do this, this will happen and you do that, that will happen". It's more like "you have to do it this way", and sort of no questions asked I think...

N3 has pointed to the time constraints that she sees nurses constantly working under, which leaves little time for the niceties of interaction with patients. N4 in fact referred to the busyness of the day to day workworlds of nurses in surgical wards in terms of "running around like headless chooks" (1st interview). Despite these time constraints, by implication N3 is suggesting that nurses are still working with the patients' interests at the forefront of their care decisions. 
Another dimension to the power relationship inherent in nurse-patient interactions is revealed in the next section through the elucidation of the theme entitled "negotiating care - making it their idea". Alongside the notion of working for the good of the patient, this discourse is characterised by the participants as an idea of partnership.

\section{Negotiating care - "making it their idea"}

The establishment of a successful working relationship built on the concept of being 'partners in care' is highlighted as an important ingredient to embodied relationships between nurses and their patients as identified and discussed in Chapter Two. This was made explicit by N4 who, in her initial interview, explained:

N4: Because they have got to have choices and they've got to know what is going on with them. You can't, I think gone are the days where doctors and nurses just commanded patients to do as they were told. I think that people need to be informed and that in order to carry out their care, you've got to form partnerships with them so you can say to them, "well, today I'm getting you up for the first time", and discuss with them the importance of getting up after an operation//

I: $\quad / / y e p / /$

N4: //like we all know and ah (.) discuss whether they would like to have a shower. Sometimes they just like a sponge the first day. But yeah, negotiate, explain to them you need to get them up in the chair, you need to get them moving, the reasons why, otherwise they, you know, if you just say "well, I'm going to get you up ... and we're going to have a shower and we'll sit you in the chair for a while, well all that they, er, what's going around in their mind is that well, it is going to be really painful for me to get out of bed and I don't want to get of bed....so I think it is important that you negotiate care with your patients so that they know exactly what to expect and 
exactly what is going to happen...

The increasing involvement of patients in decisions regarding their care is an aspect that is very much embedded in a philosophy which emphasises a patientcentred approach to care (Ashworth, Longmate \& Morrison, 1992; Scott, 1995). However, is it true participation or have nurses created the illusion for themselves that patients truly want to and are enabled to participate? Continuing the same conversation with N4:

N4: I think that it is really important (that you) explain what is intended and, um, make it their idea as well, you will get on better without just, um, saying "yeah" matter of factly "you are going to do this, this, this and this". And I think it is a bit scary for the patient if they don't understand and//

I: $\quad$ Make it their idea//

N4: //yeah//

I: How do you do that?

N4: How do you make it their idea? Well, you talk about um, when I say "make it their idea", you make it a partnership, [laughs] make it sound like they are going to, going to participate, you know....

Here we have the notion of partnership according to what the nurse has decided. What is inferred is nurses exercising their power to decide the projected chain of events, in this case, the getting out of bed to have a shower, yet hiding it behind a veneer of negotiation. So, rather than a 'real' participatory model of care, the patient is persuaded to accept a decision made by the nurse although it is made to "sound" as if they had participated in arriving at this. An integral 
component to partnership is the idea of building a relationship that allows each partner in the relationship equal decision-making capacities. Reading between the lines, as it were, it would appear this is not the case with this example.

Another of the nurse's obligations in relation to acting in the patient's best interests that emerged from the texts was expressed in terms of the role nurse's play in educating and advising on pain management. This responsibility was discussed in relation to the concept of 'balanced analgesia' in pain management, and the role the nurses played in getting patient to 'buy into' this way of thinking. This concept, promoted by scientific medicine, endorses the regular administration of medications such as paracetamol, which act to provide a 'background' of analgesia, while the stronger pain relieving drugs can be used for the more moderate to severe pains which may be more intermittent in nature (MacIntyre \& Ready, 1996; Wulf, Schug, Allvin \& Kehlet, 1998).

From my own experience, surgical nurses have enthusiastically embraced this pain management strategy. The nurses in the study also talked openly about their inclusion of regular paracetamol into their regimen of drug management for patients reporting pain. What was interesting to note, however, was the discourse of comfort that had been decided upon by the nurse, in adopting wholeheartedly the 'balanced analgesia' approach led them to 'persuade' patients about the benefits of taking it as directed. The following excerpt taken from the first interview, is a case in point:

I: Have you had patients talk to you about how they feel about panadol, you know, like have they found it different?

N1: Um, probably not a question I have really asked but I can tell you something that I think// 


\section{I: //right//}

N1: //is that quite a few will say they are comfortable and I will say "well no, keep on with the panadol 'cause that just keeps you tide over", so I usually encourage them but I mean if they don't really want it, sometimes there are occasions when I will accept that they don't want it and that's their choice.

I: $\quad$ You can't force people with things

N1: No, no

This is an interesting exchange, because it situates patient care firmly within the discourse of comfort that has been determined by the nurse based on the responsibility she has to ensure pain is "kept under control". Part of the discourse of comfort is the insistence by the nurse of knowing what is in the patient's best interests. So, although the patient might attempt to decline analgesia after a few days, the nurse persuades the patient to persist with taking it, because the nurse knows best.

This echoes the conclusions drawn by May and Purkis (1995) as commented on in Chapter Two, and reflects what they called "bureaucratic circuits of power". Put another way, by enacting an institutional discourse of comfort, the nurse becomes a conduit of power that serves to re-inforce the 'validity' of the dominant discourse.

N1 does however, recognise and accept that on occasions her advice will not be followed. This is acknowledged as patient choice, but reflects resistance by the patient to the institutional discourse of comfort. Respecting the patient's wishes was important, but as another of the nurses pointed out: 
N2: I think you find (.) I've not really come across anybody, I don't mean can't be talked into, because you're not there to talk into, but once made aware of the facts, declines it.

Here again is the idea that knowledge of what's best resides in the truth, the 'facts'. By implication most 'sensible' people would choose to follow the nurse's advice. The business of persuasion on the part of nurses is discussed at length in the article by Hewison (1995). As noted in Chapter Two, he studied the way nurses use language in their daily encounters with patients and the effects the language had on this captive population. "In contrast to overt power, 'persuasion' involved getting patients to do things without recourse to direct commands" (Hewison, 1995, p. 79). What persuasion achieves is getting patients to fall in with what the nurse has already decided is 'for the best'.

Another strategy nurses use in persuading patients to comply with what they suggest is to explain something in terms of something else, as the following example illustrates. When asked how she "convinces" patients of the usefulness of regular panadol, she replies:

N3: //that's a tricky one because people really tend to write panadol off "oh. It's just panadol". I tend to tell them, tell for example young patients that when panadol breaks down in the body it has a lot of the same properties as narcotics. And they're like "oh, Oh Okay then". They hear that narcotic word and realize that it might actually be of some good. Because yes, people do tend to write it off and I just sort of emphasise the importance of taking it regularly. Like two panadol once a day isn't going to do the trick. Two panadol four times a day will actually have remarkable effect because people usually only take it for a headache. They take two panadol and they don't take it again.

The metaphor "write it off" emphasises how the general public dismisses the 
drug in the context of a useful analgesic - hence the "oh, panadol" - especially when the pain they have is perhaps worse than a headache, which is the comparison used by the nurse. However, the association of this drug with the strong pain relievers - 'narcotics' - is a strategy designed to convince people that it can help with their pain, and as such, can be persuasive. What the nurse also uses to re-inforce her argument is the description of the amount of the drug taken. Thus, on the one hand, two tablets only once a day is not really going to be of much benefit, but two tablets up to four times a day is. Implicit in this last part of her explanation is the 'logic' of the argument.

\section{"Providing comfort"}

This final section will reveal an aspect of nursing that reflects the humanness that comes through in nursing practice, and it is the notion of nursing as "providing comfort". In the nurses' talk, this theme seemed to be an implicit part of the surgical nurses' work in pain management. Although the focus for much of the nurses' work around relieving pain was on reaching for the analgesics, another dimension that came through the texts was the work of providing comfort through means other than medicines. This following excerpt is an example of this aspect of nursing the patient in pain:

N1: I guess I feel for them, that I'm not doing enough or I wonder if there is something more I can do even though perhaps I've done everything. Ah, or perhaps it's just that I haven't got the time perhaps just to come and sit with then at that particular time, because orthopaedics can be quite demanding on you. And if sometimes I've been having that $\mathrm{R}$ and $\mathrm{R}$ time with that patient and you're called away, other staff members see it as you're wasting time because you're actually spending time just talking and that's all they see you do, just talking or perhaps giving that patient a hug...They don't see that as a priority. So even sometimes if I said "look, just give me two minutes and I'll be with you", they either hover around and then the moment 
is gone for that patient, or the patient will say "off you go, off you go", and you know very well that if you'd only given them that another ten minutes, perhaps they would've settled down a bit better. But, you've either got to come back later on and pick up or there's never that time to pick up again. And I do find it really good to be able to, if your patient's in pain, to give them that time.

This long talk sequence serves to highlight N1's concern that other nurses perceive the time spent with patients talking as "R and R", and not 'work'. Work is properly categorised as that which happens when the nurse is physically doing something with or to patients. Sitting with the patient to help settle them does not fall into this definition of real work. Furthermore, the reference to the busyness of work and other nurses not seeing this as a priority suggests a certain amount of guilt for doing something that was not always appreciated, nor legitimated by her colleagues.

For N1 however, experience has shown how important 'being with patients' is, and it is an integral part of her work to provide comfort. It was also N1 who spoke about personal experience of pain and hospitalisation and how each experience even for the same individual has to taken as uniquely different, and how this influenced her approach to patients. In this sequence, she has recognised that time spent with patients is precious, and if broken, that time either never returns, or the moment is lost. Other references to the labour of providing comfort measures were expressed as a focus on positioning, talking with the patient, or sitting with them and holding their hand:

N2: ... like getting your patient in a position most comfortable for them, supporting the limbs because often everything aches when you are in bed, and um, you know, ... if they have got a headache, offering them other things apart from, you know, analgesia. Offering them heat packs, or ice packs, or just touching them, or massaging the neck. 
You can often get rid of a lot of pain like that psychologically just by actually touching people and healing them.

Here are given a range of different strategies for treating people in pain. What is clear is that the pain for N2 could be from simply lying too long in bed, through to the headache that is a nuisance. In N2's view, treating pain therefore is not just a matter of reaching for the pills, rather it must incorporate a holistic approach. Along the way, the nurse gives a little of herself in reaching out to people. This can occur when a relationship is established, which N2 regarded as important, especially in relation to continuity of care. This was because:

N2: We can get a far greater rapport, it's like having a friend. You know what you've said before to them, you've started to get an idea of their personalities. You start to know whether they're the type of people that will come forward, when they actually start to do that. You know that they've got a bit more trust in you and understand the system a little bit more.

The conversation above suggests a relationship built on "knowing the person", establishing a routine, and building trust is important for the nurse. As the patient's nurse, the work becomes easier over time as knowledge of what has been going on for that person builds. For N2, there is also a sense of satisfaction as she bears witness to improvements in the patient's condition. On those occasions when something amiss happens, for N2 the nature of the relationship may in fact be the one element that prevents what is going on from seeming a lot worse. Implied but not explicitly stated then, is the degree of job satisfaction that results from such continuity of patient care.

This final discourse is in seeming contrast to those already discussed, and it would appear to fit the context of 'embodied' care as described by Lawler 
(1997) and others. It also serves to answer some of the questions posed in Chapter Two with regard to this discourse in relation to the nurses' work managing pain. The conversations suggested that nurses place some significance on the relations they have with their patients, particularly in this context, and mainly because the nurses acknowledged pain as an individual experience, that was different for everyone. However, it could be argued that providing comfort is still defined in terms of what the nurse has decided on as 'comfort'. As an example of professional discourse, this knowledge then determines the way in which nurses will work to enact specific comfort measures.

\section{SUMMARY}

This research has aimed at uncovering 'discourses of pain management' through an analysis of four surgical nurses' "talk" about their work with hospitalised patients reporting pain. An examination of these discourses illustrates how particular reality/ies are constructed and the relationship this has to professional knowledge and power in this context. The 'discourses of pain management' that emerged from my reading and analysis of the participants' talk have been presented and discussed in Chapters Five and Six. The themes that surfaced were entitled 'validating pain - "doling out amounts of pain"'; "getting on top of pain"; "patient participation"; "body talk"; "picking up the cues"; "for the good of the patient"; 'negotiating care - "making it their idea"'; and finally, "providing comfort".

A review of the literature on pain revealed the dominance of a biomedical conceptualisation of pain as a neurophysiological response to noxious stimuli, which has resulted in an image of pain as having an objective reality (Gamsa, 1994; Good, 1994; Melzack \& Wall, 1988; Sinatra, Hard, Ginsberg \& Preble, 1992). Alternative perspectives however have increasingly led to an 
acknowledgment of pain as an experience that is uniquely subjective and which resites the person (Bendelow \& Williams, 1995; Madjar, 1997; Morris, 1991; Turner, 1992).

Knowledge that is constructed around such understandings of the body and of the patient/person has become legitimated and authoritative, hence its relationship with power. Similarly, nursing discourses such as 'embodied' relationships (for example, Benner \& Wrubel, 1989; Gadow, 1980, 1985; Morse, 1991; Tanner, Benner, Chesla \& Gordon, 1993; Watson, 1985) which were regarded as perhaps having significance to the ways surgical nurses talk about pain management, are themselves open to critique for what they reveal about professional knowledge and power (Armstrong, 1983b; Cheek \& Rudge, 1994; May, 1992).

The four surgical nurses' "talk" revealed that their pain work is embedded primarily within a clinically driven model of pain which emphasises pain as physically located in pathological causes and effects. This came through in the themes 'validating pain - "doling out amounts of pain"' and the focus on "getting on top of pain". However, the subjective nature of pain was also acknowledged as the nurses reflected on the importance of relating to the person's experience of pain as uniquely different for each individual. In relation to surgical "acute" pain which is the specific area of interest of this research, the acknowledgement by the participants of the subjective experience of pain leads me to wonder why acute pain in surgical patients is seemingly given less status than the pain experienced by cancer patients.

Foucault (1973) conceived the notion of disciplinary power as being intimately associated with techniques of surveillance, which permit the construction of 
knowledge about the body/subject. This was also discussed in relation to nursing discourses of "knowing the patient" (Lupton, 1994), and critiqued from the point of view of being 'knowledge producing' and therefore connected to relations of power. The themes of "body talk" and "picking up the cues" were instances of surveillance work which formed an important function of the nursing role in managing pain. The last three themes were instances of the positioning of patients in relation to nurses, for instance 'negotiating care - "making it their idea"', and the construction of nursing work around ideas/discourses of "for the good of the patient" and "providing comfort". All three illustrate the influence of nursing discourses, particularly those situated around notions of nurse-patient relations, and the nurses' concerns with trying to work with and on behalf of their patients to implement effective pain management.

In summary, positioning these themes in relation to the aims of the research and the existing discourses as discussed in the literature review illuminates further the relationship between professional knowledge and power. In Chapter Seven the extent to which these results fit with the aims of and justification for the research is explored. As well, the chapter evaluates the research process and incorporates both the positive aspects as well as its limitations; it considers the relevance and implications of the research, the contribution it makes and finally outlines recommendations for further studies. 


\section{CHAPTER SEVEN}

Summary and conclusions:

A critical review of the research project

\section{INTRODUCTION}

Chapters Five and Six presented and discussed the results of the analysis of the surgical nurses' "talk". The 'discourses of pain management' that surfaced were entitled 'validating pain - "doling out amounts of pain"'; "getting on top of pain"; "patient participation"; "body talk"; "picking up the cues"; "for the good of the patient"; 'negotiating care - "making it their idea"'; and lastly, "provding comfort". Positioned in relation to the existing discourses examined in the literature review, these themes elucidate further the relationship between professional knowedge and power.

This final chapter explores the extent to which these findings fit with the overall aims of and justification for the research. In addition, the research process used in this study is reviewed, and the limitations of this study and my position as the researcher are reflected upon. The relevance and implications of the research in terms of the contribution it makes are considered, and the chapter concludes with recommendations for possible further research.

\section{REVISITING THE AIMS OF, AND JUSTIFICATION FOR, THE RESEARCH}

The purpose of this thesis was to analyse surgical nurses' 'talk' about their work with hospitalised patients reporting pain. Although surgical nurses' role in, as well as their practices of pain management has been subjected to much debate and discussion in the nursing and medical literature, it was my belief that this 
body of works fails to address important questions of why it is that nurses work with patients reporting pain in particular ways. In other words, what influences surgical nurses' thinking and practices in the context of pain management? This research aimed at finding this out in order to elucidate an alternative explanation for, and understanding of, surgical nurses' pain management practices and to stimulate debate about this area of nursing work.

Specificly, the focus of this research was on investigating how, through the medium of language, 'discourses' construct a particular way of looking at the body and the patient, and the relationship these understandings have with the construction and reproduction of professional knowledge and power as played out in social practices such as that of pain management. Power in this thesis has been regarded not as something held by any one person, but circulated through 'discourse' with both human beings and their social practices acting as conduits.

Thus, as Foucault $(1973,1977)$ and others since have theorised, techniques such as the surveillance of individuals allow the circulation of power and the creation of specific types of knowledge which is taken to be true and valid (Armstrong, 1994; Lupton, 1994, 1997; Nettleton, 1992; 1995; Turner, 1992, 1995). Such knowledge then dictates certain thinking and practices, which as 'discourses' become taken for granted. This thesis has argued that the body and the patient are regulated by both medical and nursing discourses; each has constructed knowledge of the body/patient from a particular perspective (Cheek \& Rudge, 1994; Lupton, 1994; Turner, 1984, 1992).

Medicine has constructed its specialist knowledges and disease categories around a particular understanding tied to anatomy and clinical pathology (Nettleton, 1995; Rose, 1994; Turner, 1992). The same can be said about the scientific and 
biomedical construction of 'pain' (Bendelow \& Williams, 1995; Good, 1994). In contrast, nursing has redefined its purpose around notions of the experiencing 'subject' (Armstrong, 1983b; Lupton, 1994; May, 1992) and the importance of embodied nurse-patient relationships (Carper, 1978; Gadow, 1980, 1985; Lawler, 1997; Taylor, 1994; Watson, 1985).

In the context of providing care for hospitalised patients reporting pain, it was my contention that this work is shaped in different ways by these dominant discourses. The questions the study sought to answer were to what degree does the biomedical conceptualisation of pain influence nursing work, and where do ideas about patients and the work of nursing sit in this same context? Despite the development of an alternative view of pain as 'embodied' which has meant that increasing recognition is now given to pain as a multidimensional and subjective experience, it was my impression prior to undertaking the study that nurses are still predominantly influenced by a model of pain that defines the reality of that experience in terms of clinical pathology.

Within this perspective, valid pain has a clinical trajectory embedded in a view of pain as part of a bodily dysfunction caused by injury or surgery. The focus on the patient's body means that pain can be discerned from a reading of this body through the deployment of certain surveillance techniques and tools, such as pain rating scales. It was my contention that nurses act as conduits of power through their actions of 'reading, recording and reporting', and in so doing reproduce particular discourses of pain. However prior to the study, I believed that nursing discourses which emphasise the nature of nurse-patient relationships would also come through the nurses' talk, and in ways quite different from those reflecting a biomedical influence. I had considered how these distinctly nursing 'voices' might emerge, and believed it would be in relation to how the nurses 
might perceive their working relationships with patients.

\section{EVALUATING THE RESULTS; DRAWING CONCLUSIONS}

The results of the analysis indicate that social practices such as that of pain management are shaped and constrained primarily by particular discourses which have become regarded as "expert" knowledge. This was clearly evident from the biomedically-oriented discourses that emerged from the texts of the surgical nurses' "talk". This is not to excuse the expert knowledge that has been constructed around things taken to be the domain of nurses, which was also embedded in the nurses' talk. Indeed, this "expert" knowledge as 'discourses' has been determined by both the disciplines of nursing and medicine which serves professional interests and thus is linked very much to relations of power.

This power is at once productive power because it generates particular understandings and modes of behaviour and interaction; it establishes identities, assigns roles. It can create occasions for resistance as individuals as social agents challenge and transform existing discourses. Yet it is also a source of repressive power, in that it is associated with socio-political interests of the disciplines which have become powerful primarily because of status, and this serves to perpetuate certain ways of thinking and working with patients. Indeed, the disciplinary discourses have tended to exclude other alternative realities.

Thus, biomedicine has defined pain through particular readings of the body which has come to be regarded as the 'truth'. Indeed, the nurses' talk illustrated the discursive power of clinical pathology as the basis of pain when they spoke in terms of 'validating pain - "doling out amounts of pain"'. Certain knowledge becomes "expert" in that it is based on a particular construction of the 'facts', such as that of pain, and as legitimate and authoritative knowledge, it is vested 
in the 'experts', the nurses and doctors in the hospital. Through the language used by, and the practices of, these health professionals, the discourses around what pain is and how to treat it get recirculated and become embedded as commonsense and taken-for-granted.

Although many health professionals would argue that relationships between patients and health professionals are more equal, patients are still expected to listen to the experts, and concur with that person's specialist knowledge of how to properly manage their pain. This was clearly evident in all the conversations in different ways. For instance, the nurses spoke about how they 'educated' patients about pain and its management; how patients who, once informed of the facts (as they the nurses saw them), complied with the nurses' recommendation regarding analgesia. May and Purkis (1995) spoke of this in terms of the 'disciplining of patients' into the dominant discourse of comfort. It was revealed also in the nurses' focus on explaining the importance of "getting on top of pain", of keeping it under control.

In terms of this research then, the results suggest that in the surgical wards where this study took place at least, the biomedical conceptualisation of pain still predominates over any perspective that incorporates pain as 'embodied' experience. This means that despite a growing acknowledgement of the subjective experience of pain, and nurses' attempts to incorporate a recognition of the uniqueness of the individual's experience into their approach to care of patients reporting pain, and indeed, the nurses talked openly about this, their practice is still primarily grounded in the biomedical approach to pain and pain management. Further, the findings of my small study concur with the conclusions of other writers reviewed in this work (Fagerhaugh \& Strauss, 1977; Halfens, Evers \& Abu-Saad, 1990; Taylor, Skelton \& Butcher, 1984; 
Wakefield, 1995).

The nurses' talk revealed too that surveillance work is an integral component to the work they carry out caring for patients reporting pain. Nurses observe patients and record these observations as part of assisting in the ongoing care of patients, and this was regarded as a vital part of pain work. The nurses talked in terms of "picking up the cues"; how they could read at a glance what was going on for a patient. This 'reading of the patient' would in turn direct particular actions, such as the provision of analgesia. This is a clear exposition of power, because it is through surveillance and reading of individuals such as described by the nurses that knowledge is constructed and relations of power deployed.

Similarly, nursing discourses such as that of 'knowing the patient' while at face value has been taken to give nursing practice new meaning, is another example of disciplinary power; nurses' intrusion into the private world of the 'subject' in order to construct knowledge is an exercise of power. However, although this discourse was identified as perhaps significant to nurses' work in pain management, little evidence was found to support an expectation that surgical nurses' practice is predicated on "embodied" relationships such as those described in the nursing literature (Carper, 1978; Benner \& Tanner, 1987; Gadow, 1980; Lawler, 1997). The references made to the importance of treating the patient as an individual, to the development of trust and of partnership came through in the themes entitled "patient participation" and "providing comfort". Otherwise, there was little explicit or implicit reference to the centrality of 'knowing the patient' as the means for understanding the lived experience of the person and their pain. 
Despite this, what was evident from the conversations was that nurses have constructed for themselves a discourse of acting in the patients' best interests, the "for the good of the patient" of this thesis. This discourse permits them to regard the work they do as falling within the social mandate of providing ethical care, and allows them to excuse some of what they do even though it may not always be well received by patients (or family/whanau). As perhaps an extension of this, but also in relation to the rhetoric about "embodied" relationships, nurses have taken to talking about negotiated care and partnerships as integral facets to working with patients.

Yet again what emerges from a critical analysis of how the nurses talked about such relationships is not evidence necessarily of collaborative practice so much as discourses of negotiated care which are constructed around notions of "nurses know best" and which allow the continued exercise of power. The theme 'negotiating care - "making it their idea"' illustrates this point, and demonstrates how nurses deploy persuasion as the means for getting patients to do what the nurse has actually planned they should do.

Finally, in terms of the aims of, and justification for, this research then, discourse analytic studies such as this provide alternative and critical interpretations that are vital for stimulating debate and discussion within nursing about the nurse's role in and practices of pain management. This study has considered the properties and effects of language as constitutive, and the role language plays in the construction, reproduction and transformation of discourses such as those of pain management.

The pain discourses surfaced by this study clearly demonstrate how, through language, a certain form and understanding of the body and of the patient 
emerged, and the relationship this has to professional knowledge and power. An examination of these discourses elucidates a critical understanding of their role in determining the ways in which surgical nurses talk about and respond to hospitalised patients reporting pain.

\section{REFLECTING ON THE RESEARCH PROCESS}

\section{The position of the researcher}

It is important to ponder whether the assumptions I held about pain management discourses influenced the way I designed the research, posed the questions and facilitated the conversations. Indeed, more importantly what does this research possibly reveal about the relationship between professional knowledge and power of the researcher in the context of this study? Certainly, the questions I posed, although I genuinely believed them to be broad, were nevertheless intended to stimulate remembering and discussion along specific lines. Furthermore, in relation to what the 'talk' revealed, again the assumptions held could "colour" my reading of the texts.

Clearly, the position that I held before the conducting the research influenced what I believed would emerge from the texts of the surgical nurses' "talk". However, the conversations were not coerced, and the pictures that surfaced did so from the language used by the nurses. My role was simply to analyse and pull out the themes which formed the basis of the 'discourses of pain management'. Alternatively, it was not only my reading of the texts in a particular way that resulted in my 'uncovering' the emphasis of the biomedical perspective on pain which overshadowed the nursing 'voice'. As a consequence, what other alternative 'voices' were silenced by my particular reading of the texts? Parker and Burman (1993) identified this as one of the problematic aspects of critical discourse analysis in that it surfaces important issues of power 
and control in the analysis of texts.

Perhaps too the dominance of the biomedical voice reflected how the participants themselves interpreted the intent of my research. Put another way, did they talk about those aspects of pain management that they imagined I wanted to know most about, things that reflected more of a biomedical bias? If so, this serves to reinforce my assumptions that indeed, a medical model of pain is implicit in how surgical nurses (and here I include myself) think about and work with patients reporting pain.

Another important aspect to reflect upon was the degree to which I avoided the issues and concerns that were potentially problematic for the conduct of ethical research. In particular, did I act in a non-coercive manner throughout the research process? The answer is yes I believe I did. The fact that I identified a number of potential issues with the design and implementation of the research and set in place various measures as precautions, such as the use of an intermediary, illustrates my genuine desire and ability to carry out ethical research.

\section{Did the research achieve its aims? Limitations of this study}

Perhaps one of the first drawbacks to consider is the inexperience of the researcher. My lack of previous research experience, and especially interviewing skills, meant that aspects which tentatively emerged during the conversations were not more fully explored. Features of nurse-patient relationships for instance, notions of treating each patient as an individaul which were remarked upon, were not developed. This, particularly in relation to the nursing discourses discussed as relevant in the literature review, meant that an opportunity to identify more fully the impact of such discourses in this context 
was missed.

As outlined in Chapter Four, Parker and Burman (1993) point out that there is a danger is reductionism if the analysis omits a much more in-depth analysis of the contextual and performative functions of language in which discourses are produced, reproduced and/or transformed. I don't believe that is the case with the analysis conducted in this study, but I believe a greater depth of analysis could have been carried out, which may have generated a more complete set of 'discourses' and discussion.

The problems with the method of discourse analysis as identified in Chapter Four notwithstanding, my own study had other limitations. The scope of this study was confined by my decision to conduct a discourse analysis and to interview only four nurses. Although four interviews provided a large amount of material for analysis, the choice of discourse analysis as method means that there are limits to the outcomes and conclusions of the research. As stated in Chapter Four, with discourse analysis, beyond the context in which they are situated, the results cannot be generalised (Parker \& Burman, 1993). Having said that, the discourses described in Chapters Five and Six do have a great deal in common with the discourses discussed in the literature review. This serves to validate further both the other studies and this research.

Furthermore, given the subject matter of pain and its management, a richer and more detailed discourse analysis would have included the patients' stories/accounts. Interviews with hospital patients would have offered perhaps both support for, and alternative interpretations of the nurses' perspectives of their work. In addition, an examination of the documentation of the nurses would have yielded another dimension to the analysis, as would a review of the 
clinical notes. Including these sources of material could have illuminated further the ways in which nurses are constrained by discourses other than nursing. Not only that but a reading of the patients' notes would have made more explicit the ways in which nurses work with bodies. Using these sources of data as well as the conversations would have provided a more balanced approach to my own research and to the whole question of the relationship between professional knowledge and power in the context of pain work.

Despite my reservations in these areas, the research did achieve its aims; it did succeed in uncovering discourses of pain management, and these reveal a great deal about the relationship between professional knowledge and power. There is however, also a recognition of the need for further analysis. This study does not offer the last word on surgical nurses' pain management practices. Another reading by another researcher would very probably shed another interpretation on what was said and the intent behind it.

\section{Implications of the research; Making a contribution to nursing discourse}

As identified at the outset, there is a dearth of pain research undertaken by nurses which critically examines language and the role language plays in shaping nursing realities particularly in the area of pain work. Research which investigates nurses' role in and practices of pain management largely does so from an assumption that takes the biomedical perspective as unproblematically reflecting reality. It ignores a whole other realm which this thesis has attempted to show, takes pain as a constructed reality. The power vested in such a construction is that it becomes taken as natural, as commonsense.

Moreover, the knowledge that such constructions engender has a powerful influence over how society at large, and doctors, nurses and patients in 
particular conceive of pain and the approach to pain management, as this thesis has investigated. It also raises the question "to what degree does the power of such professional knowledge mean that patients in pain 'miss out' on more effective pain relief"?

This has huge implications mainly in that such discourses are re-inforced because nurses and society continue to validate the claims that biomedicine makes through such knowledge; it also means that power vested in such discourses and in such disciplines is left unchallenged. The major contribution this thesis makes therefore, is to present an alternative reality to the dominant one. In so doing, it is hoped that this stimulates debate, particularly among nurses, about how knowledge is constructed and power circulated. This enhances critical awareness and offers nurses opportunity of critically exploring for themselves the nature of their realities as they practice nursing, and perhaps transforming those realities to something other than what they were.

\section{Directions for future research}

Given the limited scope of this current work as alluded to above, it is therefore recommended that any future study considers the incorporation of the patients' perspectives on both their pain and the nurse's role in management of that pain, or observation of patient-nurse discourses. How would patients talk about the work of nurses? Would their stories reflect similar or dissimilar concerns? What 'discourses of pain management' might emerge from an analysis of patients' 'talk'? Another approach would be to include the perspectives of family/whanau. Such a critical investigation and discussion would be useful to articulating how current thinking and practices meets the needs of this important group of people, and could offer solutions for change where indicated. 
Another dimension to the subject is the growth in specialist pain management services. A comparison of the thinking behind 'acute' pain , 'chronic' pain and cancer pain management services by examining the different voices of medicine, clinical psychology and nursing would shed light on the discourses influencing current practice and provide another critical perspective on pain management. Similarly, the literature briefly reported in this thesis which presents a phenomenological discourse could open the way for a study into patients who use chronic pain services.

How do these patients talk about their pain; what does their talk reveal about relations of knowledge/power in the context of the health care encounter? How do the doctors work with such patients? How do nurses work with chronic pain patients? A study into 'discourses of pain management' could investigate nurses and patients 'talk' from both the 'acute' and 'chronic', as well as cancer pain perspectives. Would this reveal any differences between them, and if so, what discourses might be uncovered from such an analysis? Finally, research into medical discourses of pain and examination for evidence of growing tolerance and acceptance, or not of alternative discourses would be valuable.

\section{CONCLUSION}

Discourse analysis as both methodology and method offers the researcher a fascinating opportunity to critically explore the language people use everyday to make sense of the world in order to uncover something about the effects and influences of that language, and the social contexts in which it occurs. As health professionals for instance, nurses use specific language to define and explain the work of nursing and the contexts in which it takes place. Rarely however, is that language critically reflected upon or even recognised as being embedded within sociocultural and political settings. 
In terms of the discipline of nursing, it is essential that critical studies of language are undertaken. In this way, an understanding of the place language as 'discourse' has in constructing reality, particularly the realities of nursing work, is explicated. Moreover, it is through a critical appreciation of the coercive power of language in social contexts that a challenge to, and transformation of dominant discourses can occur. By so doing, opportunities for other realities may emerge which must benefit the discipline. 


\section{REFERENCES}

Agger, B. (1991). Critical theory, post structuralism, post modernism: Their sociological relevance. Annual Review Sociology 17, 105-131.

Appleton, C. (1993). The art of nursing: the experience of patients and nurses. Journal of Advanced Nursing 18, 892-899.

Armstrong, A. (1983a). Political anatomy of the body: Medical knowledge in Britain in the twentieth century. Cambridge, UK: Cambridge University Press.

Armstrong, D. (1983b). The fabrication of nurse-patient relationships. Social Science Medicine $17(8), 457-460$.

Armstrong, D. (1994). Bodies of knowledge/knowledge of bodies. In C. Jones and R.Porter (Eds.). Reassessing Foucault: Power, medicine and the body (pp. 17-27). London: Routledge.

Armstrong, D. (1997). Foucault and the sociology of health and illness: a prismatic reading. In A.Petersen and R. Bunton (eds.). Foucault, health and medicine (pp. 15-30). London: Routledge.

Ashworth, P., Longmate, M. \& Morrsion, P. (1992). Patient participation: its meaning and significance in the context of caring. Journal of Advanced Nursing 17, 1430-1439.

Austin, J. (1962). How to do things with words. London: Oxford University Press.

Autton, N. (1986). Pain, an exploration. London: Darton, Longman \& Todd.

Barthes, R. (1977). Image-music-text, Glasgow: Collins Fontana.

Bendelow, G. \& Williams, S. (1995). Transcending the dualisms: towards a sociology of pain. Sociology of Health and Illness 17(2), 139-165.

Benner, P. (1984). From novice to expert: excellence and power in clinical nursing practice. Menlo Park, Calif.: Addison-Wesley.

Benner, P. \& Tanner, C. (1987). How expert nurses use intuition. American Journal of Nursing, 23-31.

Benner, P. \& Wrubel, J. (1989). The primacy of caring: stress and coping in health and illness. Menlo Park, Ca: Addison-Wesley.

Berger, P. \& Luckmann, T. (1971). The social construction of reality: a treatise in the sociology of knowledge. Harmondsworth: Penguin.

Billig, M.; Condor, S; Edwards, D; Gane, M; Middleton, D. \& Radley, A. (1988). Ideological 
dilemmas: a social psychology of everyday thinking. London: Sage.

Boden, D. \& Zimmerman, D. (Eds.) (1991). Talk and social structure: studies in ethnomethodology and conversation analysis. Cambridge: Polity Press.

Bonica, J. (1977). Neurophysiologic and pathologic aspects of acute and chronic pain. Archives of Surgery 112, 750-761.

Brand, P. \& Yancey, P. (1993). Pain: the gift nobody wants. New York: Harper Collins.

Bryman, A. \& Burgess, R.G. (eds.) (1994). Analyzing qualitative data. London: Routledge.

Burgess, M. (1980). Nurses' pain ratings of patients with acute and chronic low back pain. Unpublished Master's thesis, University of Virginia School of Nursing.

Carper, B. (1978). Fundamental patterns of knowing in nursing. Advances in Nursing Science $1(1), 13-23$.

Carr, E. (1990). Postoperative pain: patients' expectations and experiences. Journal of Advanced Nursing 15, 89-100.

Carroll, D. \& Bowsher, D. (1993). Pain management and nursing care. Oxford: ButterworthHeinemann.

Carter, B. (Ed.). (1998). Perspectives on pain:mapping the territory. London, U.K.: Arnold.

Cheek, J. \& Rudge, T. (1994). Nursing as textually mediated reality. Nursing Inquiry 1, 1522.

Cohen, F. (1980). Postsurgical pain relief: patients' status and nurses' medication choices. Pain 9, 265-274.

Cottrell, A. (1984). Social classes in Marxist theory. London: Routledge \& Kegan Paul.

Crowe, M. (1998). The power of the word: some post-structural considerations of qualitative approaches in nursing research. Journal of Advanced Nursing 28(2), 339-344.

Department of Social Welfare. (1998). Towards a code of social and family responsibility: Public discussion document. Wellington, N.Z.: Department of Social Welfare.

Derrida, J. (1976). Of grammatology. Baltimore: Johns Hopkins Universtiy Press

Derrida, J. (1981). Positions. Chicago: University of Chicago Press.

Diamond, I. \& Quinby, L. (Eds.). (1988). Feminism and Foucault: reflections on resistance. Boston: Northeastern University Press. 
Drew, P. \& Heritage, J. (Eds.) (1992). Talk at work: interaction in institutional settings. Cambridge: Cambridge University Press.

Dreyfus, H. \& Rabinow, P. (1982). Michel Foucault: Beyond Structuralism and Hermeneutics. Brighton:Harvester Press.

Dufault, M., Bielecki, C., Collins, E. \& Willey, C. (1995). Changing nurses' pain assessment practice: A collaborative research utilization approach. Journal of Advanced Nursing 21, 634645.

Fagerhaugh, S. \& Strauss, A. (1977). The politics of pain management: staff-patient interaction. Menlo Park, Ca.: Addison-Wesley.

Fairclough, N. (1992). Discourse and social change. Cambridge, U.K: Polity Press.

Fairclough, N. (1994). Critical discourse analysis: the critical study of language. London: Longman.

Fairclough, N. (1995). Critical discourse analysis. London: Longman.

Fairclough, N. \& Wodak, R. (1997). Critical discourse analysis. In T. van Dijk (Ed). Discourse as social interaction (pp. 258-284). London: Sage.

Flor, H., Birbaumer, N. \& Turk, D. (1990). The psychobiology of chronic pain. Advances in Behavior Research and Therapy 12, 47-84.

Foucault, M. (1965). Madness and civilization. New York: Random House.

Foucault, M. (1970. The order of things, (A.M. Sheridan Smith, Trans.). New York: Random House.

Foucault, M. (1972). The archaeology of knowledge. London:Tavistock.

Foucault, M. (1973). The birth of the clinic: an archeology of medical perception. (A.M. Sheridan Smith, Trans.). London: Tavistock.

Foucault, M. (1977). Discipline and punish: The birth of the prison. (A.M. Sheridan Smith, Trans.). New York: Pantheon Books.

Foucault, M. (1979). The history of sexuality, Vol.I: An Introduction. London: Allen Lane.

Foucault, M. (1982). Afterword The subject and power. In H.Dreyfus and P.Rabinow Michel Foucault: Beyond structuralism and hermeneutics (pp. 208-226). Brighton: Harvester Press.

Fox, N. (1997). Is there life after Foucault? Texts, frames and differends. In A Petersen and R. Bunton (Eds.). Foucault, health and medicine (pp. 31-52). London: Routledge. 
Freire, P. (1970). Pedagogy of the oppressed. New York: Seabury Press.

Freundlieb, D. (1994). Foucault's theory of discourse and human agency. In C. Jones and R. Porter (Eds.). Reassessing Foucault: Power, medicine and the body (pp. 152-180). London:Routledge.

Gadow, S. (1980). Existential advocacy: philosophical foundation of nursing. In S. Spicker \& S. Gadow (Eds.), Nursing images and ideals (pp. 71-101). New York: Springer.

Gadow, S. (1985). Nurse and patient: the caring relationship. In A. Bishop \& J. Scudder (Eds.), Caring, curing, coping (pp. 31-43). Alabama: University of Alabama Press.

Gamsa, A. (1994). The role of psychological factors in chronic pain. I. a half century of study. Pain, 57, 5-15.

Gastaldo, D. (1997). Is health education good for you? Rethinking health education through the concept of bio-power. In A. Petersen and R. Bunton (Eds.). Foucault: health and medicine (pp.113-133). London: Routledge.

Gilbert, T. (1995). Nursing: empowerment and the problem of power. Journal of Advanced Nursing 21, 865-871.

Glaser, B. \& Strauss, A. (1967). The discovery of grounded theory: strategies for qualitative research. Chicago: Aldine.

Good, B. (1994). Medicine, rationality, and experience: an anthropological perspective. Cambridge, U.K: Cambridge University Press.

Gordon, C. (Ed.) (1980). Power/knowledge: selected interviews and other writings 1972-1977. Brighton: Harvester Press.

Gujol, M. (1994). A survey of pain assessment and management practices among critical care nurses. American Journal of Critical Care 3(2), 123-128.

Gutting, G. (Ed.) (1994). The Cambridge companion to Foucault. Cambridge: Cambridge University Press.

Habermas, J. (1987). The philosophical discourse of modernity: twelve lectures, Cambridge, Mass.: MIT Press.

Habermas, J. (1994). Some questions concerning the theory of power: Foucault again. In M. Kelly (Ed.) Critique and power: recasting the Foucault/Habermas debate (pp. 79-107). Cambridge, Mass.: MIT Press.

Halfens, R., Evers, G. \& Abu-Saad, H. (1990). Determinants of pain assessment by nurses. International Journal of Nursing Studies 27(1), 43-49. 
Halliday, M. \& Hasan, R. (1989). Language, context, and text: aspects of language in a social-semiotic perspective (2nd ed.). Oxford: Oxford University Press.

Harre, R. \& Gillet, G. (1994). The discursive mind. London: Sage.

Harrison, A. (1991). Assessing patients' pain: identifying reasons for error. Journal of Advanced Nursing 16, 1018-1025.

Heartfield, M. (1996). Nursing documentation and nursing practice: a discourse analysis. Journal of Advanced Nursing 24, 98-103.

Henderson, A. (1994). Power and knowledge in nursing practice: the contribution of Foucault. Journal of Advanced Nursing 20, 935-939.

Hewison, A. (1995). Nurses' power in interaction with patients. Journal of Advanced Nursing $21,75-82$.

Ingram, d. (1994). Foucault and Habermas on the subject of reason. In G.Gutting (Ed.). The Cambridge companion to Foucault (pp. 215-261). Cambridge: Cambridge University Press.

Jones, C. \& Porter, R. (Eds.). (1994). Reassessing Foucault: Power, medicine and the body. London: Routledge.

Kelly, M. (Ed.). (1994). Critique and power: recasting the Foucault/Habermas debate. Cambridge, Mass.: MIT Press.

Kincheloe, J. \& McLaren, P. (1994). Rethinking critical theory and qualitative research. In N. Denzin \& Y. Lincoln (Eds.), Handbook of qualitative research (pp. 138-157). Thousand Oaks, Ca.: Sage.

King, S. (1996). Evaluating the project on pain assessment in ward two. Unpublished report.

Lash, S. (1991). Genealogy and the body: Foucault/Deleuze/Nietzsche. In M. Featherstone, M. Hepwroth \& B. Turner (Eds.) The body: social process and cultural theory (pp. 256-280). London: Sage.

Lather, P. (1991). Getting smart (pp. 1-18). New York: Routledge.

Lawler, J. (1991). Behind the screens: nursing, somology and the problem of the body. Melbourne: Churchill Livingstone.

Lawler, J. (Ed.). (1997). The body in nursing. Melbourne: Churchill Livingstone.

Leap, N. (1996). A midwifery perspective on pain in labour. Unpublished Master's Dissertation. South Bank University, London.

Leder, D. (1990). The absent body. Chicago: Chicago University Press. 
Lewis, S., Collier, I. \& Heitkemper, M. (1996). Medical-surgical nursing: assessment and management of clinical problems, (4th Ed.). St Louis: Mosby.

Lupton, D. (1992). Discourse analysis: A new methdology for understanding the ideologies of health and illness. Australian Journal of Public Health 16(2), 145-150.

Lupton, D. (1994). Medicine as culture: illness, disease and the body in western societies. London: Sage.

Lupton, D. (1997). Foucault and the medicialisation critique. In A Petersen and R. Bunton (Eds.). Foucault, health and medicine (pp. 94-110). London:Routledge.

Lyotard, J-F. (1984). The postmodern condition: a report on knowledge. Minneapolis: University of Minneapolis Press.

MacIntyre, P. \& Ready, B. (1996). Acute pain management: a practical guide. London: W.B.Saunders.

Madjar, I. (1991). Pain as embodied experience: a phenomenological study of clinically inflicted pain in adult patients. Unpublished $\mathrm{PhD}$ thesis. Massey University, New Zealand.

Madjar, I. (1997). The body in health, illness and pain. In J. Lawler (Ed.). The body in nursing (pp. 53-73). Melbourne: Churchill Livingstone.

May, C. (1991). Affective neutrality and involvement in nurse-patient relationships: perceptions of appropriate behaviour among nurses in acute medical and surgical wards. Journal of Advanced Nursing 16, 552-558.

May, C. (1992). Nursing work, nurses' knowledge, and the subjectification of the patient. Sociology of Health and Illness 14(4), 472-487.

May, C. (1995). Patient autonomy and the politics of professional relationships. Journal of Advanced Nursing 21, 83-87.

May, C. \& Fleming, C. (1997). The professional imagination: Narrative and the symbolic boundaries between medicine and nursing. Journal of Advanced Nursing 25, 1094-1100.

May, C. \& Purkis, M. (1995). The configuration of nurse-patient relationships: A critical view. Scholarly Inquiry for Nursing Practice: An International Journal 9(4), 283-295.

McCaffery, M. (1979). Nursing the patient in pain, London: Harper \& Row.

McCaffery M. \& Beebe, A. (1989). Pain: clinical manual for nursing practice. St. Louis, Missouri: Mosby.

McCaffery, M. \& Ferrell, B. (1997). Influence of professional vs. personal role on pain assessment and use of opioids. Journal of Continuing Education in Nursing28(2), 69-77. 
McKinley, S. \& Botti, M. (1991). Nurses' assessment of pain in hospitalised patients. The Australian Journal of Advanced Nursing 9(1), 8-14.

Melzack, R. \& Wall, P. (1988). The challenge of pain. (2nd Ed.). Harmondsworth: Penguin. Morris, D. (1991). The culture of pain. Berkley, Ca: University of California Press.

Morse, J. (1991). Negotiating commitment and involvement in the nurse-patient realtionship. Journal of Advanced Nursing 16, 455-468.

Morse, J., Bottorff, J., Anderson, G., O'Brien, B. \& Solberg, S. (1992). Beyond empathy: expanding expressions of caring. Journal of Advanced Nursing 17, 809-821.

Nagy, S. (1998). A comparison of the effects of patients' pain on nurses working in burns and neonatal intensive care units. Journal of Advanced Nursing 27, 335-340.

Nash, R., Edwards, H. \& Nebauer, M. (1993). Effects of attitudes, subjective norms and perceived control on nurses' intention to assess patients' pain. Journal of Advanced Nursing $18,941-947$.

Nettleton, S. (1992). Power, pain and dentistry. Buckingham: Open University Press.

Nettleton, S. (1995). The sociology of health and illness. Cambridge: Cambridge Universiyt Press.

Ng, S. H. \& Bradac, J. (1993). Power in language: verbal communication and social influence. California: Sage.

Novy, D., Nelson, D., Francis, D. \& Turk, D. (1995). Perspectives of chronic pain: an evaluative comparison of restrictive and comprehensive models. Psychological Bulletin $118(2), 238-247$.

Nursing Council of New Zealand (1995). The code of conduct for nurses and midwives. Wellington: Nursing Council of New Zealand.

Papps, E. \& Olssen, M. (1997). Doctoring childbirth and regulating midwifery in New Zealand: a Foucauldian perspective. Palmerston North: Dunmore Press.

Parker, I. (1992). Discourse dynamics: critical analysis for social and individual psychology. London: Routledge.

Peerson, A. (1995). Foucault and modern medicine. Nursing Inquiry 2, 106-114.

Potter, J. \& Wetherell, M. (1987). Discourse and social psychology: beyond attitudes and behaviour. London: Sage

Potter, J. \& Wetherell, M. (1994). Analyzing discourse. In A. Bryman \& R. Burgess (eds.) 
Analyzing qualitative data, pp47-66. London: Routledge.

Price, K. \& Cheek, J. (1996). Exploring the nursing role in pain management from a post structuralist perspective. Journal of Advanced Nursing 24, 899-904.

Puntillo, K. \& Weiss, S. (1994). Pain: its mediators and associated morbidity in critically ill cardiovascular surgical patients. Nursing Research 43, 31-36.

Rabinow, P. (1984). The Foucault reader. London: Penguin.

Rogers, C. (1979). Carl Rogers on personal power. New York: Delacorte.

Rose, N. (1994). Medicine, history and the present. In C.Jones and R.Porter (Eds.), Reassessing Foucualt: power, medicine and the body (pp. 48-72). London: Routledge.

Rouse, J. (1994). Power/Knowledge. In G. Gutting (Ed.). The Cambridge companion to Foucault (pp. 92-114). Cambridge: Cambridge University Press.

Rudge, T. (1997). Discourses, metaphor and bodies: Boundaries and the skin. In J. Lawler (ed.). The body in nursing, (pp. 75-93). Melbourne: Churchill Livingstone.

Salerno, E. \& Willens, J. (Eds.) (1996). Pain management handbook: An interdisciplinary approach. St. Louis, Missouri: Mosby.

Sarup, M. (1993). An introductory guide to post-structuralism and postmodernism (2nd Ed.). Athens, Georgia: University of Georgia Press.

Sawicki, J. (1994). Foucault, feminism, and questions of identity. In G. Gutting (Ed.) The Cambridge companion to Foucault (pp. 286-313). Cambridge: Cambridge University Press.

Schegloff, E. (1991). Reflections on talk and social structure. In Boden, D. \& Zimmerman, D. (Eds.), Talk and social structure: studies in ethnomethodology and conversation analysis (pp. 44-70). Cambridge: Polity Press.

Sinatra, R., Hard, A., Ginsberg, B. \& Preble, L. (1992). Acute pain mechanisms and management, St Louis: Mosby.

Smart, B. (1985). Michel Foucault. London: Tavistock.

Smith, M. (1998). Talking about pain. In B. Carter (Ed.). Perspectives on pain: mapping the territory, (pp. 26-45). London: Arnold.

Stephenson, N. (1994). A comparison of nurse and patient perceptions of postsurgical pain. Journal of Intravenous Nursing 17(5), 235-239.

Tanner, C., Benner, P., Chesla, C. \& Gordon, D. (1993). The phenomenology of knowing the patient. Image: Journal of Nursing Scholarship 25(4), 273-280. 
Taylor, B. (1994). Being human: ordinariness in nursing. Melbourne: Churchill Livingstone.

Tittle, M. \& McMillan, S. (1994). Pain and pain-related side effects in an ICU and on a surgical unit: nurses' management. American Journal of Critical Care 3(1), 25-30.

Turner, B. (1984). The body and society, explorations in social theory, Oxford: Basil Blackwell.

Turner, B. (1992). Regulating bodies: essays in medical sociology, London: Routledge.

Turner, B (1995). Medical power and social knowledge, second edition. London: Sage.

Turner, B. (1997). From governmentality to risk, some reflections on Foucault's contribution to medical sociology. In A. Petersen \& R. Bunton (Eds.). Foucault, health and medicine (pp. ix-xxii). London: Routledge.

Van der Riet, P. (1997). The body, the person, technologies and nursing. In J. Lawler (Ed.). The body in nursing (pp. 95-107). Melbourne: Churchill Livingstone.

Van Dijk, T. (1990a). The future of the field: Discourse analysis in the 1990s. Text 10(1/2), 133-156.

Van Dijk, T. (1990b). Discourse and society: A new journal for a new research focus. Discourse and Society 1(1), 5-16.

Waddie, N. (1996). Language and pain expression. Journal of Advanced Nursing 23, 868872.

Wakefield, A. (1995). Pain: An account of nurses' talk. Journal of Advanced Nursing 21, 905-910.

Watson, J. (1979). Nursing: a philosophy and science of caring. Boston: Little Brown.

Watson, J. (1985). Nursing: human science and human care: a theory of nursing. Norwalk, Connecticut: Appleton-Century-Crofts.

Watts, D. (1998). The acute pain service: continuing evolution. New Zealand Medical Journal 111(1059), 21-22.

Watt-Watson, J. (1992). Misbeliefs. In J. Watt-Watson and M. Donovan (Eds.). Pain management: nursing perspective (pp. 36-58). St Louis: Mosby.

Watt-Watson, J. \& Stevens, B. (1998). Managing pain after coronary artery bypass surgery. Journal of Cardiovascular Nursing 12(3), 39-51.

Welch, D. (1998, December 18-25). Gut reactions: How safe is our water? New Zealand Listener 166, 28-30. 
Willens, J. (1996). Introduction to pain management. In E. Salerno \& J. Willens (Eds.) Pain management handbook: an interdisciplinary approach, (pp. 3-38). St. Louis, Missouri: Mosby.

Wulf, H., Schug, S., Allvin, R. \& Kehlet, H. (1998). Postoperative patient management how can we make progress? Acute Pain 1(4), 32-44.

Zalon, M. (1993). Nurses' assessment of postoperative pain. Pain 54, 329-334. 